\title{
Examining OHV user displacement at the Oregon Dunes National Recreation Area: A ten year trend study
}

Candice J. Riley

West Virginia University

Follow this and additional works at: https://researchrepository.wvu.edu/etd

\section{Recommended Citation}

Riley, Candice J., "Examining OHV user displacement at the Oregon Dunes National Recreation Area: A ten year trend study" (2013). Graduate Theses, Dissertations, and Problem Reports. 3660.

https://researchrepository.wvu.edu/etd/3660

This Dissertation is protected by copyright and/or related rights. It has been brought to you by the The Research Repository @ WVU with permission from the rights-holder(s). You are free to use this Dissertation in any way that is permitted by the copyright and related rights legislation that applies to your use. For other uses you must obtain permission from the rights-holder(s) directly, unless additional rights are indicated by a Creative Commons license in the record and/ or on the work itself. This Dissertation has been accepted for inclusion in WVU Graduate Theses, Dissertations, and Problem Reports collection by an authorized administrator of The Research Repository @ WVU.

For more information, please contact researchrepository@mail.wvu.edu. 


\title{
Examining OHV user displacement at the Oregon Dunes National Recreation Area: A ten year trend study
}

\author{
Candice J. Riley
}

Dissertation submitted to

\begin{abstract}
the Davis College of Agriculture, Natural Resources and Design
\end{abstract}
at West Virginia University

in partial fulfillment of the requirements for the degree of
Doctor of Philosophy
in

Forest Resources Science

\author{
Chad D. Pierskalla, Ph.D., Chair \\ Robert C. Burns, Ph.D. \\ Alan R. Graefe, Ph.D. \\ David Smaldone, Ph.D. \\ Susan Williams, Ph.D. \\ Division of Forestry \& Natural Resources
}

\section{Morgantown, West Virginia 2013}

Keywords: off-highway vehicles, satisfaction, quality of outdoor recreation, restrictive management policies, trend study, management actions, crowding, conflict, displacement, structural equation modeling Copyright 2013 Candice J. Riley 


\title{
Abstract \\ Examining OHV user displacement at the Oregon Dunes National Recreation Area: A ten year trend study
}

\section{Candice J. Riley}

\begin{abstract}
Off-highway vehicle (OHV) use has become an increasingly popular form of recreation among users in national forest land in recent years. This increased use of OHVs on National Forest land has led to numerous environmental and social impacts, leading land managers to resort to restrictive management policies to contend with the impacts.

The purpose of this research is to combine data from three cross-sectional surveys (2002, 2006, and 2011) to examine OHV user displacement and other trends at ODNRA/Sand Lake. This paper uses Descriptive statistics, Chi Square, Analysis of Variance, and Structural Equation Modeling to determine relationships between the following variables: gender, year of first visit, number of visits per year, length of stay, travel distance, group size, and group type, acceptable and tolerable number of people and OHV encounters, experience use history, crowding, and conflict to determine how satisfaction/quality of visits were impacted over the ten year trend study. Results of the analysis reveal some interesting relationships: (1) Overall satisfaction and quality improved over the ten year study period; (2) Males appear to be the most displaced, particularly after regulation such as a 2003 alcohol ban and 2005 sand camping restrictions were implemented by managers; (3) Crowding went from a negative relationship in the first year of study (2002) to a positive relationship in the 2006 and 2011 studies; and (4) Conflict had a positive relationship with crowding in the 2002 study, but a negative relationship in the 2002 and 2011 studies. After new regulations such as the 2003 alcohol ban and stricter sand camping rules in 2005 were implemented, there were significant decreases in regulation sensitive visitors and increases in crowding and conflict sensitive visitors at ODNRA/Sand Lake. There was an increase in the percentage of females along with first time visitors at ODNRA/Sand Lake. Furthermore, results suggest that the crowding and conflict indicators altered as a result of displacement and the reduction of inappropriate behavior thus improving satisfaction/quality for visitors and introducing new users to the area. Managers should maintain long-term monitoring at ODNRA/Sand Lake to ensure conditions continue to improve at the area.
\end{abstract}




\section{Acknowledgements}

First I would like to thank my committee members; my committee chair, Dr. Chad Pierskalla for all of your support and knowledge in helping me through this dissertation process and for your encouraging words and guidance. I would also like to thank my committee members: Dr. Robert Burns, Dr. Alan Graefe, Dr. Dave Smaldone and Dr. Susan Williams for your additional support and guidance during this process. Next I would like to thank the Siuslaw National Forest as well as the interview subjects of Oregon Dunes/Sand Lake National Recreation Area for agreeing to participate in this study and providing us with a wealth of information to use in this study. Many thanks to Dr. Kudzayi Maumbe, Dr. Jinyang Deng, and Dr. Jerry Vaske with all of your help with Structural Equation Modeling. Thank you so much for taking time out of your very busy schedules to sit with us to create these models. Thank you to WVU Division of Forestry and Natural Resources, USDA Forest Service National Visitor Use Monitoring Program, Concord University McNair Scholars Program, Southern Regional Education Board (SREB) along with Dr. Constinia Charbonnette for providing me with funding during the course of my doctorate degree.

Last, but certainly not least, I would like to thank my friends and family for all of their love and support. To all my friends, especially my best friend, Jalea Morgan, thank you for your support and for allowing me you vent my frustrations to you. Finally to my ever-growing family; my parents, Kenny Sr. and Greta, my sisters Keisha and Margaret, my brother Kenny, Jr., my sister-in-law Danica, my brother-in-law Miles, my nieces Jenna and Milaune, and my nephews Matt and Kameron thank you for encouraging me to keep going and comforting me on both good days and bad days. Without you this would not have been possible. I love my family! 


\section{Table of Contents}

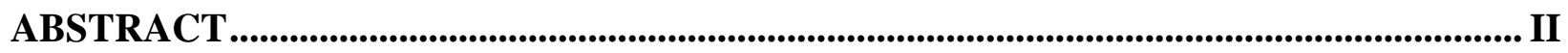

ACKNOWLEDGEMENTS ......................................................................................................III

TABLE OF CONTENTS ….......................................................................................................

LIST OF TABLES ............................................................................................................................. VII

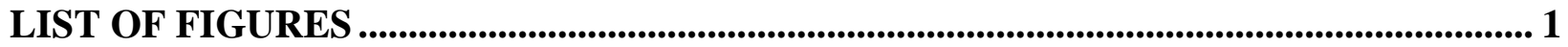

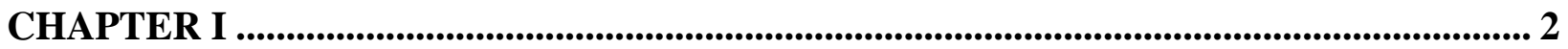

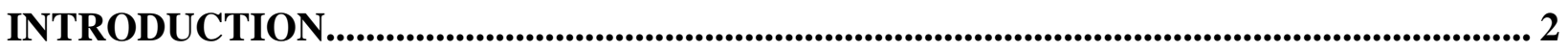

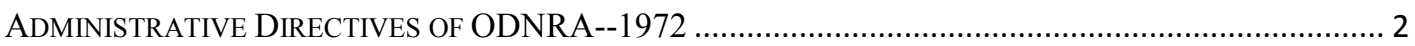

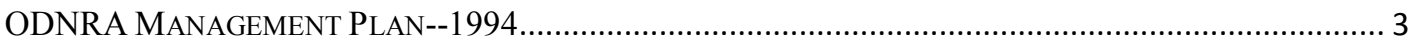

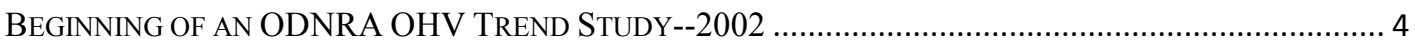

MAJOR MANAGEMENT ACTIONS IMPLEMENTED -2002 TO 2011 …............................................... 4

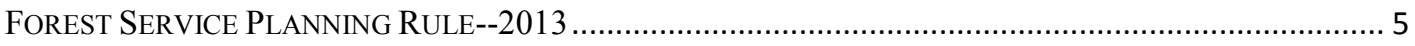

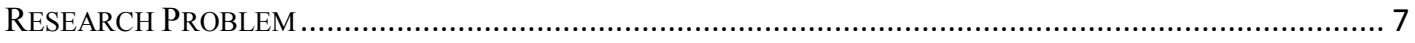

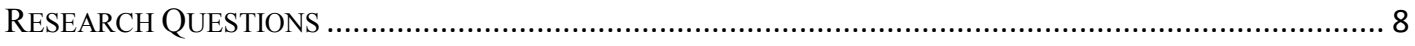

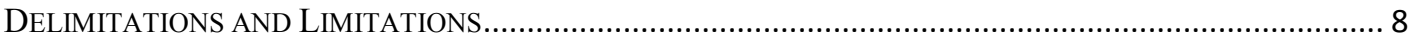

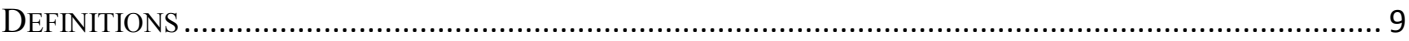

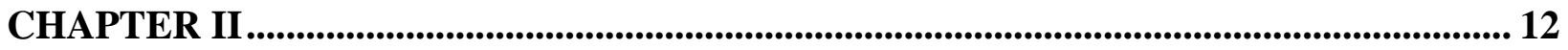

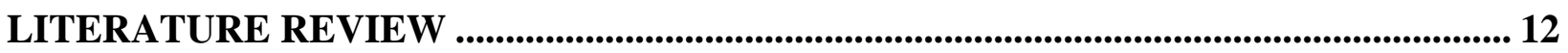

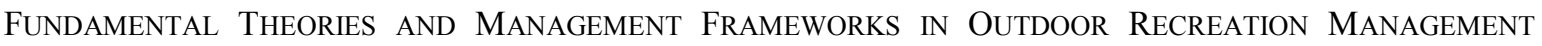

.

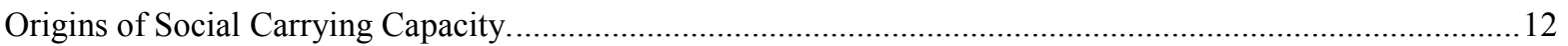

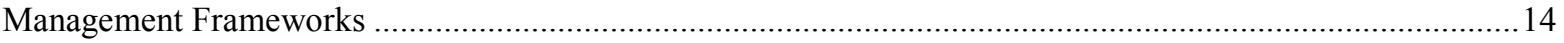

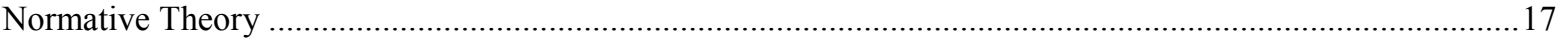

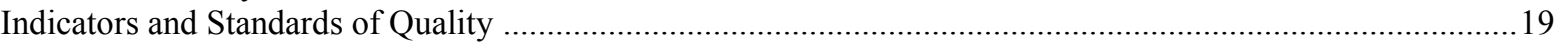

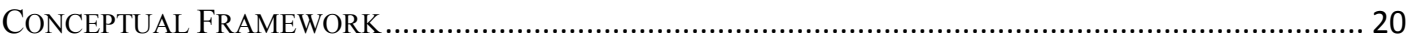

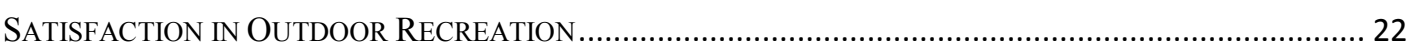

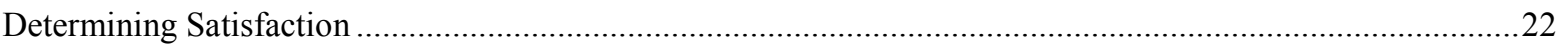

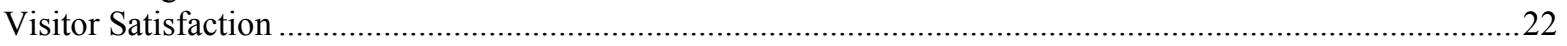

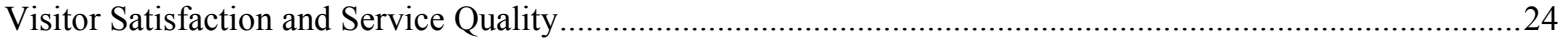

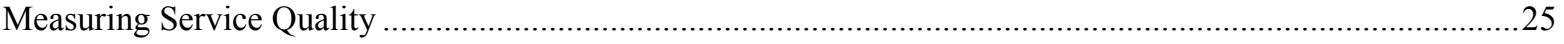

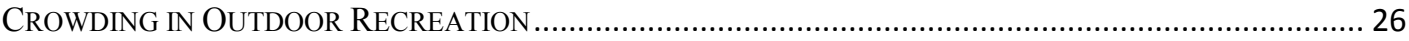

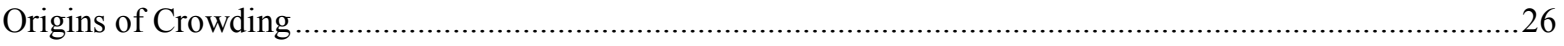

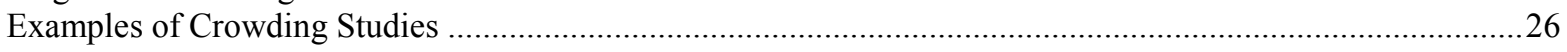

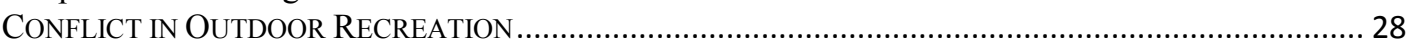

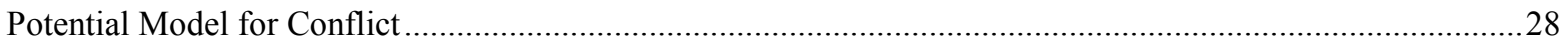

Examples of Conflict Studies. ......................................................................................................

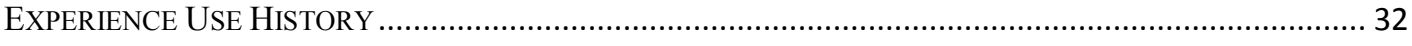

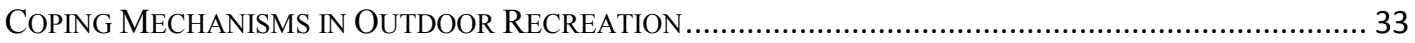

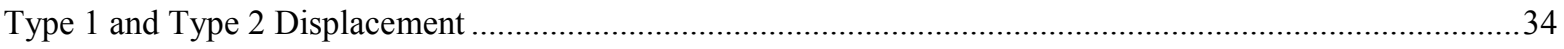

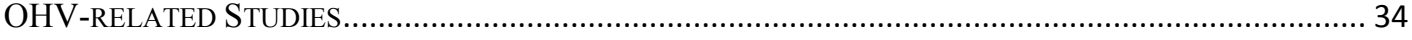

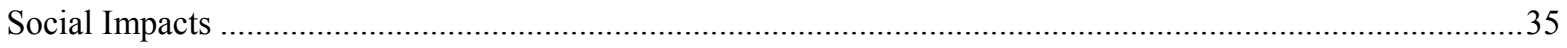

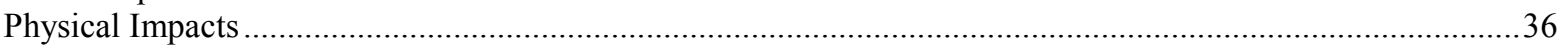

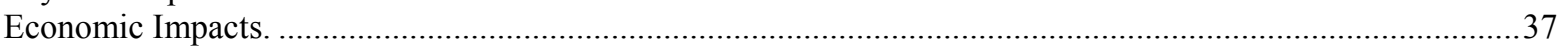

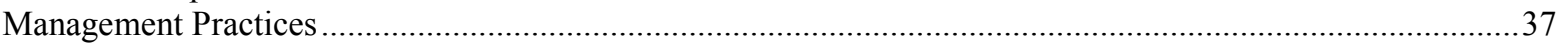

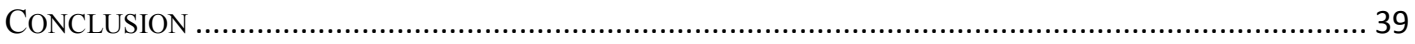


CHAPTER III ................................................................................................................................ 41

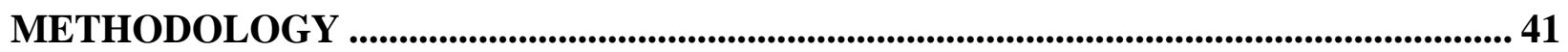

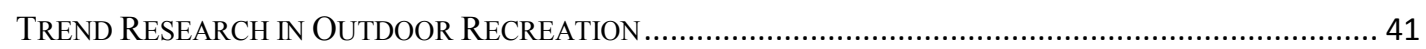

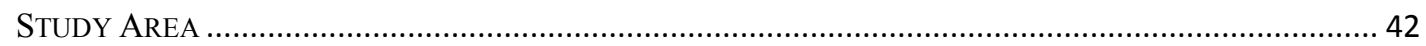

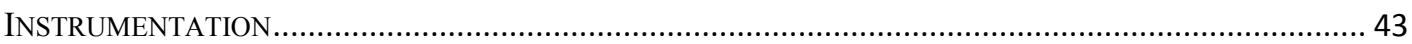

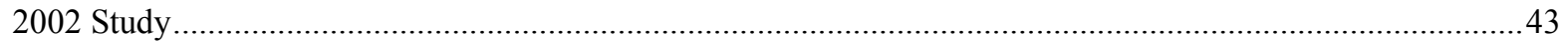

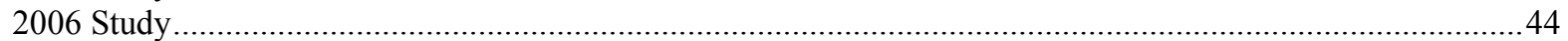

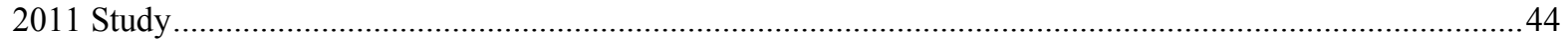

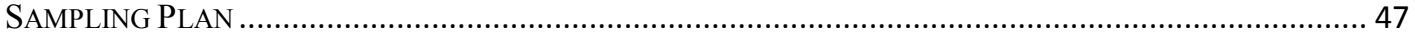

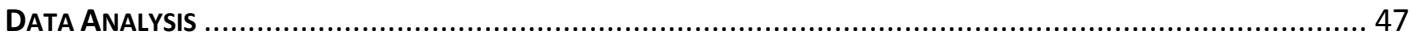

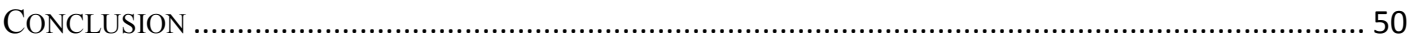

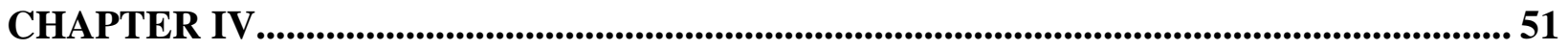

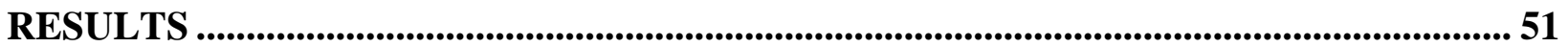

RQ1: WHO ARE THE VISITORS OF ODNRA/SAND LAKE? .............................................................. 52

RQ2: WHAT ARE THE DISPLACEMENT TRENDS OF ODNRA/SAND LAKE OVER THE TEN YEAR STUDY PERIOD

(I.E. CHANGES IN GENDER, PREVIOUS VISITS, AND TRIP CHARACTERISTICS)? ...................................... 53

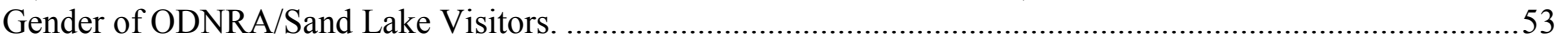

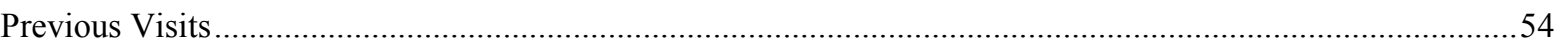

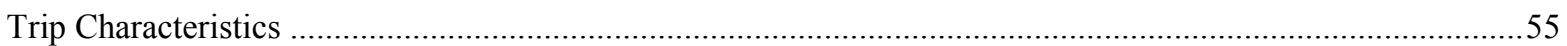

RQ3: WHAT ARE THE CROWDING AND CONFLICT SENSITIVITY TRENDS OVER THE TEN YEAR STUDY PERIOD (I.E., PERCEPTIONS OF CROWDING, PERCEPTIONS OF CONFLICT, CROWDING MATTERS, CROWDING-QUALITY

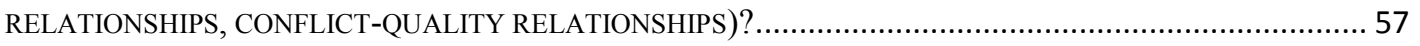

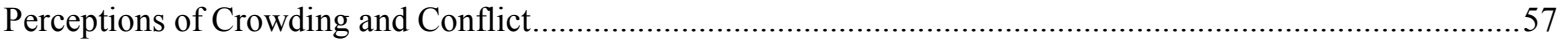

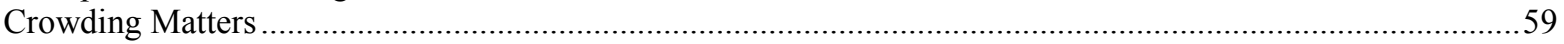

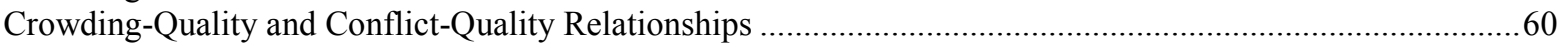

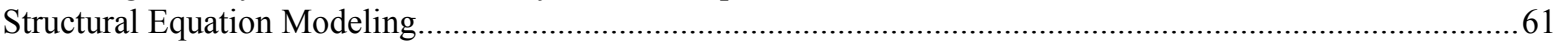

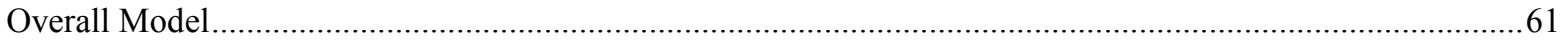

RQ4: HOW DOES CROWDING AND CONFLICT SENSITIVITY COMPARE BY GENDER AND FIRST TIME VISITORS?

. .66

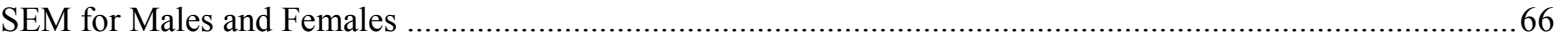

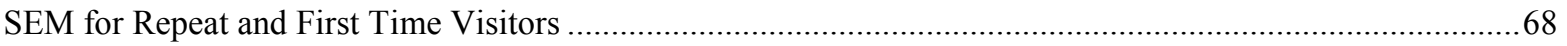

RQ5: WHAT ARE THE TRENDS IN VISITOR SATISFACTION AND QUALITY OUTDOOR RECREATION OVER THE TEN

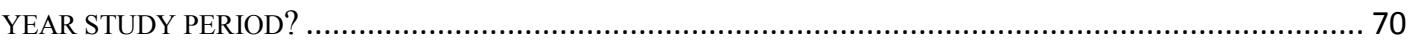

RQ6: HOW DO ENCOUNTERS WITH PEOPLE AND OHVS COMPARE TO VISITOR NORMS (I.E., ACCEPTABLE AND

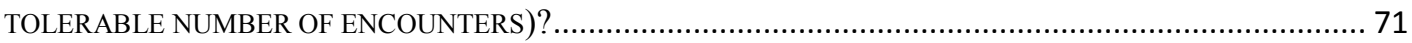

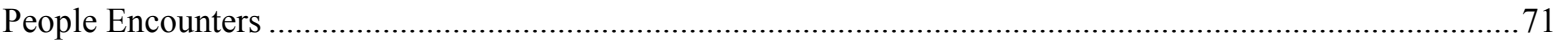

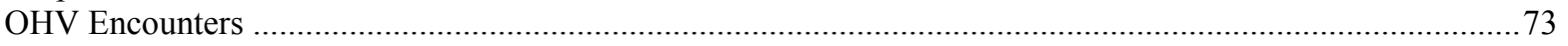

Maximum, Acceptable, and Tolerable OHV Encounter Levels ...................................................................... 75

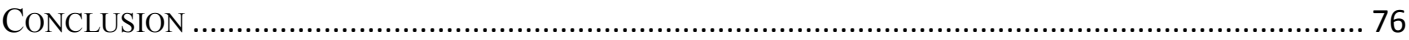

CHAPTER V ................................................................................................................................. 78

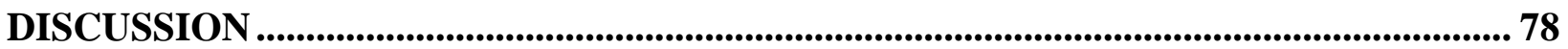

RQ1: Who are the visitors of ODNRA/Sand Lake? ...............................................................................78

RQ2: What are the displacement trends of ODNRA/Sand Lake over the ten year study period (i.e., changes in

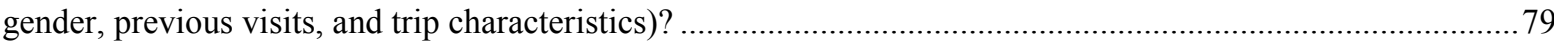
RQ3: What are the crowding and conflict sensitivity trends over the ten year study period (i.e., perceptions of

crowding, perceptions of conflict, crowding matters, crowding -quality relationships, conflict-quality

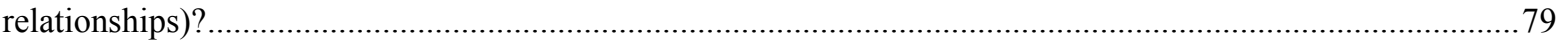

RQ4: How does crowding and conflict sensitivity compare by gender and first time visitors? ........................80

RQ5: What are the trends in visitor satisfaction and quality outdoor recreation over the ten year study period?80

RQ6: How do encounters with people and OHVs compare to visitor norms (i.e., acceptable and tolerable number of encounters)? 
SYNTHESIS OF STUDY FINDINGS

81

Short Term Trends (2002-2006). 82

Short Term Trends (2006-2011).

Long Term Trends (2002-2011).

SCIENTIFIC CONTRIBUTIONS TO THE LITERATURE. 84

MANAGEMENT IMPLICATIONS

Management Recommendations.

CONCLUSIONS

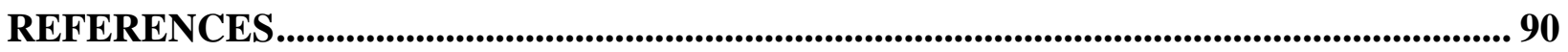

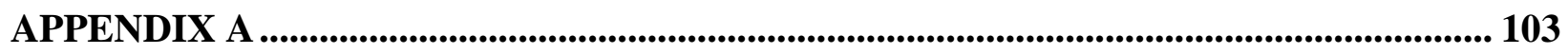

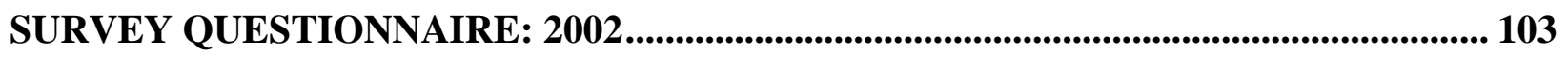

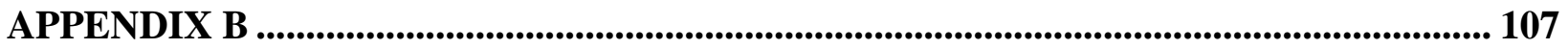

SURVEY QUESTIONNAIRE: 2006 .................................................................................................. 107

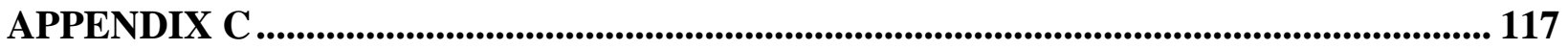

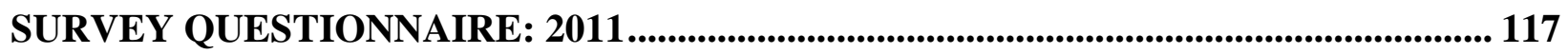




\section{List of Tables}

Table 1. Propositions for Conflict ........................................................................................2 29

Table 2. Common Variables Examined From Three Cross-Sectional Surveys. 46

Table 3. ODNRA/Sand Lake Sampling Locations ....................................47

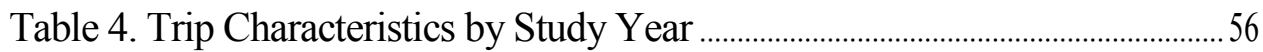

Table 5. Perceived Crowding and Conflict by Study Year ............................................58

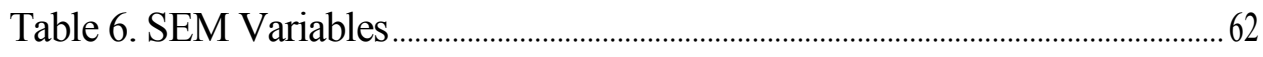

Table 7. Crowding and Quality of Outdoor Recreation...................................................... 63

Table 8. Overall Fit of Quality of Outdoor Recreation by Study Year ................... 65

Table 9. Gender Differences in Overall Fit Indicators.................................67

Table 10. Repeat and First Time Visitor Differences in Overall Fit ...............69

Table 11. Overall Satisfaction and Quality by Study Year ...........................71

Table 12. People Encounters at ODNRA/Sand Lake by Study Year...................... 73

Table 13. OHV Encounters at ODNRA/Sand Lake by Study Year ............... 75

Table 14. Actual, Acceptable, and Tolerable Encounters ............................76

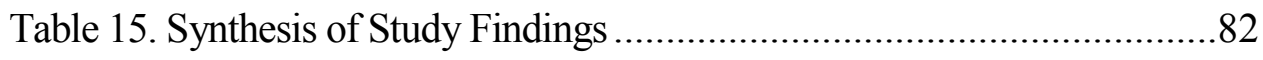




\section{List of Figures}

Figure 1. Three Dimensions of Recreation Carrying Capacity ...................................14

Figure 2. Interrelationships between Social Impact Parameters................................................ 18

Figure 3. Conceptual Model of Recreation Satisfaction ...............................................................19

Figure 4. Traditional Crowding/Satisfaction Causal Model............................................................21

Figure 5. Cooper's Modified Crowding/Satisfaction Causal Model..............................21

Figure 6. OHV Visitor Displacement Model _..............................................................................21

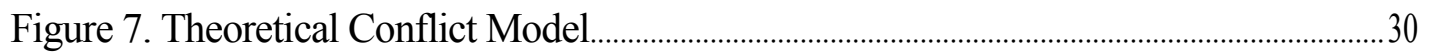

Figure 8. Location of ODNRA/Sand Lake ....................................................................................4

Figure 9. Survey Respondents at ODNRA/Sand Lake .............................................52

Figure 10. Gender of Visitors at ODNRA/Sand Lake ................................................54

Figure 11. Previous Visits by ODNRA/Sand Lake Respondents.................................................55

Figure 12. Group Types at ODNRA/Sand Lake ..................................................................................5

Figure 13. Acceptable Crowding Matters by ODNRA/Sand Lake Respondents ...................59

Figure 14. Tolerable Crowding Matters by ODNRA/Sand Lake Respondents........................60

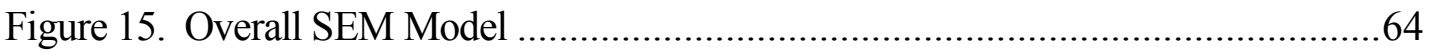

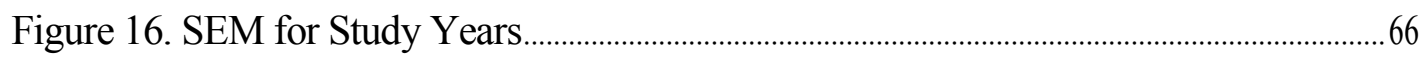

Figure 17. SEM for Males and Females..................................................................................68

Figure 18. SEM for Repeat and First Time Visitors .......................................................................... 70

Figure 19. Number of People Expected to see at ODNRA/Sand Lake ...................................... 72

Figure 20. Number of OHVs Expected to see at ODNRA/Sand Lake ...................................... 74 


\section{Chapter I}

To improve is to change; to be perfect is to change often. Winston Churchill

\section{Introduction}

National Forest Service managers have been looking for ways to deal with Off-Highway Vehicle (OHV) use for the past 30 years. This need was highlighted by the Forest Service Chief who, under the issue of unmanaged recreation, cited $\mathrm{OHV}$ use as the main reason behind unmanaged recreation. Managing OHV use has been particularly challenging for managers on the West Coast of the United States, who have dealt with OHV use longer than managers on the East Coast. The Oregon Dunes National Recreation Area (ODNRA) on the Oregon Coast is no exception when it comes to finding ways to better manage OHV use. The timeline below provides historic context for the study to better understand the changes in OHV use and user perceptions that were measured in 2002, 2006, and 2011. This timeline examines a longer history of ODNRA that begins in 1972 to provide a more complete background to this study's research problem.

\section{Administrative Directives of ODNRA--1972}

Congress designated a 31,500 acre portion of the Siuslaw National Forest as the ODNRA in March 1972. Of the 31,500 acres set aside, 28,900 acres are managed by the USDA Forest Service while the rest is managed by the Oregon State Parks System. The area was established for -public outdoor recreation use and enjoyment of certain ocean shorelines and dunes, forested areas, fresh water lakes, and recreational facilities in the State of Oregon" (Oregon Dunes National Recreation Act of 1972, p. 99). In addition to public outdoor recreation use and enjoyment of the area, Congress prescribed that the USDA Forest Service conserves the scientific, scenic, historic values for present and future generations. ODNRA is unique, being one of the largest expanses of temperate coastal sand dunes in the world, with views of dunes, 
forests, and ocean in close proximity to one another along with diverse species of plants and animals that live there either year-round or seasonally. Furthermore, the area provides an enormous economic boost to the local communities. Of the estimated 1.1 million annual visitors to ODNRA, 650,000 are OHV users who buy equipment and fuel at local stores and spend nights and dine in local hotels and restaurants (Hubbard, 2013).

\section{ODNRA Management Plan--1994}

The current management plan for ODNRA was published in July 1994. The management plan outlined several issues concerning ODNRA such as recreation, off-road vehicle use, access and facility development, education and resource interpretation, vegetation management, plants, fish and wildlife, research natural areas, wild and scenic rivers, compliance, biodiversity, local communities, land ownership adjustments, roadless areas, water, mineral entry, cultural resources, and Native American religious freedom. This study will examine recreation and offroad/off-highway vehicle use. ODNRA uses the Recreation Opportunity Spectrum (ROS) to define the range of recreation opportunities (ODNRA Management Plan, 1994). The ROS classes at ODNRA include rural, roaded natural, semi-primitive motorized and semi-primitive non-motorized. These class descriptions were used to create management zones that help define the carrying capacity of the area. Zoning helps separate competing users, reduce recreational impact and meet visitor needs. To manage OHV use, ODNRA established direct management tactics such as night riding curfews, decibel limits for noise outputs, restricted motorized dispersed camping, limiting OHV use to facilities with direct sand access, and designated routes through vegetation areas. Managers monitor the effectiveness of enforcement and education as they relate to the management objectives associated with the ROS classes. 


\section{Beginning of an ODNRA OHV Trend Study--2002}

In 2002, the first of three studies examining OHV use patterns at ODNRA and Sand Lake was conducted. The studies examined several variables including visitors' place of residence, length of stay, OHV equipment used, overall quality of recreation experience, perception of crowding and conflict and acceptability of encounters with other visitors. The study was repeated in 2006 and 2011 to identify trends in OHV usage and user perceptions.

\section{Major Management Actions Implemented-2002 to 2011}

Perhaps the most radical management action implemented during the study period was the alcohol ban. After the 2002 study was completed, the Forest Service implemented an alcohol ban on ODNRA and Sand Lake in May 2003. The alcohol ban was necessary to help reduce traumatic injuries, violent crimes, illegal behavior, resource damage at riding areas and dispersed campsites, and -drunken rowdiness" (-Alcohol Ban," 2003). The alcohol ban includes all OHV riding areas with the exception of developed sites such as campgrounds, picnic areas, or parking lots. The penalty for violation is $\$ 5,000$ fine and/or six months imprisonment (USDA Forest Service, 2012). For some, the alcohol ban was seen as a way for riders to take their business elsewhere" (Barnard, 2003), while others see the alcohol ban as a way to maintain a safe environment for all OHV users.

Examples of other major management actions implemented in the ODNRA from 20022011 include: Confining overnight dune campers at ODNRA/Sand Lake into 133 — sad-camps" in 2005 to end the -eamping free-for-alls" (Hubbard, 2013). In 2011 Siuslaw National Forest, which ODNRA/Sand Lake is a part of, is working with stakeholders to issue a proposal to close some of the illegal OHV riding trails, while other illegal riding trails will be designated as legal. Managers hope that by designating riding trails will better manage OHV use and protect native plant communities in the area such as lichens and mosses from extinction (Hubbard, 2013). 


\section{Forest Service Planning Rule--2013}

Providing sustainable recreation opportunities in OHV managed areas like the ODNRA is never easy. The ideas emphasized in a new Forest Service Planning Rule could assist OHV managers in decision making. The New Planning Rule reminds us of the important role that science plays in decision making, especially when faced with a lot of uncertainty in rapidly changing environments.

In fact, the management actions implemented at ODNRA and Sand Lake and the scientific evaluation of the new policies may be indicative of a larger national trend to improve management in National Forests. The Forest Service implemented a new planning rule in 2012 that places a greater emphasis on science based management, sustainable recreation, and collaboration. Under the Multiple Use Act of 1960, national forests, also under the National Forest Management Act (NFMA) were required to establish planning rules to help preserve the millions of acres of national forest and grasslands. These planning rules have been in place to help guide the U.S. Forest Service in decision making. The planning rules are essentially a framework used by each unit of the forest service in developing and revising land management plans. The management plans then help the forest service maintain forests and grasslands for forest health, recreation opportunities, endangered and threatened species, and sustainable communities. The first regulations for the planning rule were issued in 1979, and then revised in 1982. In the 1990s and early 2000s, there were attempts to revise the 1982 planning rule, which finally led to a revision in 2008, but it was deemed invalid by the US District Court for the Northern District of California in 2009. The new planning rule is now in its final stages of submission and will be implemented this year.

There are nine key ideas highlighted in the proposed rule. The first idea is to create a more efficient and effective framework that is more responsive to the needs of the forest land and 
communities. The second idea is to increase the role of collaboration and public participation in all management decisions. The third idea is to improve response to economic impacts such as climate change. The idea of climate change has become a global issue in recent years and the proposed rule by the Forest Service will combat that by creating healthy ecosystems. The fourth idea is to increase protection of water resources including watersheds and wetlands. The fifth idea includes effectively protecting native plant and animal species and their habitats. The sixth idea is to create social and economic sustainability of the landscape. The seventh idea is to update provisions for sustainable recreation and consider the different types of air, water, and land recreation. The eighth idea is provide resource management for the multiple uses in a national forest including recreation, timber, and grazing. Lastly, the ninth idea is to establish new requirements for the local and landscape-scale monitoring program that is based on the latest science. From these ideas, the proposed rule developed a three-part framework that comprises of 1) Assessment, 2) Revision or Amendment, and 3) Monitoring. The Forest Service begins the process by assessing the current conditions on the Forest and determines if there is a need to revise or amend the plan. Finally, the Forest Service would monitor the changes to determine if those changes to the plan were effective or not. As opposed to the 1982 rule, the proposed rule tends to place a greater emphasis on using science and collaboration, taking into account other forms of knowledge such as local information and national perspectives when making decisions. In addition, the Forest Service will be taking more proactive steps toward ecological, social, and economic sustainability of forest and grasslands under the new planning rule by supporting ecosystems and watersheds as well as diverse plant and animal communities. The New Planning Rule will improve science in the planning process by taking the best available scientific information as well as local knowledge, public input, and expertise of the land managers. As a 
result the Forest Service hopes that it will improve transparency among the agency. To improve collaboration, under the New Planning Rule, the Forest Service will be required to reach out to all aspects of the public including youth, low-income families, minorities, and local and state government agencies. Also, the public must be involved in all aspects of the planning framework. The provision of sustainable recreation is also emphasized in the Planning Rule. The Planning Rule defines sustainable recreation as opportunities that, individually and combined, are economically, ecologically, and socially sustainable. Those recreation opportunities can be any motorized, non-motorized, developed, or dispersed activity on land, air, or water.

Trend studies, like the one presented in this Dissertation, are the type of projects that compliment many of the ideas presented in the New Planning Rule. This Dissertation examines a large number of questionnaires that were completed by OHV users over a 10 year period of time, thus increasing the role of public participation. By exploring these longer trends, managers can also better understand and respond to the ongoing (and often complex) social changes that take place on the Forest. Furthermore, trend studies allow managers to assess unexpected and planned changes to the managerial, social, and physical environment of the Forest. This particular trend study will examine the changing social and managerial conditions of the ODNRA/Sand Lake to help managers more fully engage in the type of science based management that was emphasized in the New Planning Rule, especially as it relates to assessment, management revision, and monitoring. In conclusion, the ideas presented in the New Planning Rule may be particularly important to ODNRA/Sand Lake managers given the economic, social and physical impact that OHV use has in the region.

\section{Research Problem}

The purpose of this research is to combine data from three cross-sectional surveys (2002, 
2006, and 2011) to examine OHV user displacement trends, trends in levels of sensitivity to crowding and conflict, and satisfaction trends at ODNRA/Sand Lake. This study is consistent with the new planning rule requirements, in particular its emphasis on the use of science to accomplish the following objectives: increase the role of collaboration and public participation in OHV management decisions, assess the social impact of management decisions, help managers assess the relevancy of existing OHV management plans, help guide new management directions, help support sustainable recreation, and continue a longitudinal study of ODNRA/Sand Lake.

\section{Research Questions}

1. Who are the visitors of ODNRA/Sand Lake?

2. What are the displacement trends of ODNRA/Sand Lake over the ten year study period (i.e., changes in gender, previous visits, and trip characteristics)?

3. What are the crowding and conflict sensitivity trends over the ten year study period (i.e., perceptions of crowding, perceptions of conflict, crowding matters, crowding-quality relationships, conflict-quality relationships)?

4. How does crowding and conflict sensitivity compare by gender and first-time visitors?

5. What are the trends in visitor satisfaction and quality outdoor recreation over the ten year study period?

6. How do encounters with people and OHVs compare to visitor norms (i.e., acceptable and tolerable number of encounters)?

\section{Delimitations and Limitations}

This study is limited to OHV users that recreated at ODNRA/Sand Lake during the summers 
of 2002, 2006, and 2011. This study used a cross-sectional method, in which a single round of exit interviews was administered. This study relied on self-report measures from respondents. The validity of these findings is subject to selection biases and systematic response distortion. In addition, the study did not include recreation use level counts to compare with the survey participants' responses. Furthermore, medical records regarding OHV-related injuries or deaths were not used for this study. Overall satisfaction was measured using a single item measure in this study. Although a global measure of quality has been widely used in previous research, it does have limitations and may not provide a complete picture of the overall performance of management. For example, visitors have uniformly reported high levels of quality even when recreation opportunities and conditions changed, and this type of feedback to managers sometimes led to unintended incremental changes in standards of quality. The variable's lack of sensitivity to changing conditions is understandable given that visitors often self-select places that meet their recreational needs and are sometimes able to cope with less than high quality conditions (Manning, 2011). The scope of this dissertation was further narrowed by the number of common variables examined in each study. A total of 343 variables were measured in all three studies. This study examined 15 of those variables to address the research questions. So elements such as safety and trail preference are not examined in this dissertation.

\section{Definitions}

Conflict- Defined as goal interference attributed to another`s behavior (Jacob \& Schreyer, 1980)"

Crowding- The notion that when too many people use the same area, some traditional wildland values are lost (Manning, 2011)"

Direct Management Practices- A type of management practice that stresses behavior regulation, 
restriction of individual choice, and a high degree of control (Manning, 2011).

Displacement- A process in which visitors cease using a recreation site because of sensitivity to crowding or other impacts. Furthermore, recreationists are driven away from a preferred place due to changes in conditions resulting from management action or lack thereof (Hall \& Cole, 2000).

Experience Use History (EUH)- Refers to the amount of past experience, usually measured in terms of total visits, total years of use, and frequency per year of participation with an activity and/or resource at a specific site and/or other sites (Hammitt \& McDonald, 1983; Schreyer, Lime, \& Williams, 1984).

Forest Service Planning Rule- A new planning rule provides the opportunity to help protect, reconnect, and restore national forests and grasslands for the benefit of human communities and natural resources (USDA Forest Service, 2012).

Indicators and Standards- Indicators are measurable and manageable variables that can help define quality of outdoor recreation areas. Standards define the minimum acceptable condition of indicator variables (Manning, 2007).

Indirect Management Practices- A type of management practice that stresses behavior modification, freedom of individual choice, and a lesser degree of control (Manning, 2011). Off-highway vehicle (OHV) - Described as any motorized vehicle capable of travel over land and water (Albritton, Stein, \& Thapa, 2009). This study, OHVs include: 4 wheelers (Quads), 3 wheelers, motorcycles such as dirt bikes, as well as sand rails, dune buggies, and jeeps.

Satisfaction- Defined as the fulfillment of needs or wants (Merriam-Webster, 2012). Social Carrying Capacity- Explained as the level of recreational use an area can withstand while providing a sustained quality of recreation (Wagar, 1964). 
$\underline{\text { Structural Equation Modeling- A method that utilizes and distinguishes actual measured }}$ variables (observe) versus concepts that underlie these variables (latent) (Vaske, 2008).

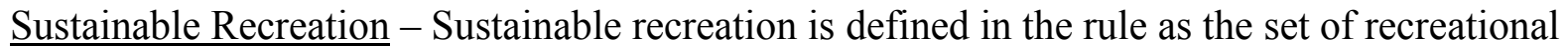
opportunities, uses and access that, individually and combined, are ecologically, economically, and socially sustainable, allowing the responsible official to offer recreation opportunities now and into the future (USDA Forest Service, 2012).

Trend Study- Identified as a form of longitudinal study in which data are gathered on the same variables over a period of time to analyze ongoing patterns, and allow researchers to track change within some general population (Menard, 2002; Tairs, 2000). 


\section{Chapter II}

\section{Literature Review}

In three sections, this chapter summarizes the literature in outdoor recreation that is most

relevant to this $\mathrm{OHV}$ study. The chapter begins with the introduction of the broader theories and management frameworks that are fundamental to social carrying capacity in outdoor recreation. Those theories provide the broader context of a conceptual framework used to examine the relationships between OHV user satisfaction and perceptions of crowding and conflict. The conceptual framework examined in this study was adapted from the literature and presented in Figure 6. It is a satisfaction model that includes OHV user characteristics and crowding and conflict indicators, wherein, the distribution of OHV user characteristics of the population are influenced by displacement behavior. The final section of Chapter 2 presents specific studies of OHV users. The studies present a range of impacts that OHV use has on the social, physical, economic, and managerial conditions of an environment.

\section{Fundamental Theories and Management Frameworks in Outdoor Recreation Management}

Origins of Social Carrying Capacity. The idea of carrying capacity first originated in range and wildlife management. Range and wildlife managers were trying to determine the availability of suitable living conditions for particular species (McCool \& Lime, 2001). Initially it was a simple issue but then became difficult as managers began to be aware of how certain practices such as adding fences and grass seeding could increase the capacity of an area. Also, species such as cattle and deer have different food requirements, so carrying capacity in range and wildlife management - as a function of land owner objectives as well as characteristics of the environment" (McCool \& Lime, 2001, p. 374). Furthermore, changing conditions of the 
environment, whether caused by the species population or otherwise made calculating carrying capacity difficult.

Social carrying capacity started with Wagar's (1964) work. Although the earliest definition comes from Sumner (1942), Wagar (1964) defined carrying capacity as —thdevel of recreational use an area can withstand while providing a sustained quality of recreation (p. 3)." Wagar's (1964) definition is still the most commonly used definition by researchers (Graefe, Cahill, \& Bacon, 2011). Social carrying capacity became a concern in the 1960 s after the advancement of the automobile and the end of World War II allowed individuals to go out and participate in outdoor recreation. This concern of social carrying capacity was echoed in The Tragedy of the Commons" paper written by Garrett Hardin in 1968. In that paper, Hardin asserted that if management did not act on carrying capacity issues, particularly in parks and protected areas, that there would be tragic environmental and associated consequences" (Manning, 2007, p. 5). To manage carrying capacity, Wagar (1964) posits that the objective is to sustain the highest quality of recreation areas at acceptable costs. Some ways to support high quality recreation include: not using products such as timber that could be produced in recreation areas, paying more for those products used in recreation areas, enforcing regulations such as staying on marked trails, and resource hardening like paving trails. Other ways to maintain high quality recreation include encouraging users to spend more time and money to reach quality recreation areas, and managing recreation areas through taxes and entrance fees. Some ways managers can achieve quality recreation, are through zoning, engineering, persuasion, interpretation, and biodiversity management. By achieving quality recreation, managers can reduce conflict, reduce the destructiveness of people, increase the area's durability, and provide more opportunities for enjoyment (Wagar, 1964). 
Other early studies of carrying capacity also address management objectives. Lime and Stankey (1971) and Lucas and Stankey (1974) list management objectives along with visitor attitudes and recreational impact on physical resources as the three basic components of carrying capacity. Without establishing management objectives, the authors assert, efforts to manage carrying capacity at a location would be ineffective (Lime \& Stankey, 1971), so managers need to be able to define the recreational opportunities they want to provide. Also, managers have to understand visitor attitudes to identify what may be acceptable to some visitors but unacceptable to others as well as the impacts on physical resources so they can recognize how much wear and tear the area can take. Another issue in managing carrying capacity is that there is - no mgic number" to establish carrying capacity, meaning you cannot determine how many people are too many people at an area (Lucas \& Stankey, 1974). This was also discovered to be an issue in range and wildlife management as well. So the policy constraints managers have can trigger difficulty in determining how much use an area can withstand over a period of time without causing unacceptable change in the experience and environment.

Management Frameworks. Manning and Lime (1996) illustrate the resource, social, and managerial dimensions of recreational carrying capacity. The three dimensions (Figure 1) are key components of carrying capacity frameworks.

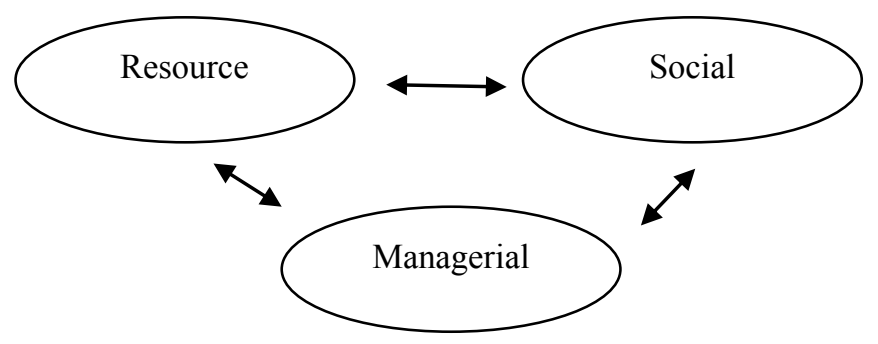

Figure 1. Three dimensions of recreation carrying capacity 
The most common frameworks for carrying capacity are: Recreation Opportunity Spectrum (ROS), Limits of Acceptable Change (LAC), Visitor Experience and Resource Protection (VERP), and Visitor Impact Management (VIM). These frameworks became the inspiration for the USDA Forest Service's new planning rule.

ROS was created as a result of the National Forest Management Act. ROS was developed simultaneously by researchers Clark and Stankey as well as Brown and Driver (Manning, 2011), and is defined as the combination of physical, biological, social, and managerial conditions that give value to a place" (Clark \& Stankey, 1979, p. 1). ROS is used by numerous public land agencies including the USDA Forest Service and Bureau of Land Management (BLM). The purpose of ROS is to define the range of opportunities provided at an outdoor recreation area. There are six classes associated with the ROS. Each class has a different description of experience and setting opportunities, thus offering different management objectives. For Primitive $(\mathrm{P})$, the user is seeking complete isolation from other users and managers, in an environment $\rightarrow$ fee from evidence of man-induced restrictions and controls" (Manning, 2011, p. 194). The Semi-Primitive Non-Motorized (SPNM) class also requires isolation from other users and managers but it is not as important to those seeking Primitive opportunities. Semi-Primitive Motorized (SPM) is the same as SPNM but with motorized equipment allowed in the area. Roaded Natural (RN) are areas where human-made features are present but blend in with the natural environment, and contact with other uses is moderate. In Rural (R) areas, the environment is —substanally modified" and an encounter with other users is high. Finally, Urban $(\mathrm{U})$ areas feature an obvious managerial presence, such as manicured vegetation with constant encounters with other users. By utilizing ROS, planners and managers can allocate the 
appropriate amount of resources to each opportunity class as well as define management objectives specific for that area (Manning, 2011).

LAC was created in 1985 for several reasons. First, LAC was established as part of legislation (General Authorities Act of 1978 and National Forest Management Act of 1976) requiring National Parks and National Forests to develop — visor carrying capacities" (Cole \& Stankey, 1997). Secondly, LAC was formed out of concern of increasing recreational impacts on public lands and growing management concerns. LAC was also created as a result of a lack of accountability for quality management, current management programs being arbitrary, and managers' lack of knowledge of existing trends and conditions (Cole \& Stankey, 1997). There are nine steps to LAC: 1) Identify area concerns and issues, 2) Define and describe opportunity classes, 3) Select indicators of resource and social conditions, 4) Inventory resource and social conditions, 5) Specify standards for resource and social indicators, 6) Identify alternative opportunity class allocations, 7) Identify management actions for each alternative, 8) Evaluation and selection of an alternative, and 9) Implement actions and monitor conditions. LAC's goal is to address acceptable change at an area with the decisions ultimately being made by the managers, researchers, and citizens who use the resource (Stankey, McCool, \& Stokes, 1984). According to National Park Service (NPS, 1997), VERP is:

A planning and management framework that focuses on visitor use impacts on the visitor experience and the park resources. These impacts are primarily attributable to visitor behavior, use levels, types of use, timing of use, and location of use (p. 9).

Similar to LAC, VERP was created in response to legislation of the General Authorities Act of 1978 but was developed by NPS. VERP, like LAC has nine elements 1) Assemble an interdisciplinary project team, 2) Develop a public involvement strategy, 3) Develop statements 
of primary park purpose, significance, and primary interpretive themes, 4) analyze park resources and existing visitor use, 5) Describe a potential range of visitor experiences and resource conditions, 6) Allocate potential zones to specific locations, 7) Select indicators and specify standards for each zone; develop a monitoring plan, 8) Monitor resource and social indicators, and 9) Take management actions. It is important to note that although the VERP process seems linear, it is in fact repetitive, with comments occurring throughout the process (Hof \& Lime, 1997).

Finally, VIM was created by researchers working with NPS and the National Parks and Conservation Association (Graefe, Kuss, \& Vaske, 1990). VIM was developed to address problem conditions, potential causal factors, and potential management strategies (Nilsen \& Tayler, 1997). Unlike LAC and VERP, VIM has only eight steps: 1) Conduct pre-assessment database review, 2) Review management objectives, 3) Select key indicators, 4) Select standards for key impact indicators, 5) compare standards and existing conditions, 6) Identify probable causes of impacts, 7) Identify management strategies, and 8) Implement. VIM is helpful in deciding fundamental factors to determine management strategies as well as classifying strategies and evaluating them (Nilsen \& Tayler, 1997). VIM as well as LAC, are incorporated with the VERP system making each framework effective in determining if existing conditions meet specified standards (Manning, 2007).

Normative Theory. The theoretical basis for most carrying capacity literature is normative theory (Cooper, 2010). Normative theory is derived from sociology and psychology disciplines in which a methodology for measuring norms was developed by Jackson (1965). Norms represent the generally accepted conditions within a cultural context" (Manning, 2007, p. 42). Norms describe what people think conditions should be at a recreation area (Vaske \& 
Donnelly, 2002). In outdoor recreation, norms are often used to determine perceived crowding among individuals at recreation areas. Researchers examine the -expectations and preferences" at an area (Kuentzel \& Heberlein, 2003, p. 352). For instance, if a person was expecting to encounter fewer people yet see more people than they expected to, that person may feel crowded (Kuentzel \& Heberlein, 2003). There are two ways to measure norms, either using a norm curve to define the range of acceptable conditions" (Manning, 2011, p. 139), or an open ended question that asks visitors to report the maximum number of people or group they would find acceptable at an area. In a study of backpackers at Grand Canyon National Park, Cole and Stewart (2002) found that normative evaluations of backpackers changed during different times of the trips. Encounter preferences mattered to backpackers on some days but did not matter on other days. So norms are an important item to measure because not only do preferences vary among individuals, but they also vary at different times.

Prior Satisfaction and Carrying Capacity Models. There have been several models developed by researchers to describe carrying capacity and satisfaction parameters. Graefe et al. (1984) -introduced a sequence of interrelated impacts that result when recreation use influences visitors in the recreation area" (Lee, 1997, p. 66). Graefe et al.‘s (1984) model (Figure 2) utilizes use level and resource impacts to influence the visitors' perceptions of crowding/dissatisfaction, resource impact, and conflicts. This model provides an overview of the impacts and processes of recreation perception and behavior.

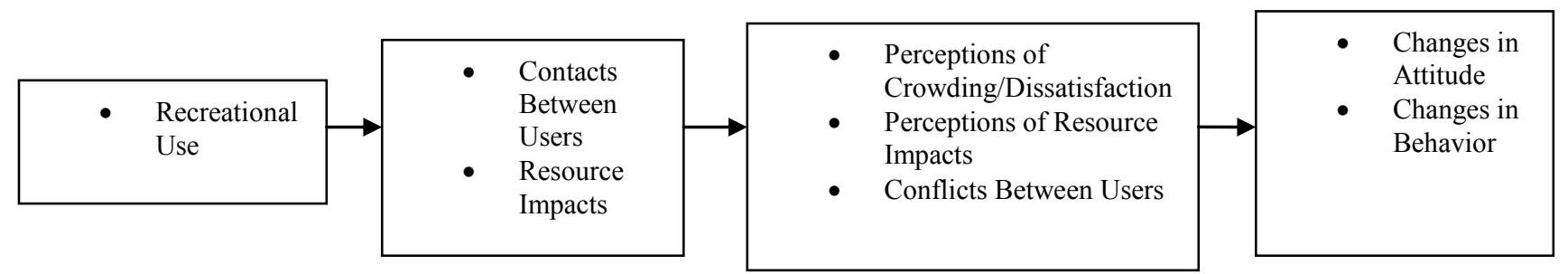

Figure 2. Interrelationships between social impact parameters (Graefe et al., 1984) 
Whisman and Hollenhorst's (1998) model describes overall satisfaction considerations. In a study of boaters on the Cheat River, WV, the authors found that although situational factors can influence overall satisfaction, those influences are mediated by subjective factors of individuals (Manning, 2011). Situational factors include biophysical, social, and managerial factors. Examples of situational variables are specific attributes of a recreation setting or activity, such as the presence of litter, biting insects, too many other people, or the number and difficulty of whitewater rapids. Subjective factors include perceptions of crowding, the extent to which participation goals or motives were fulfilled, and perceptions or evaluations of resource impacts (Williams, 1989). Subjective variables are more affective or evaluative on the part of recreationists. Socioeconomic characteristics such as education, cultural characteristics such as social and political life, experience, and values are all important components in understanding satisfaction (Tindall, Harshaw, \& Taylor, 2011). Figure 3 illustrates the recreation satisfaction model.
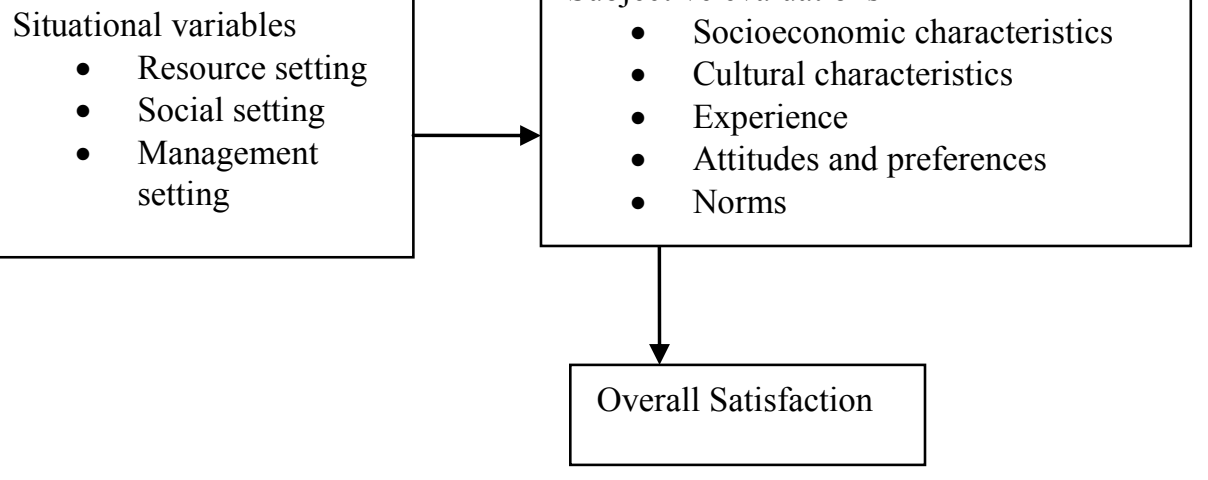

Figure 3. A conceptual model of recreation satisfaction (adapted from Whisman \& Hollenhorst, 1998)

Indicators and Standards of Quality. Current studies in carrying capacity research examine indicators and standards of carrying capacity. According to Manning (2007), indicators 
are measurable and manageable variables that can help define the quality of outdoor recreation areas, while standards are the minimum acceptable condition of indicator variables. There are nine characteristics of good indicators: specific, objective, reliable and repeatable, related to visitor use, sensitive, manageable, efficient and effective to measure, integrative or synthetic, and significant. As for standards, there are five characteristics of good standards: quantitative, time or space bounded, expressed as a probability, impact-oriented, and realistic (Manning, 2007). These indicators and standards are helpful in managing carrying capacity because the indicators can be monitored while implementing management actions so that standards are maintained (Manning, 2007). Overall quality is an important factor in land management, particularly in off highway vehicle management.

\section{Conceptual Framework}

The first model presented below (Figure 4) is the traditional crowding-satisfaction model used by Heberlein and Shelby (1977) and Graefe, Vaske, and Kuss (1984). The second model, (Figure 5), used by Cooper (2010) is similar to the traditional crowding-satisfaction model, but was modified by adding a conflict measure to the model. The conceptual model (Figure 6) examined in this dissertation was adapted from Cooper (2010), Whisman and Hollenhorst (1998), and Hall and Cole (2000). This OHV visitor displacement model was created to be more comprehensive; however, only the subjective evaluations of crowding and conflict were included. As Manning (2011) posits, although situational variables such as resource, social, and managerial settings can influence overall satisfaction, those influences are facilitated by subjective evaluations of individual visitors. The conceptual framework used in this dissertation also builds on the aforementioned frameworks by adding feedback loops that connect the quality of outdoor recreation opportunities with visitor characteristics including Experience Use History 
(EUH) and Visitor Demographics. The adapted conceptual framework suggests that visitors become displaced as a result of management action or inaction intended to address crowding and conflict related issues. Visitor displacement can change the user population's Experience Use History (EUH) and Demographics. A summary of studies that examined each model concept (i.e., quality in outdoor recreation, perceived conflict and crowding, experience use history, and user displacement) and their relationships with each other are summarized.

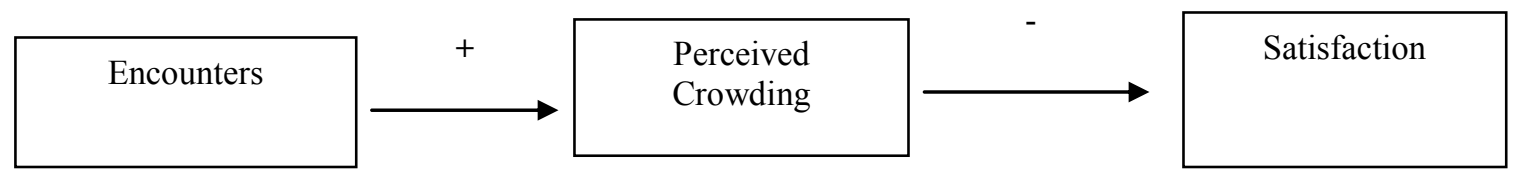

Figure 4. Traditional Crowding/Satisfaction Causal Model

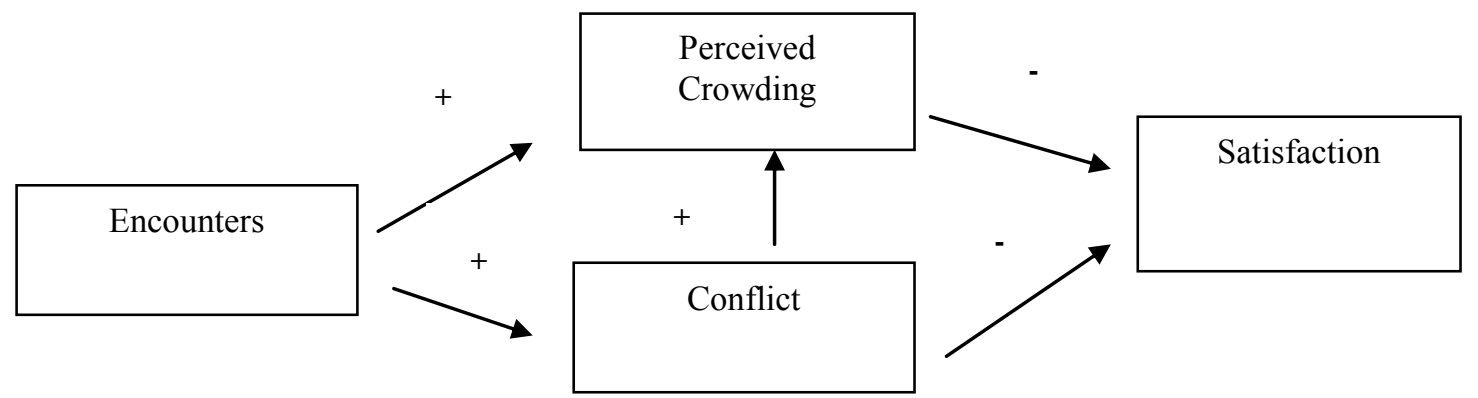

Figure 5. Cooper's (2010) Modified Crowding/Satisfaction Causal Model

Type 1 Displacement-- Crowding and conflict sensitive visitors

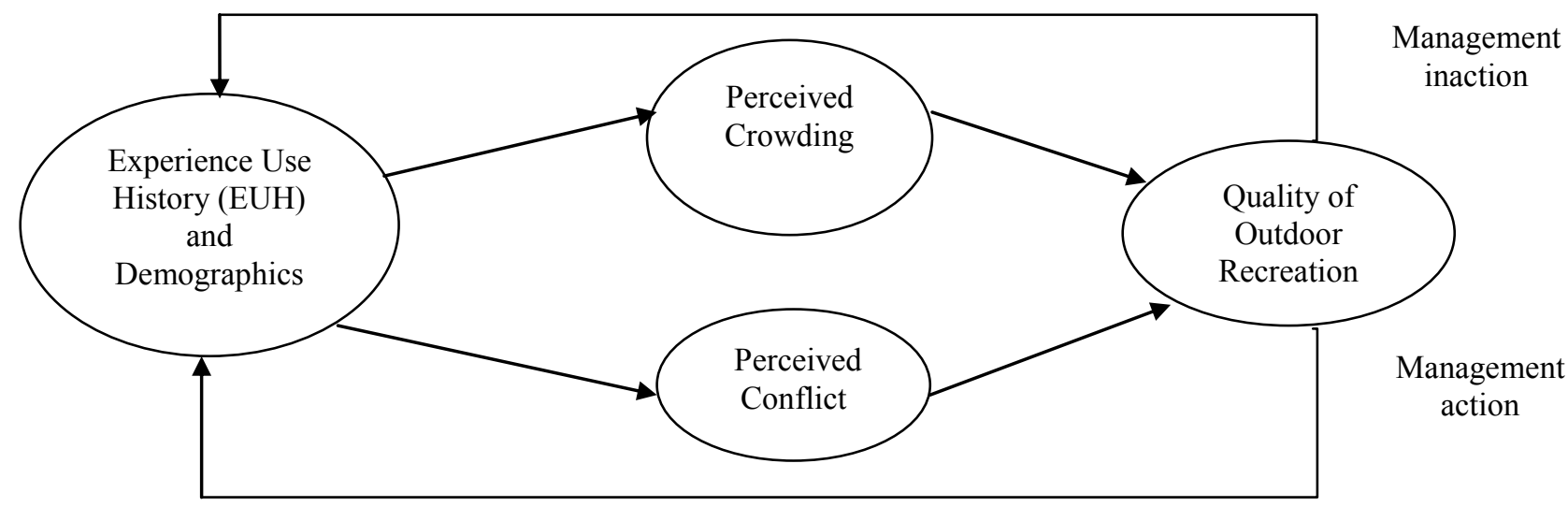

Type 2 Displacement--Regulation sensitive visitors 
Figure 6. OHV Visitor Displacement Model (adapted from Whisman \& Hollenhorst (1998); Cooper (2010); Hall \& Cole (2000))

\section{Satisfaction in Outdoor Recreation}

Determining Satisfaction. Satisfaction is defined as the fulfillment of a need or want

(Merriam-Webster, 2011). In outdoor recreation, the focus on satisfaction comes from a need for some evaluative communication between visitors and managers" (Manning, 201, p. 12). Managers want to know what visitors think of their areas and what can be done to improve visitor satisfaction. The quality of outdoor recreation was first examined by Wagar (1966). Wagar noted that quality in outdoor recreation is highly subjective and based on the varied needs of an individual. The recreation settings and subjective evaluations of participants both contribute to overall satisfaction (Whisman \& Hollenhurst, 1998). For example, the resource setting (natural or unnatural), social setting (low-density or high-density use), and managerial setting (low control or high control) can be perceived differently by participants based on their socioeconomic characteristics, cultural characteristics, experience, attitudes and preferences, and norms, thus suggesting that overall satisfaction involves a transaction between participants and the perceived environment (Williams, 1989). Further, expectancy/discrepancy theory suggests that satisfaction is a function of the degree of congruence between aspirations and the perceived reality of experiences (Bultena \& Klessig, 1969). When visitor perceptions of reality meet their expectations, they tend to be more satisfied. The measurement of quality is often used to assist visitors and managers when communicating about the success of recreation management (Manning, 2011; Fulton \& Manfredo, 2004).

Visitor Satisfaction. Visitor satisfaction is the reason agencies exist and its evaluation is a tool that can be used to assess management goals (Burns, 2000). Since satisfaction is dependent on service quality (Crompton \& MacKay, 1989), it can be structured by recreation managers. 
Some of the first ideas about ways to improve quality recreation opportunities were presented by Wagar (1966). He suggests that the quality of recreation can be increased by zoning the area to allow different user groups different times to enjoy the area, offering a variety of opportunities such as camping areas that have simple camping facilities and other camping areas with more elaborate camping facilities (Wagar, 1966). Also, managers can improve quality by regulation. For example, managers can limit the amount of fish caught per person at a stream or limit the amount of licenses sold for game animals. Lastly, Wagar (1966) suggests that managers can improve quality through interpretation. Providing interpretive exhibits, talks, and presentations can make the experience more meaningful to a visitor and increases the quality of their experience.

Recreation users, as any other consumers demand high quality products (Parasuraman, Zeithaml, \& Berry, 1985). However, unlike most products that are developed and delivered to consumers, the service provided to recreation users cannot be easily measured or tested and varies from person to person. So it can be difficult for managers to determine the quality of their area and how satisfied people are with the place. Other complexities of measuring satisfaction include general measures of satisfaction being too broad (Manning, 2011). For example, many comment cards will ask if a person was satisfied with his/her visit using a yes or no response. But it is difficult to determine why a person is satisfied or dissatisfied with his/her visit based on a yes or no response, so managers do not know how they can continue to improve their services. Secondly, measuring satisfaction allows for -substantial interpretation" (Manning, 2011) meaning that satisfaction varies from person to person. Third, satisfaction may lead to a diminished quality if some people are more sensitive to environmental and social impacts than other people. Fourth, since recreation experiences are self-selected by visitors, most studies show 
high levels of satisfaction among visitors. High satisfaction ratings may not necessarily reflect on high quality management, rather it may be a reflection of high demand for the recreation experience (Burns, 2000). Finally, measuring satisfaction can be complicated because recreation experiences evolve over time (Manning, 2011). From what used to be a person simply hiking in the woods could now be a person hiking in the woods to locate a geocache.

Visitor Satisfaction and Service Quality. Crompton and Love (1995) describe satisfaction as visitor`s quality of experience. However, Cole and Crompton (2003) outline several conceptualizations that try to differentiate visitor satisfaction and service quality. The first concept is that service quality and visitor satisfaction have different reference standards. The reason for this concept is that service quality is defined by desired expectations and visitor satisfaction is defined by predicted exception (Cole \& Crompton, 2003). So the concept states that service quality is what someone hopes to get from their experience while satisfaction is what actually happens from the experience. The second concept is that disconfirmation differs in both satisfaction and service quality (Cole \& Crompton, 2003). Disconfirmation defines the quality of service but a different psychological state defines service quality.

The third, fourth, and fifth concepts deal with visitor satisfaction, service quality, or both being transaction-specific and the other being an attitude (Cole \& Crompton, 2003). The reason, the authors posit are that visitor satisfaction is a precursor for service quality or that service quality is in fact a precursor to visitor satisfaction. Finally the sixth concept is that service quality and satisfaction are global attitudes and since satisfaction depends on the visitors' experience it can contribute to service quality (Cole \& Crompton, 2003). So if someone is satisfied or dissatisfied with their experience, then it will contribute to his/her perceptions of quality. The six concepts described therefore represent the heavy debate in measuring service quality and 
satisfaction.

Measuring Service Quality. Since Wagar‘s (1966) article, researchers have used several techniques in measuring service quality in recreation (Burns, Graefe, \& Absher, 2003).

Parasuraman, Zeithaml, \& Berry (1985) first introduced ten determinants of service quality which were later condensed into five under the SERVQUAL instrument (Parasuraman, Zeithaml, $\&$ Berry, 1988). The five dimensions have been used in numerous studies (Crompton \&MacKay, 1989; Crompton, MacKay, \& Fesenmaier, 1991; Wright, Duray, \& Goodale, 1992) and are tangibles: physical facilities and equipment, reliability: ability to accurately and dependably perform service, responsiveness: willingness to assist customers, assurance: inspiring trust and confidence, and empathy: providing caring individualized attention to customers. SERVQUAL can be used across a wide range of fields including recreation (Carman, 1990). Of the five dimensions first introduced by Parasuraman, Zeithaml, \& Berry (1988), only four dimensions were used to describe quality in parks; tangibles, reliability, responsiveness and assurance. The most important dimension was tangibles (Hamiliton, Cromption, \& More, 1991). A reason for tangibles being the most important dimension of service quality in parks is because tangibles represent the physical facilities, equipment, and appearance of personnel" (Hamiliton, Cropmtion, \& More, 1991, p. 213). People go to parks not only to recreate, but to use the park's facilities as well as equipment, and to speak with staff regarding any questions or concerns they might have. Although SERVQUAL is commonly used in studies, it has been heavily debated because it can be challenging to determine if satisfaction comes from the service quality provided or if the service quality provided triggers satisfaction. Also it can be difficult to define what the importance or expectation of a person's visit would be based on their encounters (Burns, Graefe \& Absher, 2003). Because of the debate of SERVQUAL, other researchers have 
used gap scores in determining trend data of use over time (Burns, Graefe \& Absher, 2003). Although it is still being tested and refined (Absher, 1998), gap scores can help managers see whether use is increasing or decreasing in a particular area and whether or not that increased or decreased use is affecting the quality of that area. If quality is affected, managers need to determine what indicators are involved, handle the issue, and continue to monitor so that satisfaction is not diminished.

\section{Crowding in Outdoor Recreation}

Origins of Crowding. The concept of social carrying capacity provided a suitable foundation for the study of crowding. Wagar's (1964) analysis of carrying capacity suggested that traditional wildland values are lost when too many people use the same area (Manning, 2011). The earliest studies of crowding were conducted for the Outdoor Recreation Resources Review Commission (ORRRC). The ORRRC report found that 20 percent of visitors surveyed at different outdoor recreation sites around the country felt that too many people were using the area (Manning, 2011). However, an equal number of visitors stated that they would have been satisfied with more people at the area. Prior research of crowding focused mainly on wilderness areas since these areas were required by law to provide opportunities for solitude. Since then, crowding has become - - ne of the most frequently studied issues in outdoor recreation (Manning, 2011, p. 99). Crowding is - evaluative concept that is based on users' standards or preferences concerning appropriate use levels within a recreation setting." (Cooper, 2010, p. 3). A normative approach to crowding suggests that perceived crowding occurs when the presence or behavior of other users interferes or disrupt one's objectives or values (Manning, 2011; Shelby, Vaske \& Heberlein, 1989).

Examples of Crowding Studies. Previous research has measured perceived crowding 
using a single item, nine-point crowding scale $(1=-$ not at all crowded" to $9=$-extremely crowded") (Shelby, Vaske, \& Heberlein, 1989; Shelby \& Vaske, 2007; Arnberger \& Mann, 2008; Vaske \& Shelby, 2008). In addition, crowding has also been measured by asking respondents to report the actual number of groups seen at a location (Hammitt \& Rutlin, 1995), as well as acceptability, tolerance, and preference for conditions of indicator variables either numerically or visually. Budruk and Manning (2002) used photographs to determine the highest number of visitor encounters respondents thought would be acceptable. In a comprehensive analysis of 615 outdoor recreation areas, researchers found that 25 percent of the locations surveyed were over or significantly over capacity based on visitor's perceived crowding (Vaske \& Shelby, 2008). However, the research suggests that perceived crowding has declined over time. This indicates that reaction to crowding can be inconsistent over time and varies by activity, location of the recreation area, country or region (Shindler \& Shelby, 1995; Manning 2011). Outdoor recreation managers are concerned with crowding as well. A study conducted by Washburne and Cole (1983) discovered that managers considered two-thirds of all areas to be past capacity, and most capacity problems were of a social or crowding nature as opposed to resource damage. When crowding becomes an issue, managers as well as visitors are faced with making tradeoffs at an area, for managers, the tradeoff is between limiting visitor use to ensure a high quality experience or allow high levels of visitor use to let large numbers of visitors retain access to park and outdoor recreation resources (Lawson \& Manning, 2001). With visitors, the tradeoff is between solitude and access to a resource. A study done at Delicate Arch, Arches National Park, Utah discovered that 48 percent of respondents had a -solitude oriented" preference, therefore managers should limit visitor use to ensure that the solitude the visitors seek are met. If managers do not meet the needs of visitors, satisfaction among those visitors is 
likely to decrease and lead to conflict.

\section{Conflict in Outdoor Recreation}

Conflict occurs when one recreation user feels that another visitor or groups of visitors are interfering with his/her goals (Jacob \& Schreyer, 1980). As demand for outdoor recreation continues to grow along with the innovation and technology of new recreation equipment and activities and diverse lifestyles, the potential for conflict continues to expand (Manning, 2011). Examples of conflicting activities include skiers and snowboarders, hikers and mountain bikers, cross-country skiers and snowmobilers, OHV users and non-users, anglers and water skiers, and canoeists and motor boaters. Conflict can be direct or indirect between recreation users. Direct contact refers to the overt behavior of others while indirect contact is the mere presence (seen or unseen) of undesirable out groups. The mere presence can include artifacts such as litter or environmental impacts such as trail erosion.

A distinctive finding of conflict research is that conflict is often asymmetric or - - ne way" (Manning, 2011). Meaning that one group of visitors may object to the presence or behavior of visitors in another group, but the reverse is not true, at least not to the same degree. An example of asymmetrical conflict is between motorized versus non-motorized users. Non-motorized users often object to the actions of motorized users, but the reverse is not the case. Again, the asymmetric pattern is not universal for all conflict studies; skiers and snowboarders object to the actions of both groups equally (Manning, 2011).

Potential Model for Conflict. Jacob and Schreyer's (1980) theoretical model suggests that conflict can be caused by four major factors: Activity style, resource specificity, mode of experience, and lifestyle tolerance. Activity style consists of intensity of participation, status defined by equipment and expertise, range of experience, and definition of quality. Resource 
specificity consists of evaluation of resource quality, sense of possession and status based on intimate knowledge of a recreation area. Experience refers to the varying expectations of how the natural environment will be perceived. Finally, lifestyle tolerance consists of level of technology, resource consumption and prejudice. Those factors give way to a set of ten propositions that highlight the conditions under which recreation conflict is most likely to occur.

Table 1. Propositions for conflict (from Jacob \& Schreyer 1980; Manning, 2011, p.209)

1. The more intense the activity style, the greater the likelihood of a social interaction with less intense participants will result in conflict.

2. When the private activity style confronts that status-conscious activity style, conflict results because the private activity style's disregard for status symbols negates the relevance of the other participant's status hierarchy.

3. Status-based interactivity conflict occurs when a participant desiring high status must interact with another viewed as lower status.

4. Conflict occurs between participants who do not share the same status hierarchies.

5. The more specific the expectations of what constitutes a quality experience, the greater the potential for conflict.

6. When a person who views the place's qualities as unequaled confronts behaviors indicating a lower evaluation, conflict results.

7. Conflict results when users with a possessive attitude toward the resource confront users perceived as disrupting traditional uses and behavioral norms.

8. Conflict occurs for high status users when they must interact with the lower status users who symbolize devaluation of a heretofore exclusive, intimate relationship with the place.

9. When a person in the focused mode interacts with a person in the unfocused mode, conflict results.

10. If group differences are evaluated as undesirable or a potential threat to recreation goals, conflict results when members of these two groups confront one another.

Another theoretical model illustrated in Figure 7 is the -social values" conflict model (Vaske, et al. 1995; Ewert, Pieser, and Voight, 1999; Carothers, Vakse, and Donnelly 2001; Vaske, Dyar, and Timmons 2004; Vaske, Needham, and Cline 2007). This model suggests that conflict arises from fundamentally different beliefs, values, and norms held by diverse groups of recreation users. The -social values" conflict model proposes that conflict can occur even when there is no direct contact between different user groups. The mere presence or behavior of the 
other group would be enough for conflict to occur. For instance, non-hunters may be in conflict with hunters simply because non-hunters feel that hunting is an inappropriate activity or nonmotorized users may be in conflict with motorized users because they believe motorized devices are bad for the recreation environment.

\begin{tabular}{|c|c|c|c|}
\hline & & Percei & oblem \\
\hline & & Yes & No \\
\hline & Yes & $\begin{array}{c}\text { Goal interference/ } \\
\text { Interpersonal } \\
\text { conflict }\end{array}$ & No conflict \\
\hline & No & $\begin{array}{l}\text { Social Values } \\
\text { conflict }\end{array}$ & No conflict \\
\hline
\end{tabular}

Figure 7. Theoretical conflict models. (Adapted from Vaske et al., 1995; Vaske, Needham, \& Cline, 2007)

Examples of Conflict Studies. Many studies of conflict have been investigated. Most studies indicate several variables associated with conflict such as motivations, skill level, type and level of technology, level of experience, place attachment, tolerance, and safety concerns (Manning, 2011). A study conducted by Vaske, Dyar and Timmons (2004) of skiers and snowboarders in Colorado found that users who considered themselves to be at a high skill level also reported high levels of in-group (same activity) and out-group (different activity) conflict. Also snowboarders reported more out-group conflict than in-group conflict. A study of skiers and snowboarders examined tolerance, which found that users who had a high tolerance for alternative activities experiences less conflict than users with a lower tolerance for alternate 
activities (Thapa \& Graefe, 2004). Another study of conflict and tolerance was conducted by Albritton, Stein, and Thapa (2009) between and within OHV recreationists in Florida. The research posits that four-wheel drive users had the lowest tolerance toward other OHV user groups and perceived the most conflict. Conversely, all-terrain vehicle users held the highest tolerance toward other user groups and perceived the least amount of conflict.

Researchers operationally defined conflict in three ways. Study respondents have been asked to report (1) the extent to which encounters with other users are desirable or undesirable, (2) the extent to which encounters with other users interferes with enjoyment, and (3) the acceptability of specific recreation-related behaviors (Manning, 2011). The last operational definition, influenced by the theory of social values conflict, can be illustrated using a Potential for Conflict Index (PCI). PCI was developed to facilitate understanding and interpretation of statistical information" which requires minimal statistical training to understand results thus diminishes efforts required to process information, and improves comprehension (Vakse, et al. 2010, p.241). The $\mathrm{PCI}_{2}$ is a second generation of the PCI that further enhances neutral respondents on conflict issues. The $\mathrm{PCI}$ and $\mathrm{PCI}_{2}$ provide graphical information to managers so that they could see what has the greatest potential for conflict at their recreation area and take steps to manage conflict.

There are several ways managers can manage conflict. The most common approach is zoning or separating activities using the Recreation Opportunity Spectrum (ROS) framework. The ROS separates conflicting activities such as motorized and non-motorized recreation so that both users are able to enjoy their activities in separate areas. Another management approach to conflict includes educational programs. Educational programs can help reduce conflict by increasing tolerance of different user groups and different activities. Educational programs can 
also establish a code of conduct, basic etiquette, and other behavioral norms that could lessen direct and indirect conflict (Manning, 2011). As managers reduce conflict, visitors will likely be satisfied with their recreation experience.

\section{Experience Use History}

Experience use history (EUH) involves the amount of past experience a visitor has in a recreation area. EUH is usually measured in terms of total visits, total years of use and frequency of participation with an activity or resource (Hammitt, Backlund, \& Bixler, 2004). Past experience at a site and with similar sites are important dimensions of EUH. Previous research into EUH suggests that more experienced users have a greater knowledge concerning activities and/or resource places. Additionally, the more experienced a user is the more attached the user becomes to an area or an activity (Budruk, et al., 2008). EUH can also be defined as a spectrum where users start as novices and as they become more experienced, become veterans (Schreyer, Lime, \& Williams, 1984). Users who are more experienced have been found to be more sensitive to crowding conditions, perceived conflicts, and attitudes toward management practices (Schreyer, Lime, \& Williams, 1984; Williams, Schreyer, \& Knopf, 1990). In a study of visitors to the Danube Floodplains National Park in Austria, Arnberger and Brandenburg (2007) found that local residents and regional visitors with the most experience use history to the park reported the highest level of crowding. The visitors also indicated that they modified their behavior (displacement) such as changing routes or visit times to adjust to the crowding.

Wynveen et al. (2007) conducted a study of visitors to Sumter National Forest in South Carolina. The purpose of the study was to use Structural Equation Modeling to explore the relationship between experience use history, place bonding, and resource substitution among visitors who were camping at campgrounds in Sumter National Forest. The authors developed a 
model that theorized EUH and place bonding would be significantly related to campers willingness to substitute their camping location for another local campground. The study found that the relationships between EUH, place bonding, and resource substitution differed between setting type. The findings also suggest that the effect of setting type on the relationship is due to how the type of setting impacts the visitors' place bonding. So managers would have to develop ways to segment those visitors based on their preferred setting type. Setting type can also influence visitor's perception of crowding. If an experienced visitor is unhappy with his/her experience, he/she may resort to coping mechanisms to deal with changes in their recreation experience.

\section{Coping Mechanisms in Outdoor Recreation}

In outdoor recreation, coping behaviors can occur in response to changing conditions at a recreation area. Examples of coping behaviors include displacement, rationalization, and product shift (Manning, 2011). Displacement occurs when visitors cease using a recreation site because of sensitivity to crowding or other impacts Rationalization occurs when a visitor invests a vast amount of resources into their trip and is determined to be highly satisfied with their trip regardless of conditions. Product shift is when visitors encounter higher use levels than expected, but alter their characterization of their experience in correspondence to the conditions experienced.

Manning and Valliere (2001) studied displacement of residents living in communities in and around Acadia National Park and found that due to -publem behaviors" and increased recreational use, residents either no longer used the carriage roads in the park or began using them during off-season periods. Additionally, Anderson (1983) found that frequent visitors of the Boundary Waters Canoe Area, Minnesota would change their trip patterns over time by entering 
on a different day of the week. Heberlein and Shelby (1977) studied rationalization of rafters on the Colorado River in Grand Canyon National Park who, after paying high fees or waiting years for a permit, were still highly satisfied with their trip. Substantial product shift was found in a study of visitors to Aravaipa Canyon Wilderness who, after encountering larger numbers of visitors, reported a lessened sense of solitude, yet reported unspoiled wilderness (More, Echelberger, \& Koenemann, 1990).

Type 1 and Type 2 Displacement. Hall and Cole (2000) describe displacement as a process in which recreationists are driven away from a preferred place due to changes in conditions resulting from management action or lack thereof. Displacement comes in two forms: Type 1 and type 2 . Type 1 displacement occurs when the area is heavily used, impacted, and there is no management action happening. As a result of type 1 displacement, visitors sensitive to crowding and impacts are displaced. Type 2 displacement occurs when the area is highly regulated by way of use limits or permits. As a result of type 2 displacement, visitors sensitive to regulation are displaced (Hall \& Cole, 2000). Types 1 and 2 displacement will be further examined in this OHV study.

\section{OHV-related Studies}

Off Highway Vehicle (OHV) recreation is defined as any motorized vehicle capable of travel over land and water (Albritton, Stein, \& Thapa, 2009). OHV recreation has increased dramatically from 28 million users in 1995 to 36 million users in 2000 (Barnard, 2003). Because of the increasing demand of $\mathrm{OHV}$ use on public lands, managers are having a difficult time identifying what needs to be done in order to maintain the designated OHV areas on their public lands. Recently, the chief of the USDA Forest Service listed four major issues facing national forests. Those issues include: fire and fuel, invasive species, habitat fragmentation, and 
unmanaged recreation (Chavez \& Knap, 2006). Unmanaged recreation is defined as $\rightarrow$ broad environmental decision and management problem involving multiple stakeholders and numerous outdoor recreation activities and conflicts, occurring simultaneously in and around urbanizing National Forests" (Brooks \& Champ, 2006, p. 785). The main concern under the heading of unmanaged recreation is the need for better management of OHV areas. As part of the Forest Service's Planning Rule, OHV use and other forms of recreation need to be more sustainable. It would be interesting to ascertain how users cope to the quality of changing conditions as well as whether OHV use can be a sustainable form of recreation.

This dissertation examines displacement of OHV users at ODNRA/Sand Lake that may have resulted from unacceptable social impacts such as crowding or conflict. These and other resource, management, and economic-related impacts have been examined in other OHV studies throughout the US. Several examples of those studies follow.

Social Impacts. Social impacts will be the focus of this study of OHV users at ODNRA/Sand Lake. Social impacts include conflict, negative impacts on the land, inappropriate behavior of OHV users, and crowding (Pierskalla, Schuett, \& Thompson, 2011). Examples of conflict are conflicts with non-motorized users such as hikers and backpackers, conflicts with private landowners, and conflicts with other OHV users (Chavez \& Knap, 2006). Negative impacts on the land consist of social trails and excessive noise. Instances of inappropriate behavior of OHV users include OHVs going off designated trails, OHVs going too fast, lack of safety gear such as helmets, flags, and pads, alcohol use, and inexperienced drivers (Chavez \& Knap, 2006). Lastly, crowding includes crowding on trails and access points. Although crowding is reported as a social issue in OHV use, previous studies find that crowding is not a concern at areas (e.g. staging areas). For instance, Chavez and Knap (2006) discovered that after managers 
provided several access points and staging areas, crowding issues were resolved. In addition, Deisenroth, Loomis, and Bond (2009), performed a study of OHV users in National Forest Lands in Larimer County, Colorado who also reported not much crowding on trails. Alternatively, conflict between users, specifically between non-motorized and motorized groups has been widely reported such as canoeists and motor boaters (Adelman, Heberlein, \& Bonnickson, 1982; Ivy, Stewart, \& Lue, 1992; Shelby, 1980); cross-country skiers and snowmobilers (Jackson \& Wong, 1982; Jackson, Haider, \& Elliot, 2002; Vaske, Needham, \& Cline, 2007); and off-road vehicle users and hikers (Noe, Wellman, \& Buhyoff, 1981). Albritton, Stein and Thapa (2009) explored conflict not only between OHV users and other user groups, but also within different OHV users such as four-wheel drive users, ATV users, and off-highway motorcycle users. The study, which was conducted at Ocala National Forest in Florida, found four-wheel drive users such as jeeps perceived the most conflict and felt that they were different than ATV users and off-highway motorcycle users. In contrast, ATV users perceived the least amount of conflict and were more tolerant of four-wheel drive users and off-highway motorcycle users. In Minnesota, there is ongoing contention between OHV users and stakeholders such as private landowners and environmental advocates about how OHV use should be managed (Asah, Bengston, Wendt, \& DeVaney, 2012). Therefore it is up to managers to focus on management actions that can -ease tensions between stakeholders" (Asah, Bengston, Wendt, \& DeVaney, 2012, p. 192).

Physical Impacts. Environmental impacts of OHV use include habitat damage, wildlife interactions, and dangerous terrain (Pierskalla, Schuett, \& Thompson, 2011). Examples of habitat damage include spread of invasive weeds, reduction of species diversity, soil erosion with trampling and compaction, litter at trails and access points, vegetation damage, smoke output from vehicles, fuel leakage from vehicles, and vandalism. (Chavez \& Knap, 2006; Silberman \& 
Andereck, 2006). Wildlife interactions consist of harassment of wildlife as well as injury or death of wildlife, while dangerous terrain includes naturally occurring cliffs called drop-offs (Pierskalla, Schuett, \& Thompson, 2011). Soil erosion is also a concern with OHV use because the weight of the OHVs can compact the soil, therefore reducing the amount of water that gets absorbed into the ground (Switalski \& Jones, 2012).

Economic Impacts. Despite the negative social and environmental impacts, OHV use offers a considerable amount of economic benefits to local communities through revenue and jobs, helping some rural areas like Oregon's southern coast make up for the loss of timber and fishing jobs with tourism dollars (Silberman \& Andereck, 2006; Alcohol Ban,” 2003). Communities with heavy OHV use see revenue through grocery sales, restaurant and bar sales, lodging sales such as campgrounds and hotels, and sales from OHV repairs and parts (Ouren et al., 2007). Because of the revenue OHV use brings in, service industry jobs such as sales clerks, campground hosts, and OHV repairmen are essential. Forest Service also generates revenue from OHV use through fines, permits, and user fees. A study done in 1999 found that OHV riders spent $\$ 74$ million on equipment and \$46 million for groceries, gas, motels, and other necessities in Oregon (-Alcohol Ban," 2003). More specifically, a study conducted in Central Oregon in 2008 showed that an OHV user spent an average $\$ 411$ on their trip (Burns et al., 2009). Consequently, OHV users spend a significant amount of money thus providing a substantial economic boost for local communities and land managers.

Management Practices. To combat social impacts, managers turn to four types of practices (i.e., indirect, direct, resource hardening, and collaboration). (1) Indirect management tactics consist of education using posters, signs, brochures, and bulletin boards, etc. (2) Direct management tactics include law enforcement patrols, designating OHV trails, and closing or 
limit use to areas. Furthermore, indirect and direct practices McCool and Christensen (1996) posit, can be applied in an unobtrusive or obtrusive fashion. For example, indirect, unobtrusive management tactics would include an educational program on the ecological impacts of OHV riding off designated OHV trails, while a more direct, obtrusive management tactic would be uniformed rangers regularly patrolling the area to ensure OHV users are staying on designated trails. Thus, unobtrusive tactics have a sporadic presence, while obtrusive tactics require a constant presence. Although visitors commonly prefer indirect, unobtrusive management tactics, managers find that direct, obtrusive management tactics are needed when it comes to protecting the land's resources (Bullock \& Lawson, 2007). (3) Resource hardening comprises of developing staging areas with parking facilities at trail access points, designated campsites, lengthening trails to disperse riders, and trail maintenance. (4) Lastly, collaboration practices consist of meeting with OHV groups, volunteer patrols, adopt-a-trail programs, trail clean ups, and working with other agencies (Chavez \& Knap, 2006). Of these management actions, Chavez and Knap (2006) found that National Forest OHV managers in California discovered that the collaboration action was the most effective in managing $\mathrm{OHV}$ use. Collaboration has become a popular tool for managers to use because of growing differences and knowledge among individuals as well as a time when information is more widely distributed to networked societies (Innes \& Booher, 1999). The second most effective action National Forest OHV managers in California use are direct management tactics such as law enforcement. A challenge land managers face is finding the balance between the different management practices so that not only the resources are protected, but visitors can still freely enjoy the area (Bullock \& Lawson, 2007).

Several studies have explored social and managerial impacts of OHV use. Pierskalla, Shuett, and Thompson (2011) surveyed District Rangers across 14 National Forests in the 
Appalachian Region. They found that Districts with a high concentration of trails reported users ${ }^{6}$ lack of safety gear (i.e. helmets, goggles) as well as inexperienced users riding in difficult terrain areas. Other social impacts reported consist of user-created trails, users not staying on designated OHV trails, users going too fast, and alcohol or drug use. Preferred management tactics of the District Rangers were a combination of indirect and direct actions. The top three tactics include law enforcement, bulletin boards, and closing or limiting use. Another study was conducted by Martin, Marsolais, and Rolloff (2009) of motorized users in the American River watershed in California including the Eldorado National Forest. It concluded that motorized users felt direct management such as law enforcement and indirect management such as information and education were the most appropriate in their setting, while use restrictions were less appropriate in their setting. Finally, Kuehn, Luzadis, Malmsheimer and Schuster (2010) conducted a study of state and federal forest managers in Northeast U.S. including Maine, New Hampshire, and Connecticut. The authors described social impacts such as going off designated OHV trails and passing other users too fast. To combat this, managers believed that the most effective management strategy was to list regulations at access points and educate riders about the fines for breaking those regulations. Educating OHV users about proper OHV practices can allow those users with more experience to spread the word to first time users of the rules and regulations at the area.

\section{Conclusion}

This section examined the fundamental theories and management frameworks in outdoor recreation management most relevant to this OHV study. Social carrying capacity is important to the management of OHV use because managers need to be able to determine the level of recreational use an area can withstand while maintaining a quality recreation experience. If a 
quality recreation experience is being negatively impacted, managers need to know what is the underlying problem. Impacts such as crowding and conflict could be causing more experienced OHV users as well as other visitors sensitive to crowding and conflict to become displaced.

Because crowding and conflict indicators can be inconsistent over time and vary by activity and location (Schindler \& Shelby, 1995; Manning, 2011), this research will give managers more than just one datum point when making difficult decisions about if and when crowding and conflict should be addressed. 


\section{Chapter III}

\section{Methodology}

This chapter presents the methodology used in this OHV study. (1) The chapter begins with an introduction of other trend research in outdoor recreation to demonstrate its value and use to managers. (2) The ODNRA/Sand Lake study area is described in detail. (3) The survey instrumentation used for this OHV study is described. (4) The sampling plan used for this OHV study is described. (5) Finally, the statistical analysis used to address each research question is presented.

\section{Trend Research in Outdoor Recreation}

Conditions of outdoor recreation areas and visitor perceptions of those conditions are constantly changing. For example, crowding conditions at a recreation area may change over time (Schindler \& Shelby, 1995). What may be considered as overcrowded at one time may be considered acceptable at a later time, so managers are beginning to look at trend studies to track change among the population (Menard, 2002; Taris, 2000). Trend studies call for data to be gathered on the same variables over a period of time to analyze ongoing patterns (Legare \& Haider, 2008). In addition, trend studies in outdoor recreation provide more than mere -snapshots" of the current situation (Crompton \& Kim, 2004), so managers are able to monitor changes over time and implement management actions when the extent of change is unacceptable.

In a study conducted at the Apostle Islands National Lakeshore in Wisconsin, Kuentzel and Heberlein (2003) -incorporated time into an analysis of crowding and carrying capacity to investigate how change affects visitor evaluations and experiences" (p. 350). The authors used 
three cross-sectional surveys (i.e., 1975, 1985, and 1997) of boaters over a 22 year span.

Kuentzel and Heberlein (2003) found that encounter norms and perceived crowding changed dramatically at the Apostle Islands over the years studied. Some reasons for the shift included an increased amount of tolerance of encounters with other boaters as well as a transformation in the age and experience of the boaters. Furthermore, the authors state that it is unwise to assume that increased use levels will lead to more crowding. As the encounter norms for an area changes so does the tolerance for increased numbers. Long term monitoring is essential for managers to understand these changes over time.

\section{Study Area}

Oregon Dunes National Recreation Area (ODNRA) was established in March 1972. Located along the Oregon Coast in the Siuslaw National Forest, congress designated this 31,500 acre area for public outdoor recreation use and enjoyment" as well as -eonservation of scenic, historic, scientific, and other values contributing to public enjoyment" (ODNRA Management Plan, 1994, p. 8). It is interesting to note that out of the 31,500 acres designated for ODNRA, the Forest Service only manages 28,900 acres. The remaining land is mostly managed by the Oregon State Parks System. ODNRA is unique because it has one of the targest expanses of temperate costal sand dunes in the world," and the close proximity of ocean, forests, and sand dunes make the area home to plant and animal species not commonly found in other areas of the world (ODNRA Management Plan, 1994, p. 8). ODNRA rests on approximately 40 miles of Oregon coastline beginning north in Florence and ending south in Coos Bay (Figure 8). ODNRA averages 1.5 million visitors annually due to its mild climate and its convenient location off U.S. Highway 101. ODNRA provides a significant economic boost to communities located within the area's boundaries that once relied on fishing and wood products industries that have since 
declined. Sand Lake is another popular sand dunes riding area that is also managed by Siuslaw National Forest. Sand Lake covers 1,076 acres and is located on Oregon's North Coast. Sand Lake's features are similar to ODNRA with closer proximity to the Pacific Ocean as well as closer proximity to the Portland, OR metro area (USDA Forest Service, 2012).

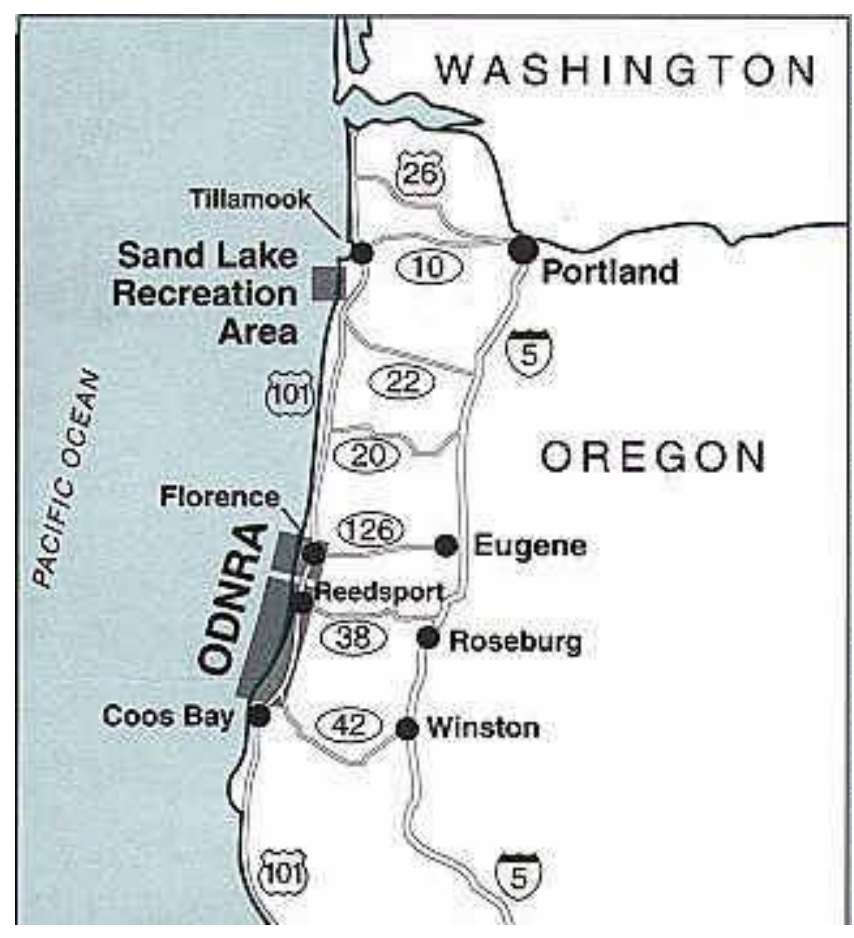

Figure 8. Location of ODNRA and Sand Lake

\section{Instrumentation}

2002 Study. The 2002 study was conducted in response to growing visitation and peak use congestion" at sites within ODNRA/Sand Lake (Graefe, Burns, Robinson, \& Lee, 2003, p. 2). The surveys consisted of exit interviews with mostly closed-ended questions. Some questions asked respondents to rate their overall satisfaction on a ten point scale $(1=-$ worst possible experience" to $10=$ - best possible experience"), as well as crowding, conflict and quality of recreation items on a five point scale ( $1=-$ strongly disagree" to $5=-$ strongly agree") (Appendix 
A). A participant was randomly sampled within his/her travel group. The survey was limited to individuals who were riding OHVs on the day they were contacted. The study was used to identify visitor characteristics, use patterns, perceptions, and management preferences. A total of 442 surveys were completed during the summer 2002 season that started in July and ended in September.

2006 Study. The 2006 study was a continuation of the 2002 study. The sampling procedures as well as most of the questions on the on-site interview were identical (Appendix B). However, in response to the 2003 alcohol ban enacted by the Siuslaw National Forest, survey questions were added to address managers' concern about the safety awareness of OHV users and the type of OHVs they use in the area. Also, as a result of the 2005 sand camping restrictions managers were interested in the types of campsites used by visitors, whether in the sand or at a developed campsite, and their perceptions of the sites. The surveys were completed from July to September 2006, and a total of 487 surveys were completed.

2011 Study. The 2011 study was another expansion of the 2002 and 2006 studies. Again, the sampling procedure was identical to the previous studies. The on-site interviews followed the same format as the 2006 survey with similar questions from the 2002 study (Appendix C), although the 2011 instrument did not ask any of the safety awareness questions that were asked in 2006. Instead the 2011 study focused on the socio-demographic characteristics of the OHV user. The survey asked questions about the age, race, income, and education background of the user. The 2011 study was also done during the summer season, but started around mid-June instead of July and lasted until the end of September. A total of 844 surveys were completed. Table 2 details the common variables from three cross-sectional surveys that were examined in this study. 
Table 2

Common variables included in the three cross-sectional surveys and examined in this dissertation 


\begin{tabular}{|c|c|c|c|c|}
\hline Visitor Characteristics & Satisfaction & $\begin{array}{l}\text { Crowding and } \\
\text { Conflict Items }\end{array}$ & Quality Items & Normative Variables \\
\hline Gender & $\begin{array}{l}\text { Overall experience at } \\
\text { ODNRA/Sand Lake }\end{array}$ & $\begin{array}{l}\text { I avoided my } \\
\text { favorite parts of } \\
\text { ODNRA/Sand Lake } \\
\text { because of too many } \\
\text { people (Crowding } \\
\text { Indicator) }\end{array}$ & $\begin{array}{l}\text { I thoroughly enjoyed } \\
\text { my trip }\end{array}$ & $\begin{array}{l}\text { Maximum number of } \\
\text { OHV encounters per day } \\
\text { that are acceptable }\end{array}$ \\
\hline First time visit & & $\begin{array}{l}\text { The number of } \\
\text { OHVs at the } \\
\text { recreation area } \\
\text { reduced my } \\
\text { enjoyment } \\
\text { (Crowding } \\
\text { Indicator) }\end{array}$ & $\begin{array}{l}\text { I thought the } \\
\text { recreation area and } \\
\text { its surroundings } \\
\text { were in good } \\
\text { physical condition }\end{array}$ & $\begin{array}{l}\text { Maximum number of } \\
\text { OHV encounters per day } \\
\text { tolerated }\end{array}$ \\
\hline Year of first visit & & $\begin{array}{l}\text { I stayed off the } \\
\text { dunes during parts of } \\
\text { the day because } \\
\text { there were too many } \\
\text { OHVs in the area } \\
\text { (Crowding } \\
\text { Indicator) }\end{array}$ & $\begin{array}{l}\text { My trip was well } \\
\text { worth the money I } \\
\text { spent to take it }\end{array}$ & \\
\hline Number of visits per year & & $\begin{array}{l}\text { The behavior of } \\
\text { other people at the } \\
\text { recreation area } \\
\text { lowered the quality } \\
\text { of my experience } \\
\text { (Conflict Indicator) }\end{array}$ & $\begin{array}{l}\text { I was disappointed } \\
\text { with some aspects of } \\
\text { my trip }\end{array}$ & \\
\hline $\begin{array}{l}\text { Number of days per visit } \\
\text { Primary residence } \\
\text { Travel distance } \\
\text { Group size } \\
\text { Group type }\end{array}$ & & & & \\
\hline
\end{tabular}




\section{Sampling Plan}

The ODNRA/Sand Lake study is part of a larger project conducted in the Siuslaw

National Forest to better understand visitors and help inform decision making. The survey areas and sites are listed in Table 3 . The study used a stratified sampling method similar to the USDA Forest Service‘s NVUM study. Survey days were conducted during a six hour period, 8 am-2pm, $10 \mathrm{am}-4 \mathrm{pm}, 11 \mathrm{am}-5 \mathrm{pm}$, and 2pm-8pm. Survey times as well as survey participants were randomly selected. The interviewers were stationed at a visible area, normally in the staging area of the OHV study site. The interviewers approached users as they were exiting the trail. The exit survey was administered once the interviewer received consent to proceed with the interview.

Table 3

ODNRA/Sand Lake OHV Sampling Locations

\begin{tabular}{ll}
\hline Survey Area & \multicolumn{1}{c}{ Study Site } \\
\hline Oregon Dunes & Hauser \\
& Horsfall \\
& South Jetty \\
& Spinreel \\
& Umpqua Beach \\
& Siltcoos \\
\hline Sand Lake & Derrick Road \\
& East Dunes \\
& Sand Beach CG \\
& West Winds \\
\hline
\end{tabular}

\section{Data Analysis}

Data from variables that were collected in all three study years were merged into a single dataset. The data were analyzed using SPSS version 20 and Analysis of Moment of Structures (AMOS) was used to create the Structural Equation Models. This section presents the statistical analysis that was used to address each of the research questions. 
RQ1: Who are the visitors of ODNRA/Sand Lake?

Descriptive statistics of OHV users were reported and data were checked for normality (Barker \& Dawson, 2010). As stated earlier, only the 2011 study focused on the sociodemographic characteristics of the OHV user. Descriptive statistics of trip characteristics such as trip length, group size, and group type were reported for the entire dataset.

RQ2: What are the displacement trends of ODNRA/Sand Lake over the ten year study period (i.e., changes in gender, previous visits, and trip characteristics)?

Descriptive statistics of gender across the three study periods $(2002,2006$, and 2011) at Siuslaw Nation Forest were collected from the USDA Forest Service National Visitor Use Monitoring (NVUM) webpage. For ODNRA/Sand Lake, descriptive statistics of visitor and trip characteristics were also compared across the three study periods. The variables examined include gender, number of previous visits, and other trip characteristics. A Chi-square statistical test was used to examine associations between gender and study year. The chi-square tests were helpful in determining the types of visitors that may have been displaced over the ten year study period.

RQ3: What are the crowding and conflict sensitivity trends over the ten year study period (i.e., perceptions of crowding, perceptions of conflict, crowding matters, crowding-quality relationships, conflict-quality relationships)?

Mean scores were compared using a one-way analysis of variance and Scheffe post hoc to determine if perceptions of crowding and conflict changed over the study period (Cooper, 2010). A Chi-square statistical test was used to examine associations between crowding and whether or not it mattered to visitors by study year.

Reliability of the scale items that operationally define perceived crowding and quality of 
outdoor recreation were examined by calculating Cronbach`s alpha. Structural Equation Modeling (SEM) was used to assess the fit of the model with the data in the Analysis of Moment of Structures (AMOS). AMOS was used because of its ability to go beyond the usual capabilities found in other structural equation modeling programs. When confronted with missing data, AMOS perform state-of-the-art estimation by full maximum likelihood instead of relying on adhoc methods like listwise or pairwise or mean imputation. The program can analyze simultaneously data from several populations. It can also estimate means for exogenous variables and intercepts in regression equations (Arbuckle, 2010). Confirmatory factor analysis (CFA) was used to assess the observed-latent variables relationships (Shestha, et al., 2012). Structural model assessment was performed by calculating path coefficients (regression weights). The fit of the measurement model and structural model was assessed using Chi-square fit index. However, because of the high sensitivity of Chi-square to sample size (Garson, 2011), other popular goodness of fit measures were applied (Arbuckle 2010; Jaccard \& Wan 1996; Kline 1998). These measures include CMIN/DF ratio, Comparative Fit Index (CFI), Normed Fit Index (NFI), and the Root Mean Square Error of Approximation (RMSEA). According to Kline (1998), a CMIN/DF ratio between 2:1 and 5:1 Likewise, RMSEA below .08 is considered as an adequate fit and both CFI and NFI should be equal to or greater than .90 to accept the model (Garson, 2011). Path coefficients and their critical ratios (CRs - an equivalent of $t$-value for regression weights) were used for testing the hypothesis at $(\alpha=.05)$. A critical ratio of 1.96 indicated that the path coefficient was significant at $(\alpha=.05)$. An overall SEM model was created as well as a SEM model for each study year (i.e. 2002, 2006, and 2011). The model variables include crowding, conflict, and quality of outdoor recreation.

RQ4: How does crowding and conflict sensitivity compare by gender and first-time visitors? 
Similar to Research Question 3, SEM was used to assess the fit of the models. Two SEM models were created for gender, one model for females, and another model for males, while two more SEM models were created for repeat and first time visitors.

RQ5: What are the trends in visitor satisfaction and quality outdoor recreation over the ten year study period?

Mean scores were compared using a one-way analysis of variance and Scheffe post hoc to determine if satisfaction/quality of visits changed over the ten year study period.

RQ6: How do encounters with people and OHVs compare to visitor norms (i.e., acceptable and tolerable number of encounters)?

Mean scores were compared using a one-way analysis of variance and Scheffe post hoc to determine if encounter levels of people and OHVs differ at ODNRA/Sand Lake. Using the entire dataset, mean values and other measures of central tendency were computed for actual, acceptable, and tolerable OHV encounters.

\section{Conclusion}

This section examined the methodology and data analysis used in this ODNRA/Sand Lake study. The conceptual framework presented in Figure 6 guided the development of these six research questions. They are based on carrying capacity concerns at ODNRA/Sand Lake and what management action needs to be implemented in order to contend with these carrying capacity issues. 


\section{Chapter IV}

\section{Results}

The purpose of this research is to combine data from three cross-sectional surveys (2002, 2006, and 2011) to examine OHV user displacement trends, trends in levels of sensitivity to crowding and conflict, and satisfaction trends at ODNRA/Sand Lake. To address this problem, six research questions were examined. This chapter presents the results of each of those questions including: (1) Who are the visitors of ODNRA/Sand Lake? (2) What are the displacement trends of ODNRA/Sand Lake over the ten year study period (i.e., changes in gender, previous visits, and trip characteristics)? (3) What are the crowding and conflict $\underline{\text { sensitivity trends }}$ over the ten year study period (i.e., perceptions of crowding, perceptions of conflict, crowding matters, crowding-quality relationships, conflict-quality relationships)? (4) How does crowding and conflict sensitivity compare by gender and first-time visitors? (5) What are the trends in visitor satisfaction and quality outdoor recreation over the ten year study period?

(6) How do encounters with people and OHVs compare to visitor norms (i.e., acceptable and tolerable number of encounters)?

Figure 9 illustrates the number of respondents for each study year. A total of 1,773 surveys were analyzed. There were 442 respondents in 2002 (24.9\% response rate), 487 respondents in 2006 (27.5\% response rate), and 844 respondents in 2011 (47.6\% response rate). The increased number of respondents does not reflect an increase in population, rather more interviewers were available at more locations during the 2011 study. 


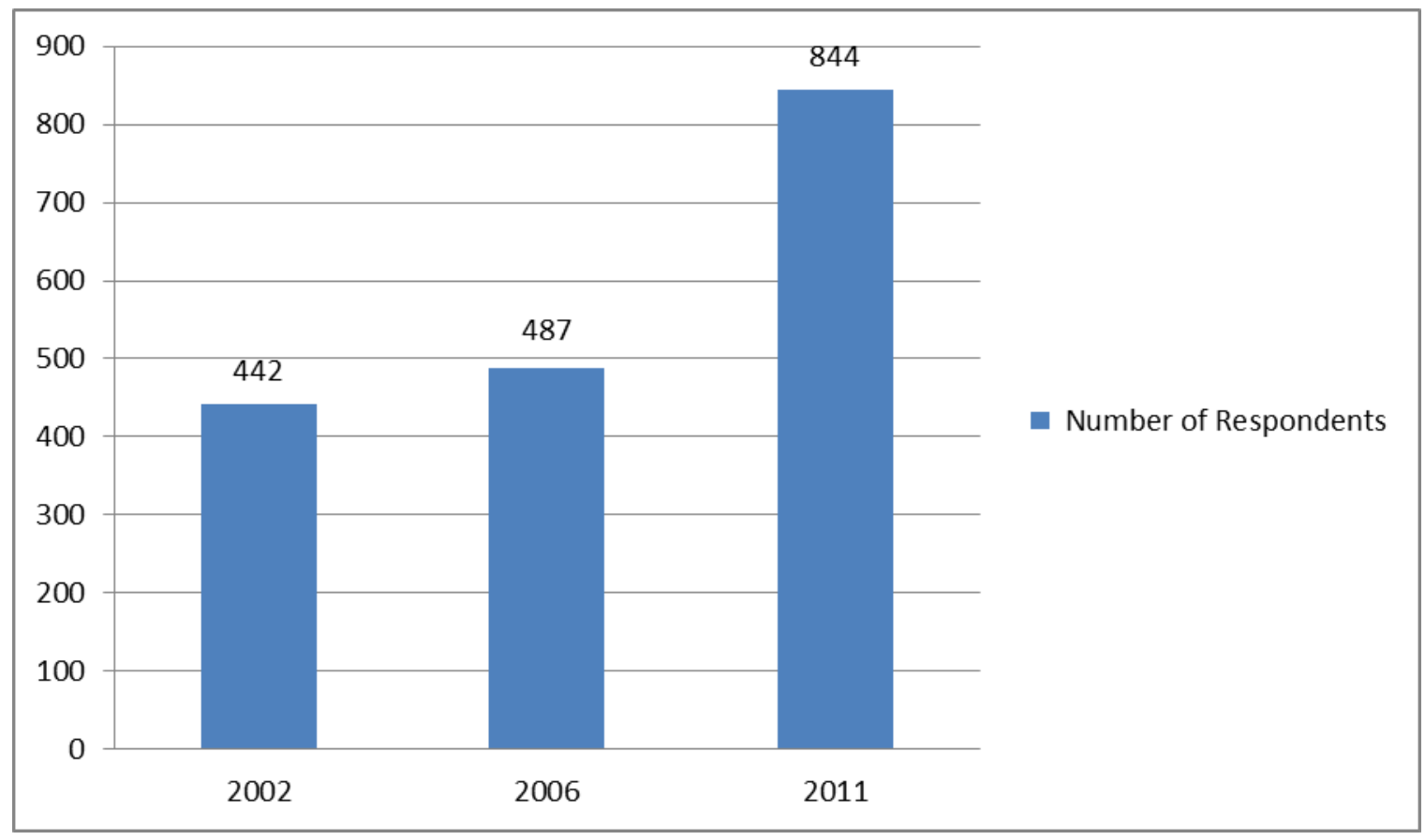

Figure 9. Survey respondents at ODNRA/Sand Lake for 2002, 2006, 2011

\section{RQ1: Who are the visitors of ODNRA/Sand Lake?}

Of the 1,773 respondents completed the survey instrument, 1,213 were males $(68 \%)$ and 501 were females (28\%) during 2002, 2006, and 2011. As previously stated, most demographic information was reported only in the 2011 study. Using the information from $2011(\mathrm{n}=844)$, the respondents $^{6}$ ages ranged from 16 to over 70 with the average respondent between 41-50 years. The majority of respondents had a high school diploma or less $(50 \%)$, followed by technical school/two year college (29\%), Bachelor's degree (13\%), Master's degree (4\%), and Ph.D. or professional (1\%). Most respondents“ income was $\$ 50,000-\$ 100,000$ per year $(27 \%)$, followed by $\$ 25,000-\$ 50,000(18 \%)$, and $\$ 100,000-\$ 150,000(14 \%)$. The majority of respondents were white and not of Hispanic origin (82\%).

Of the 1,773 total respondents, 85 percent have been to ODNRA/Sand Lake before, with the average year of first visit in 1993. Respondents visited ODNRA/Sand Lake and average 12 
times per year and three days per trip at the area. The mean driving distance from home to ODNRA/Sand Lake is 232 miles for respondents. Respondents had an average of seven individuals in their group, and the majority of groups consisted of family members (38\%), family and friends (27\%), more than one family (13\%), unrelated friends (11\%), organized group or club $(7 \%)$, or one person traveling alone $(2 \%)$.

\section{RQ2: What are the displacement trends of ODNRA/Sand Lake over the ten year study period (i.e. changes in gender, previous visits, and trip characteristics)?}

Visitor and trip characteristics were compared across the three study periods to better understand what displacement trends OHV visitors may have been encountering. The variables examined include gender, previous visits, and trip characteristics.

Gender of ODNRA/Sand Lake Visitors. From 2002 to 2011 gender of ODNRA/Sand Lake visitors changed significantly (Chi-square $=33.21, p<.001)$ (Figure 10). The number of males went from 82 percent in 2002 to 66 percent in 2006. The number of males increased to 68 percent in 2011. The number of females went from 18 percent in 2002 to 34 percent in 2006 . The number of females decreased to 32 percent in 2011. A chi-square goodness of fit was performed with gender and year of study. The relationship between gender and year of study was significant $X^{2}(2, N=1714)=33.21, p<.001$. 


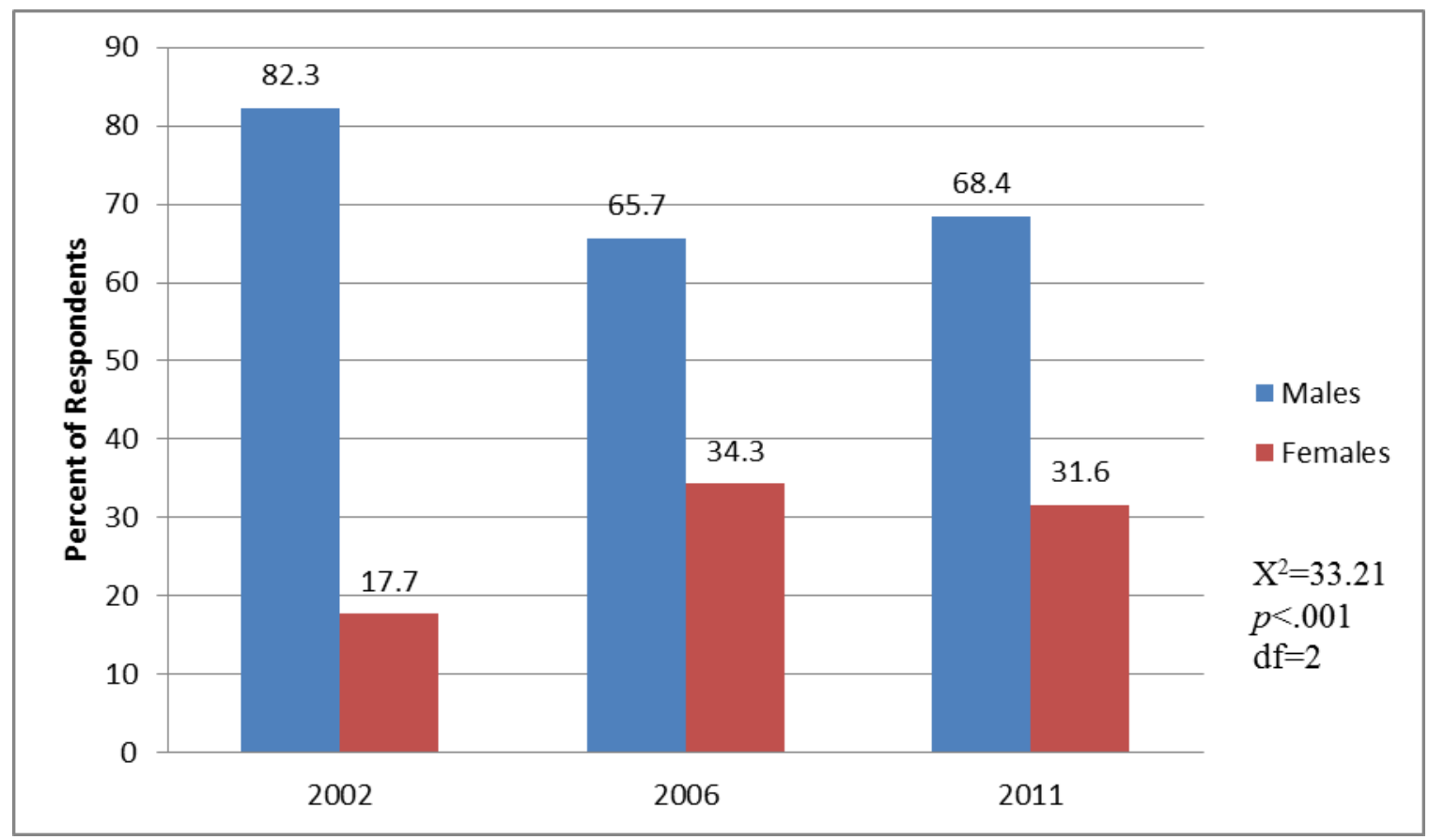

Figure 10. Gender of visitors at ODNRA/Sand Lake in 2002, 2006, and 2011

Previous Visits. Between 2002 and 2011 the number of repeat visitors of ODNRA/Sand Lake was much higher than first time visitors (Figure 11.) The association between repeat visitors and year of study was significant $X^{2}(2, N=1675)=11.15, p<.005$. Repeat visitors dropped from 93 percent in 2002 to 86 percent in 2006. It is interesting to note that more repeat visitors returned in $2011(90 \%)$. 


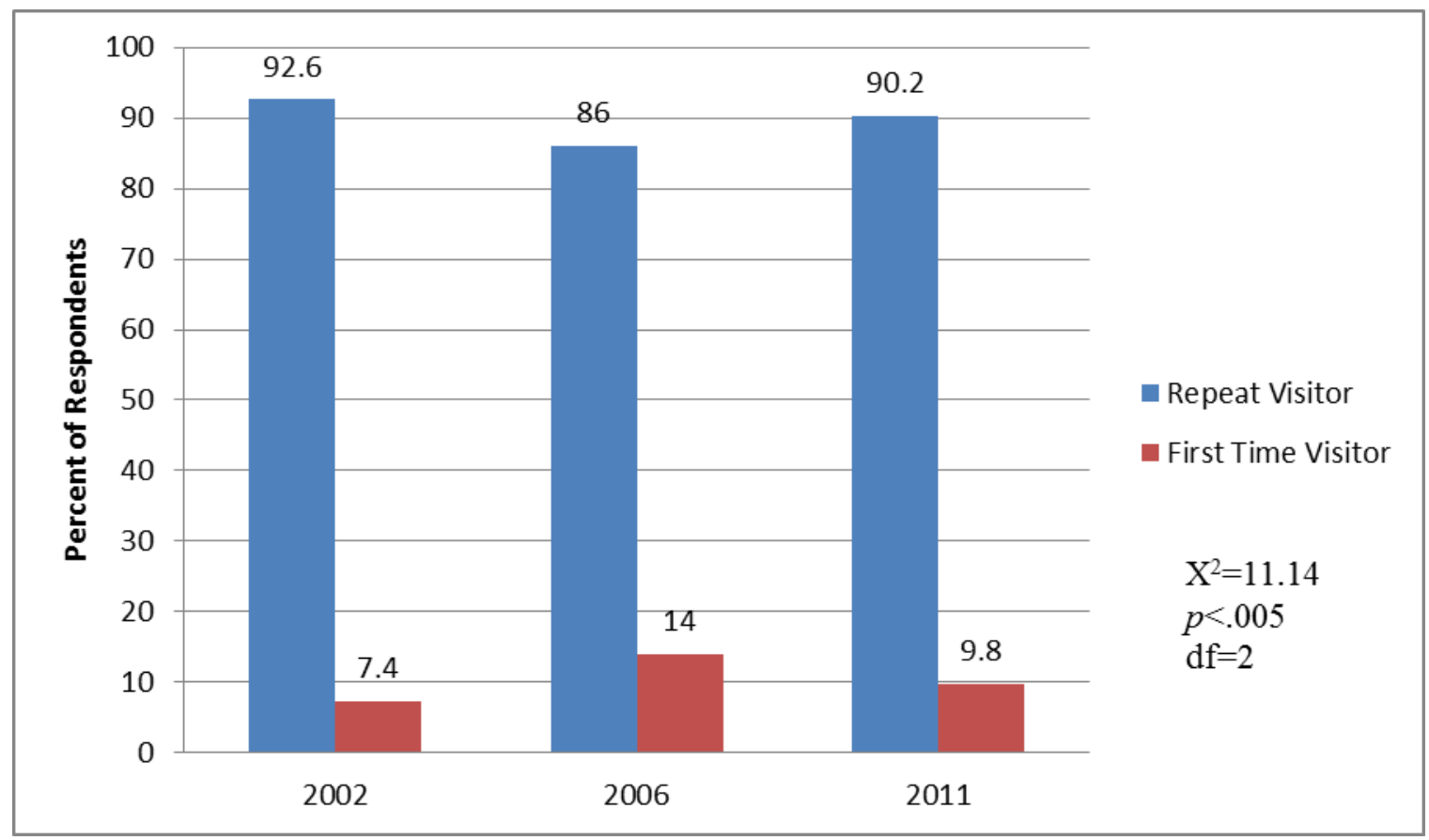

Figure 11. Previous Visits by ODNRA/Sand Lake Respondents in 2002, 2006, and 2011

Trip Characteristics. The trip characteristics that were examined include: years visited ODNRA/Sand Lake, number of visits per year, length of stay, travel distance, group size, and group type (Table 4). Years visited-- The total number of years a respondent visited ODNRA/Sand Lake were calculated by subtracting the year of study from the year the respondent first visited ODNRA/Sand Lake. From 2002 to 2011, the average years visited increased from 11.85 years in 2002, to 13.19 years in 2006, and 15.45 years in 2011. Number of visits per year-- Between 2002 and 2006, the average annual visits of respondents changed significantly $(\mathrm{p}<.05)$. The average annual visits went from 17.01 times per year in 2002 , to 8.31 times per year in 2006. The annual visits increased in 2011 to 10.62 times per year. Length of stay--The average number of days spent at ODNRA/Sand Lake increased from 2.84 days in 2002 to 4.00 days in 2006. The number of days spent at ODNRA/Sand Lake decreased in 2011 to 3.54. Travel distance--Although most respondents reported being from the Coos Bay, OR area, 
the average number of miles from primary residence to ODNRA/Sand Lake increased, moving from 184.68 miles in 2002 , to 226.71 miles in 2006 , then to 262.29 miles in 2011 . Group size-The number of people in a group at ODNRA/Sand Lake averaged 7.29 in 2002, and remained roughly the same at 6.93 in 2006, and 6.33 in 2011. Group type--Between 2002 and 2011, groups consisted mostly of family members as well as family and friends (Figure 12). In 2002, 33 percent of respondents were family members while 35 percent were family and friends. Family members increased to $35 \%$ in 2006 , while family and friends stayed the same at 35 percent. The percentage of respondents who were with family members was 42 percent in 2011 and the percentage who was with family and friends was 41 percent. The association between group type and year of study was significant $X^{2}(10, N=1666)=626.50, p<.001$.

Table 4

Trip Characteristics by Study Year

\begin{tabular}{|c|c|c|c|c|c|}
\hline Variable & $\begin{array}{c}2002(a) \\
M\end{array}$ & $\begin{array}{c}2006(\mathrm{~b}) \\
\mathrm{M}\end{array}$ & $\begin{array}{c}2011(\mathrm{c}) \\
\mathrm{M}\end{array}$ & $F$ & $\begin{array}{l}\text { Scheffe } \\
\text { Post Hoc }\end{array}$ \\
\hline Years visited & 11.85 & 13.19 & 15.45 & $12.93 * * *$ & $\mathrm{a}<\mathrm{c}, \mathrm{b}<\mathrm{c}$ \\
\hline Number of visits per year & 17.01 & 8.31 & 10.62 & $9.68 * * *$ & $a>b, c$ \\
\hline Length of stay & 2.84 & 4.00 & 3.54 & $15.98 * * *$ & $\mathrm{a}<\mathrm{b}>\mathrm{c}$ \\
\hline Travel distance & 184.68 & 226.71 & 262.29 & $5.46^{*}$ & $\mathrm{a}<\mathrm{c}$ \\
\hline Group Size & 7.29 & 6.93 & 6.33 & 1.14 & ns \\
\hline
\end{tabular}




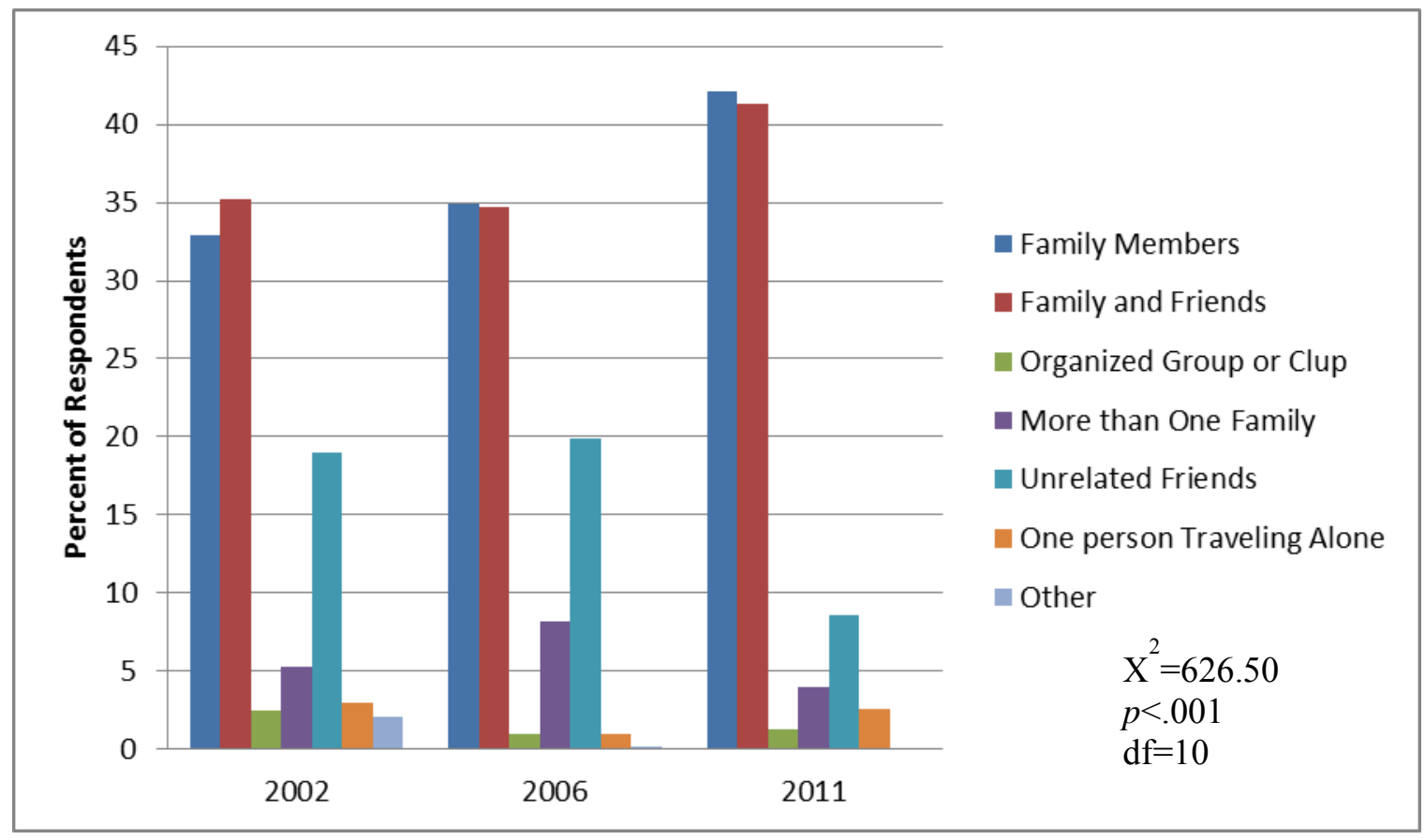

Figure 12. Group Types at ODNRA/Sand Lake in 2002, 2006, and 2011

RQ3: What are the crowding and conflict sensitivity trends over the ten year study period (i.e., perceptions of crowding, perceptions of conflict, crowding matters, crowding-quality relationships, conflict-quality relationships)?

Perceptions of Crowding and Conflict. OHV visitor perceptions of crowding and conflict were examined. Respondents were asked to rate their level of crowding during their visit to ODNRA/Sand Lake on a nine point scale (1= not at all crowded" to 9 -extremely crowded"). The level of crowding was rated as low to moderate $(M=2.93)$ by respondents in 2002 .

Crowding levels significantly $(p<.001)$ increased $(M=4.11)$ in 2006 and then returned to more moderate levels $(M=2.47)$ in 2011 . The same trend was observed for other measures of crowding (i.e., I avoided my favorite parts of ODNRA/Sand Lake because there were too many people ${ }^{6}$ I I stayed off the dunes during parts of the day because there were too many OHVs in the area $^{6}$, and the number of OHVs at the recreation area reduced my enjoyment') and conflict (i.e., the behavior of other people at the recreation area lowered the quality of my experience $\left.{ }^{6}\right)$. The 
latter crowding and conflict items were measured on a five point scale ( $1=-$ strongly disagree" to $5=-$ strongly agree") (Table 5). Respondents reported a significant difference $(p<.001)$ between the crowding and conflict items and the three study years. In 2011, respondents disagreed with all of the crowding and conflict items the most: _avoided' $(M=1.99)$, stayed off dunes“ $(M=1.73)$, number of OHVs reducing enjoyment $(M=1.94)$, and _behavior of other people at the recreation area' $(M=1.79)$. In 2006, the crowding and conflict items that respondents disagreed with the least were:_avoided‘ $(M=2.32)$, stayed off dunes' $(M=2.31)$, number of OHVs reducing enjoyment' $(M=2.19)$, and _behavior of other people at the recreation area' $(M=2.31)$. These results suggest that crowding and conflict was less of a concern in 2011 than it was in 2006.

Table 5

Perceived Crowding and Conflict by study year (ANOVA)

\begin{tabular}{|c|c|c|c|c|c|}
\hline Variable & $\begin{array}{l}2002 \\
\text { (a) } \\
\mathrm{M}\end{array}$ & $\begin{array}{c}2006 \\
(\mathrm{~b}) \\
\mathrm{M}\end{array}$ & $\begin{array}{c}2011 \\
(\mathrm{c}) \\
\mathrm{M}\end{array}$ & $F$ & $\begin{array}{l}\text { Scheffe } \\
\text { Post Hoc }\end{array}$ \\
\hline $\begin{array}{l}\text { How crowded did you feel on } \\
\text { ODNRA/Sand Lake during your visit? } \\
\text { (overall crowding) }\end{array}$ & 2.93 & 4.11 & 2.47 & $104.86^{* * *}$ & $\mathrm{a}<\mathrm{b}>\mathrm{c}$ \\
\hline $\begin{array}{l}\text { I avoided my favorite parts of } \\
\text { ODNRA/Sand Lake because there were too } \\
\text { many people (crowding item) }\end{array}$ & & & & & \\
\hline $\begin{array}{l}\text { I stayed off the dunes during parts of the day } \\
\text { because there were too many OHVs in the } \\
\text { area (crowding item) }\end{array}$ & 1.96 & 2.31 & 1.73 & $55.09 * * *$ & $a<b>c$ \\
\hline $\begin{array}{l}\text { The number of OHVs at the recreation area } \\
\text { reduced my enjoyment (crowding item) }\end{array}$ & 2.03 & 2.19 & 1.94 & $10.68^{* * *}$ & $a<b>c$ \\
\hline $\begin{array}{l}\text { The behavior of other people at the } \\
\text { recreation area lowered the quality of my } \\
\text { experience (conflict item) }\end{array}$ & 2.16 & 2.31 & 1.79 & $50.00 * * *$ & $\mathrm{a}>\mathrm{c}, \mathrm{b}>\mathrm{c}$ \\
\hline
\end{tabular}


Note: Overall crowding was measured on a 9-point scale (1="not at all crowded" to 9="extremely crowded") and crowding and conflict items were measured on a 5 -point scale ( $1=$ "strongly disagree to $5=-$-strongly agree")

$* \mathrm{p}<0.05, * * \mathrm{p}<0.01, * * * \mathrm{p}<0.001$

Crowding Matters. Respondents were asked about the maximum number of OHVs they would find acceptable to see and tolerate seeing at ODNRA/Sand Lake. The options were either -does not matter" or -does matter (including those that could not specify number).” This question was used to determine if crowding mattered to respondents. From 2002 to 2011, acceptable matters changed significantly (Chi-square $=55.14, p<.001)$ (Figure 13). In 2002 and 2006 , the majority of respondents ( $53 \%$ and $63 \%$ respectively) state that the maximum number acceptable mattered but could not specify a number. In 2011, the majority of respondents (58\%) say the maximum number acceptable did not matter. A chi-square goodness of fit was performed with acceptable matters and year of study. The relationship between acceptable and year of study was significant $X^{2}(2, N=1672)=55.14, p<.001$.

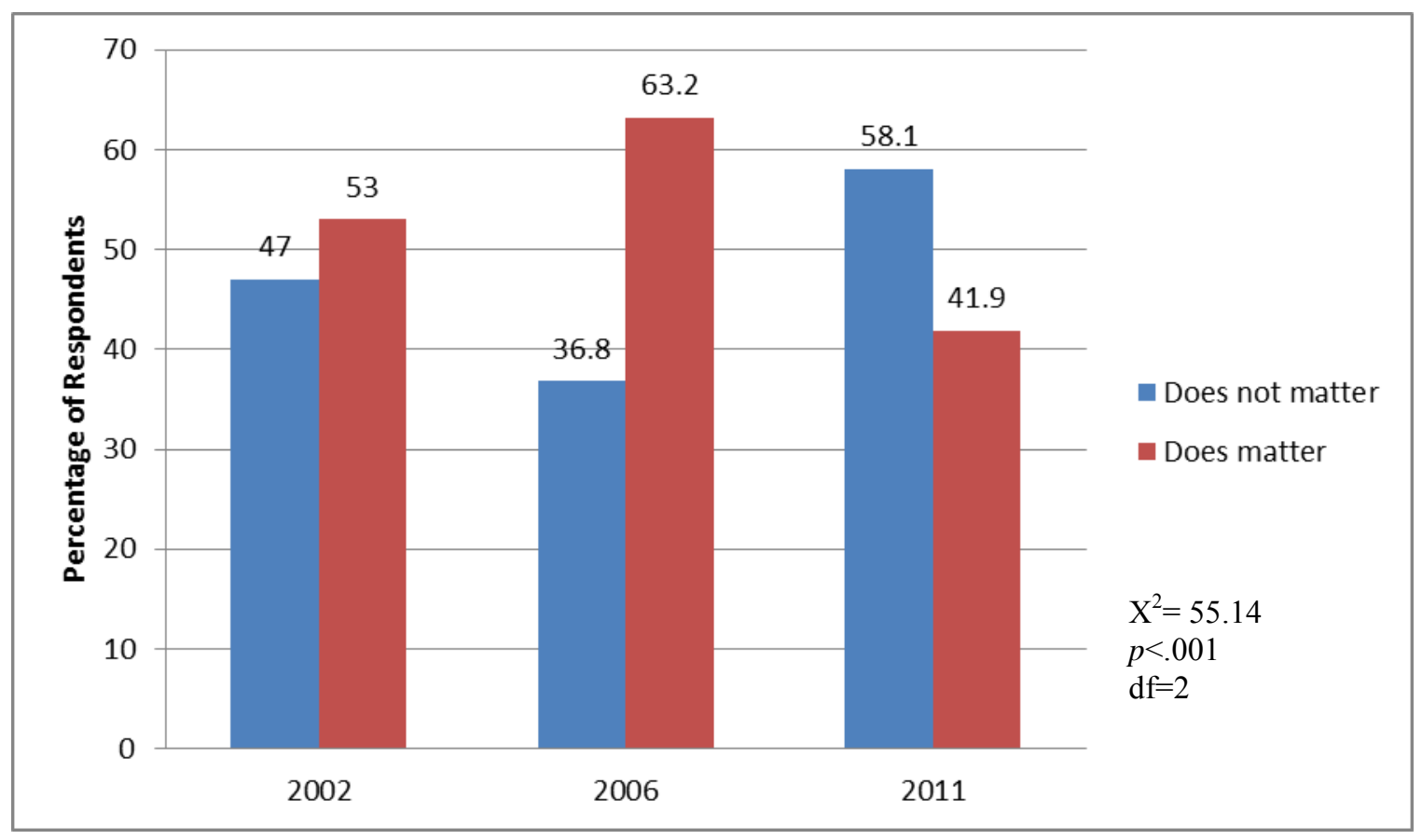

Figure 13. Crowding Matters (acceptability scale) by ODNRA/Sand Lake Respondents in 2002, 
2006, and 2011

From 2002 to 2011, tolerable matters changed significantly (Chi-square $=34.15, p<.001)$ (Figure 14). The number of respondents who state that the maximum number tolerable did not matter went from 48 percent in 2002 to 32 percent in 2006, and then increased to 47 percent in 2011. The number of respondents who state that the maximum number tolerable mattered but could not specify a number went from 53 percent in 2002 to 68 percent in 2006, then decreased to 53 percent in 2011. A chi-square goodness of fit was performed with tolerable matters and year of study. The relationship between tolerable matters and year of study was significant $X^{2}(2$, $N=1773)=34.15, p<.001$.

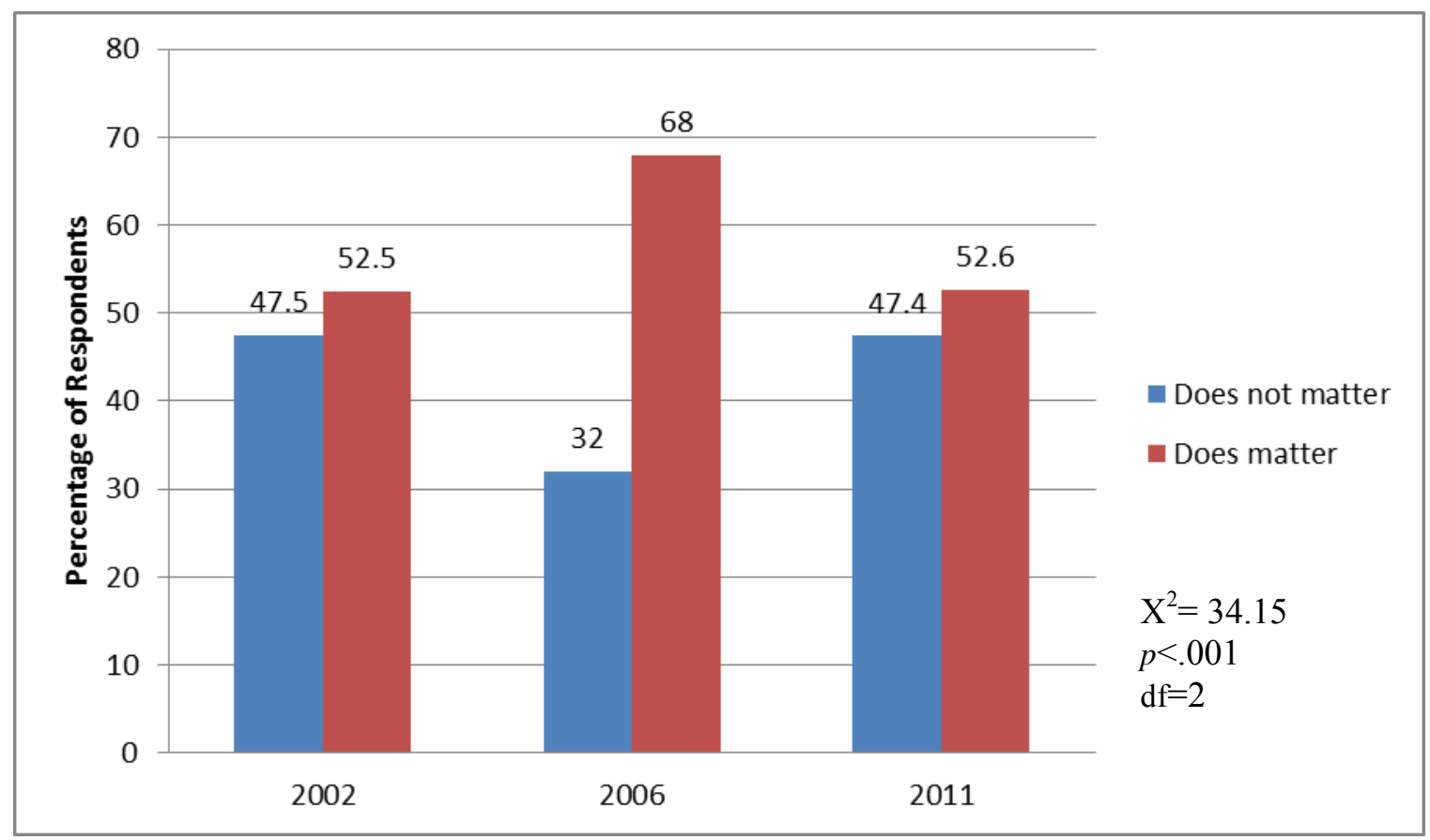

Figure 14. Crowding Matters (tolerance scale) by ODNRA/Sand Lake Respondents in 2002, 2006, and 2011

Crowding-Quality and Conflict-Quality Relationships. Structural Equation Modeling will help provide additional clarification regarding the relationships between crowding and quality and conflict and quality of OHV users. 
Structural Equation Modeling. Structural Equation Modeling (SEM) is a combination of path analysis and factor analysis. For instance, in a path analysis model $\mathrm{X} \rightarrow \mathrm{Y} \rightarrow \mathrm{Z}, \mathrm{X}, \mathrm{Y}$, and $\mathrm{Z}$ are measured variables while the arrows are hypothesized, causal effects (Klem, 2000). In SEM, X, Y, and Z are still measured (observed) variables and the arrows are hypothesized causal effects, but the concern is with the factors. Factors are unmeasured (latent) variables that underlie the observed variables. SEM attempts to explain relationships among many observed variables relative to a small number of latent variables as well as allowing both measured and latent variables to be examined at the same time (Vaske, 2008). SEM is a useful tool in longitudinal studies, because it becomes possible to make stronger interpretation of the current situation than it is possible with data from a single time point (Klem, 2000). Confirmatory factor analysis (CFA) is the first step in SEM. CFA is used to determine whether the constructs of the variables provide an acceptable fit to the data (Allegretti, Vaske, \& Cottrell, 2012). CFAs are used to assess psychological properties of a measurement and assess the adequacy of measured latent factors in preparation for a full latent model assessment (Vaske, 2008).

Overall Model. The confirmatory factor analysis demonstrated that the data provided an acceptable fit to the constructs of experience use history (EUH), crowding, conflict, and quality of outdoor recreation (Table 6). Cronbach's alpha calculated for crowding and quality of outdoor recreation and were .716 and .605 respectively. These reliability scores are within the range of what is normally deemed as acceptable (Vaske, 2008). The item means, standard error, critical ratio and Cronbach alpha are reported in Table 7. 
Table 6

Structural Equation Model Variables

\begin{tabular}{llll}
\hline $\begin{array}{l}\text { Experience Use } \\
\text { History (EUH) } \\
\text { Years Visited }\end{array}$ & Crowding & Conflict & $\begin{array}{l}\text { Quality of Outdoor } \\
\text { Recreation }\end{array}$ \\
Visits per Year & $\begin{array}{l}\text { Avoided because too } \\
\text { many people } \\
\text { (Crowding 1) }\end{array}$ & $\begin{array}{l}\text { Behavior of others } \\
\text { reduced enjoyment }\end{array}$ & $\begin{array}{l}\text { Thoroughly enjoyed trip } \\
\text { (Quality 1) }\end{array}$ \\
& $\begin{array}{l}\text { Number of OHVs } \\
\text { reduced enjoyment } \\
\text { (Crowding 2) }\end{array}$ & & $\begin{array}{l}\text { Recreation area in good } \\
\text { condition (Quality 2) }\end{array}$ \\
& $\begin{array}{l}\text { Stayed off dunes } \\
\text { because crowded } \\
\text { (Crowding 3) }\end{array}$ & & $\begin{array}{l}\text { Trip well worth money } \\
\text { spent (Quality 3) }\end{array}$ \\
& & & $\begin{array}{l}\text { Disappointed with } \\
\text { aspects of trip (Quality 4) }\end{array}$ \\
\hline
\end{tabular}


Table 7

Crowding and Quality of Outdoor Recreation $(N=1,645)$

\begin{tabular}{|c|c|c|c|c|c|}
\hline Factor & Statement & Mean & $\mathrm{SE}$ & $\mathrm{CR}$ & $\alpha$ \\
\hline \multirow[t]{4}{*}{ Crowding } & I avoided my favorite parts of Oregon & 2.10 & .044 & $20.09 *$ & .716 \\
\hline & $\begin{array}{l}\text { Dunes/Sand Lake because there were too } \\
\text { many people }\end{array}$ & & & & \\
\hline & $\begin{array}{l}\text { The number of OHVs at the recreation area } \\
\text { reduced my enjoyment }\end{array}$ & 2.04 & .039 & $20.69 *$ & \\
\hline & $\begin{array}{l}\text { I stayed off the dunes during parts of the day } \\
\text { because there were too many OHVs in the } \\
\text { area }\end{array}$ & 1.96 & ns & ns & \\
\hline \multirow{4}{*}{$\begin{array}{l}\text { Quality of } \\
\text { Outdoor } \\
\text { Recreation }\end{array}$} & I thoroughly enjoyed my trip & 4.51 & .065 & $13.98 *$ & .605 \\
\hline & $\begin{array}{l}\text { I thought the recreation area and its } \\
\text { surroundings were in good physical condition }\end{array}$ & 4.08 & ns & ns & \\
\hline & $\begin{array}{l}\text { My trip was well worth the money I spent to } \\
\text { take it }\end{array}$ & 4.38 & .068 & $14.12 *$ & \\
\hline & $\begin{array}{l}\text { (reverse coded) I was disappointed with some } \\
\text { aspects of my trip }\end{array}$ & 3.80 & .095 & $13.75^{*}$ & \\
\hline
\end{tabular}

$*$ Significant at $\mathrm{p}<.05$

Having demonstrated the reliability of the constructs, the structural equation model (SEM) was examined. The overall fit of the model was assessed using $X^{2}, X^{2} / \mathrm{df}$ (or CMIN, CMIN/DF in AMOS), NFI, CFI, and RMSEA. In SEM, a non-significant chi-square indicates no statistical differences between the observed variables (i.e. survey statements) and the latent concepts (i.e. crowding), implying the model fits the data. The chi-square in relation to the degrees of freedom should be between 2:1 and 5:1 (Kline, 1998). The model assessment statistics such as CMIN (253.549), CMIN/DF ratio (7.923), CFI (.918), NFI (.908), RMSEA (.063) and $\mathrm{R}^{2}$ (.38) indicated the data provided an adequate fit to the model (Table 12). While the overall model's chi-square was significant $\left(X^{2}=253.549, p<.001\right)$, the NFI and CFI were greater than 
.90 to indicate a good fit to the model. Finally, RMSEA was .063, also demonstrating a good fit of the data.

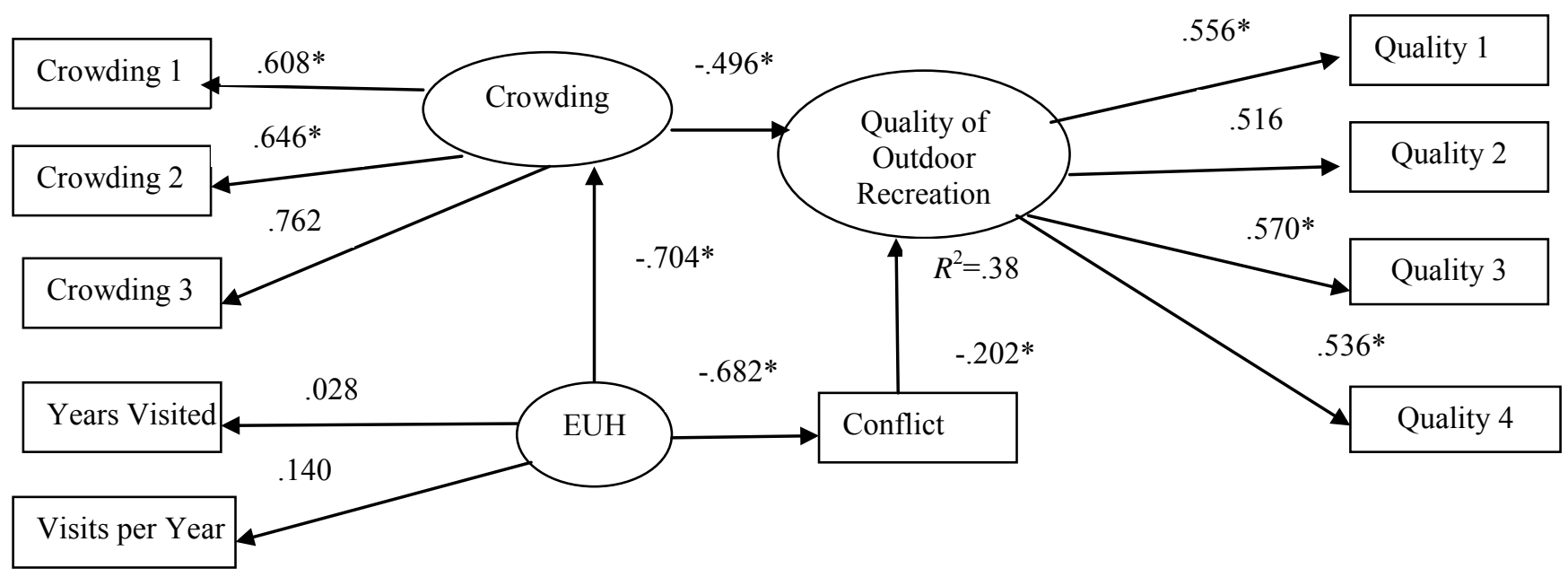

Figure 15. Overall SEM Model

$*$ Significant at $\mathrm{p}<.05$

Figure 15 displays the overall SEM model. A significant negative relationship between crowding and quality of outdoor recreation was observed $(\beta=-.496, p<.05)$. Similarly, there were significant negative and relationships between EUH and crowding $(\beta=-.704, p<.05)$ and conflict and quality $(\beta=-.202, p<.05)$. There was also a significant negative relationship between EUH and conflict $(\beta=-.682, p<.05)$. The negative coefficients indicate that as crowding, EUH, and conflict increase, quality decreases. Taken together, these three concepts explained 38 percent of the variability in quality of outdoor recreation.

Separate confirmatory analyses and SEM were examined for each study year (2002, 2006, and 2011). The fit indicators of these models are compared in Table 8. The SEM models for 2002, 2006, and 2011 are presented in Figure 16. Of the models tested for study years, the 2002 model had an adequate fit $\left(\mathrm{X}^{2} / \mathrm{DF}=5.130, \mathrm{CFI}=.891, \mathrm{NFI}=.872, \mathrm{RMSEA}=.097, \mathrm{R}^{2}=.47\right)$, the 2006 model had a poor fit $\left(\mathrm{X}^{2} / \mathrm{DF}=6.498, \mathrm{CFI}=.824, \mathrm{NFI}=.804, \mathrm{RMSEA}=.106, \mathrm{R}^{2}=.08\right)$, 
and the 2011 model had an adequate fit $\left(\mathrm{X}^{2} / \mathrm{DF}=16.318, \mathrm{CFI}=.747, \mathrm{NFI}=.739, \mathrm{RMSEA}=.135\right.$, $\mathrm{R}^{2}=.36$ ). Significant negative relationships between crowding, conflict and quality were documented for each of the three study years. In determining if crowding and conflict indicators of quality of outdoor recreation function differently over time, crowding had its greatest negative influence on quality in $2002(\beta=-.669, p<.05)$ and explained 47 percent of the variance.

Crowding decreased significantly in $2006(\beta=-.168, p<.05)$ and only explained 8 percent of the variance of quality. Crowding then increased again in $2011(\beta=-.485, p<.05)$ and explained 36 percent of the variance of quality. Conflict had its lowest negative influence on quality in 2002 $(\beta=-.152, p<.05)$, then gradually increased in $2006(\beta=-.226, p<.05)$, and $2011(\beta=-.374, p$ $<.05)$. The different coefficients for crowding between study years indicate instability of crowding over time at ODNRA/Sand Lake, while conflict becomes more prominent over time. Table 8

Overall Fit Indicators of Quality of Outdoor Recreation by Study Year

\begin{tabular}{lccc}
\hline Indicator & 2002 & 2006 & 2011 \\
\hline $\mathrm{X}^{2} / \mathrm{df}$ & 5.130 & 6.498 & 16.318 \\
$\mathrm{CFI}$ & .891 & .824 & .747 \\
$\mathrm{NFI}$ & .872 & .804 & .739 \\
$\mathrm{RMSEA}$ & .097 & .106 & .135 \\
$R^{2}$ & .47 & .08 & .36 \\
\hline
\end{tabular}




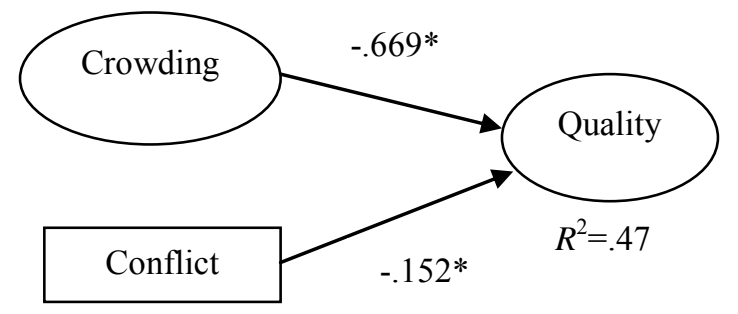

(a) 2002 Study

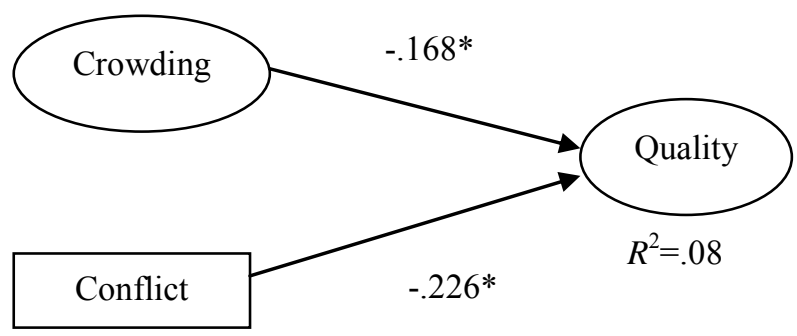

(b) 2006 Study

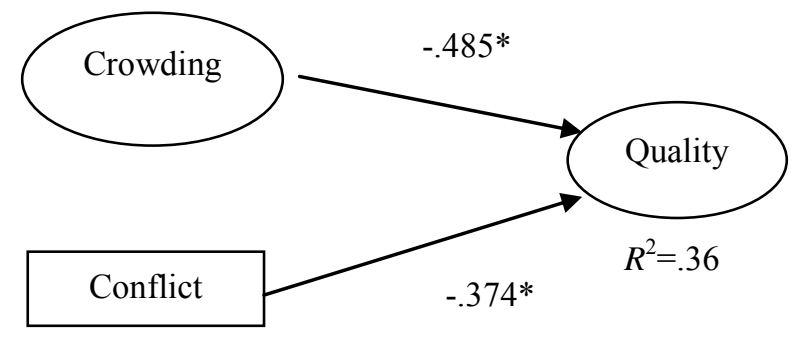

(c) 2011 Study

Figure 16. SEM for Study Years

$*$ Significant at $\mathrm{p}<.05$

RQ4: How does crowding and conflict sensitivity compare by gender and first time visitors?

SEM for Males and Females. Given males were displaced in 2006; we were interested in how the models function differently by gender. Separate confirmatory analyses and SEM were conducted for males and females. The fit indicators of these models are presented in Table 9, and 
the SEM models for males and females are presented in Figure 17. Both models had an adequate fit with the data. The model including male respondents fit the data slightly better than $\left(\mathrm{X}^{2} / \mathrm{DF}\right.$ $=10.669, \mathrm{CFI}=.819, \mathrm{NFI}=.807, \mathrm{RMSEA}=.089, \mathrm{R}^{2}=.30$ ), the model developed from female responses $\left(\mathrm{X}^{2} / \mathrm{DF}=6.888, \mathrm{CFI}=.762, \mathrm{NFI}=.741, \mathrm{RMSEA}=.109, \mathrm{R}^{2}=.35\right)$. Significant negative relationships between gender and crowding, EUH, conflict and quality were observed. Conflict had a stronger influence on quality in the model developed from female respondents $(\beta=-.368, p$ $<.05)$ when compared to male $(\beta=-.255, p<.05)$. EUH had weak relationships for crowding and conflict for both male and female models. It appears females are more sensitive to conflict than males based on the differing strength of relationships between conflict and quality in the two models. The weak relationships between EUH and crowding and conflict are not significant.

Table 9

Gender Differences in Overall Fit Indicators of Quality of Outdoor Recreation

\begin{tabular}{lll}
\hline Indicator & Males & Females \\
\hline $\mathrm{X}^{2} / \mathrm{df}$ & 10.669 & 6.888 \\
$\mathrm{CFI}$ & .819 & .762 \\
$\mathrm{NFI}$ & .807 & .741 \\
$\mathrm{RMSEA}$ & .089 & .109 \\
$R^{2}$ & .30 & .35 \\
\hline
\end{tabular}




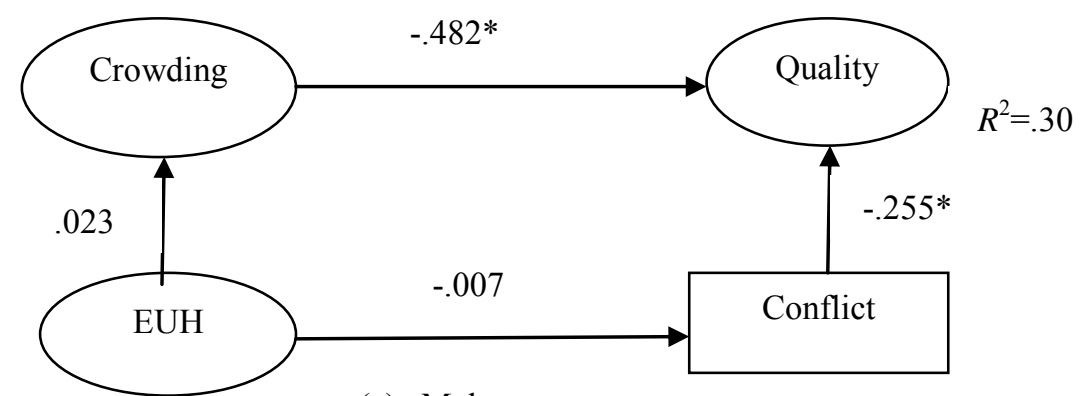

(a) Males

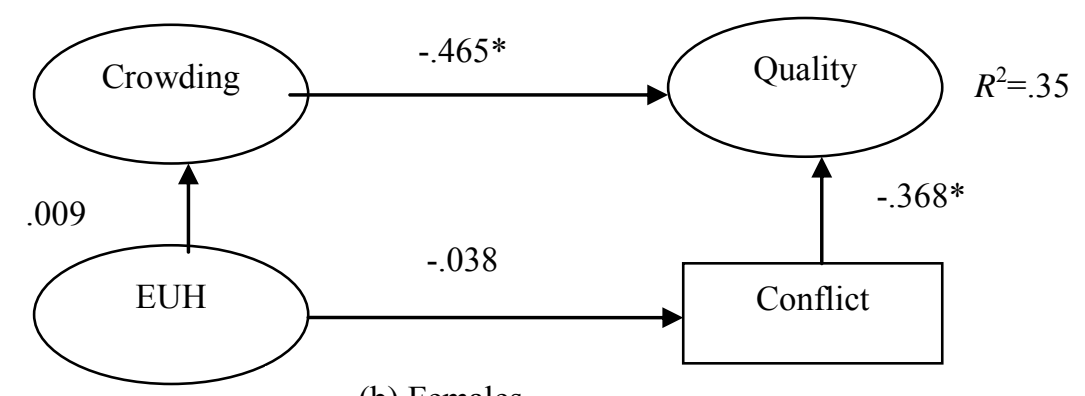

(b) Females

Figure 17. SEM for Males and Females

$*$ Significant at $\mathrm{p}<.05$

SEM for Repeat and First Time Visitors. Given repeat visitors were displaced in 2006, we were interested in how the model compared between repeat and first time visitors. Separate confirmatory analyses and SEM were conducted for repeat and first time visitors. The models had an adequate fit with the data (Kline, 1998). The fit indicators of these models are presented in Table 10. The SEM models are presented in Figure 18. Responses from repeat visitors had a slightly better fit with the model $\left(\mathrm{X}^{2} / \mathrm{DF}=21.274, \mathrm{CFI}=.819, \mathrm{NFI}=.813, \mathrm{RMSEA}=.116, \mathrm{R}^{2}=.30\right)$ when compared to first time visitors $\left(\mathrm{X}^{2} / \mathrm{DF}=6.483, \mathrm{CFI}=.587, \mathrm{NFI}=.573, \mathrm{RMSEA}=.178, \mathrm{R}^{2}\right.$ $=.34$ ). Significant negative relationships between crowding, conflict and quality were observed 
between repeat and first time visitors. Crowding had a stronger influence on quality in the model developed from repeat visitors $(\beta=-.482, p<.05)$ when compared to first time visitors $(\beta=-.424$, $p<.05)$. Conflict had a stronger influence on quality in the model developed from first time visitors $(\beta=-.587, p<.05)$ when compared to repeat visitors. The different coefficients between repeat and first time visitors indicate that repeat visitors are slightly more sensitive to crowding than first time visitors, while first time visitors are more sensitive to conflict than repeat visitors. Table 10

Repeat and First Time Visitor Differences in Overall Fit Indicators of Quality of Outdoor Recreation

\begin{tabular}{lll}
\hline Indicator & Repeat Visitor & First Time Visitor \\
\hline $\mathrm{X}^{2} / \mathrm{df}$ & 21.274 & 6.483 \\
$\mathrm{CFI}$ & .819 & .587 \\
$\mathrm{NFI}$ & .813 & .573 \\
$\mathrm{RMSEA}$ & .116 & .178 \\
$R^{2}$ & .30 & .34 \\
\hline
\end{tabular}




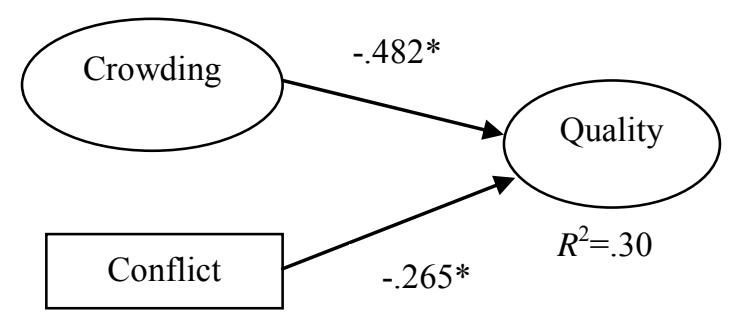

(a) Repeat Visitors

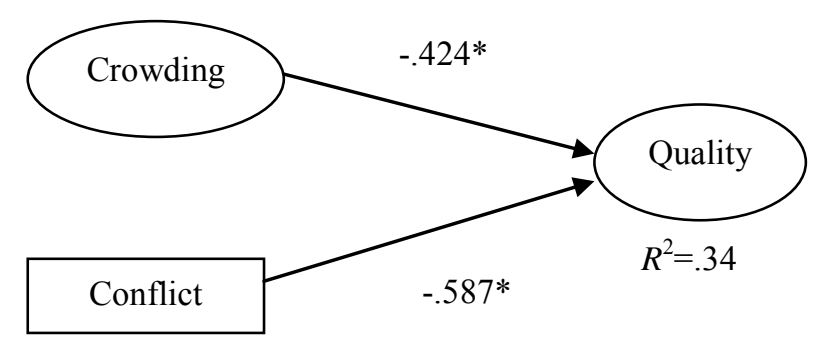

(b) First Time Visitors

Figure 18. SEM for Repeat and First Time Visitors

$*$ Significant at $\mathrm{p}<.05$

\section{RQ5: What are the trends in visitor satisfaction and quality outdoor recreation over the ten year study period?}

Overall satisfaction and quality items were examined by study year to assess whether the overall experience of OHV visitors improved over the ten year study period. Overall satisfaction significantly differed by study year $(F=17.36, d f=2, p<.001)$ and was greatest in $2011(\mathrm{M}=8.75)$. The other items that differed significantly by study year include: trip enjoyment' $(F=8.14, d f=2$, $p<.001)$, condition of recreation area' $(F=47.97, d f=2, p<.001)$, trip worth money spent ${ }^{\star}(F=$ $4.24, d f=2, p<.05)$, disappointed with aspects of trip “ $(F=47.65, d f=2, p<.001)$ by year of study (Table 11). All of those items were also greatest in 2011, with no significant difference between 2002 and 2006. These results suggest that satisfaction and quality of recreation opportunities did improve over the ten year study period. 
Table 11

Overall Satisfaction and Quality Outdoor Recreation Items by Study Year (ANOVA)

\begin{tabular}{|c|c|c|c|c|c|}
\hline Variable & $\begin{array}{c}2002 \\
\text { (a) } \\
M\end{array}$ & $\begin{array}{c}2006 \\
\text { (b) } \\
M\end{array}$ & $\begin{array}{l}2011 \\
(\mathrm{c}) \\
\mathrm{M}\end{array}$ & $\bar{F}$ & $\begin{array}{l}\text { Scheffe } \\
\text { Post Hoc }\end{array}$ \\
\hline Overall Satisfaction & 8.29 & 8.37 & 8.75 & $17.36 * * *$ & $\mathrm{a}<\mathrm{c}, \mathrm{b}<\mathrm{c}$ \\
\hline I thoroughly enjoyed my trip & 4.49 & 4.42 & 4.57 & $8.14 * * *$ & $\mathrm{~b}<\mathrm{c}$ \\
\hline $\begin{array}{l}\text { I thought the recreation area and its } \\
\text { surroundings were in good } \\
\text { physical condition }\end{array}$ & 3.97 & 3.86 & 4.28 & $47.97 * * *$ & $\mathrm{a}<\mathrm{c}, \mathrm{b}<\mathrm{c}$ \\
\hline $\begin{array}{l}\text { My trip was well worth the money I } \\
\text { spent to take it }\end{array}$ & 4.38 & 4.30 & 4.42 & $4.24 *$ & $\mathrm{~b}<\mathrm{c}$ \\
\hline $\begin{array}{l}\text { I was disappointed with some } \\
\text { aspects of my trip (reverse coded) }\end{array}$ & 3.63 & 3.55 & 4.07 & $50.51 * * *$ & $\mathrm{a}<\mathrm{c}, \mathrm{b}<\mathrm{c}$ \\
\hline
\end{tabular}

Note: Overall satisfaction was measured on a 10-point scale (1="worst possible experience" to $10=$ "best possible experience") and quality items were measured on a 5 -point scale ( $1=$ "strongly disagree to $5=$-strongly agree") $* \mathrm{p}<0.05, * * \mathrm{p}<0.01, * * * \mathrm{p}<0.001$

RQ6: How do encounters with people and OHVs compare to visitor norms (i.e., acceptable and tolerable number of encounters)?

People Encounters. Respondents were asked how the number of people they saw at ODNRA/Sand Lake compared with what they expected to see (Figure 19). Overall, the majority of respondents in all three studies (46\% in 2002, 54\% in 2006, and 52\% in 2011) stated that the number of people they saw was what they expected to see. Other respondents felt that the number of people were a little less than expected (17\% in $2002,21 \%$ in 2006 , and $18 \%$ in 2011$)$. The association between people expected to see and year of study was significant $X^{2}(10$, $N=1,669)=65.85, p<.001$. 


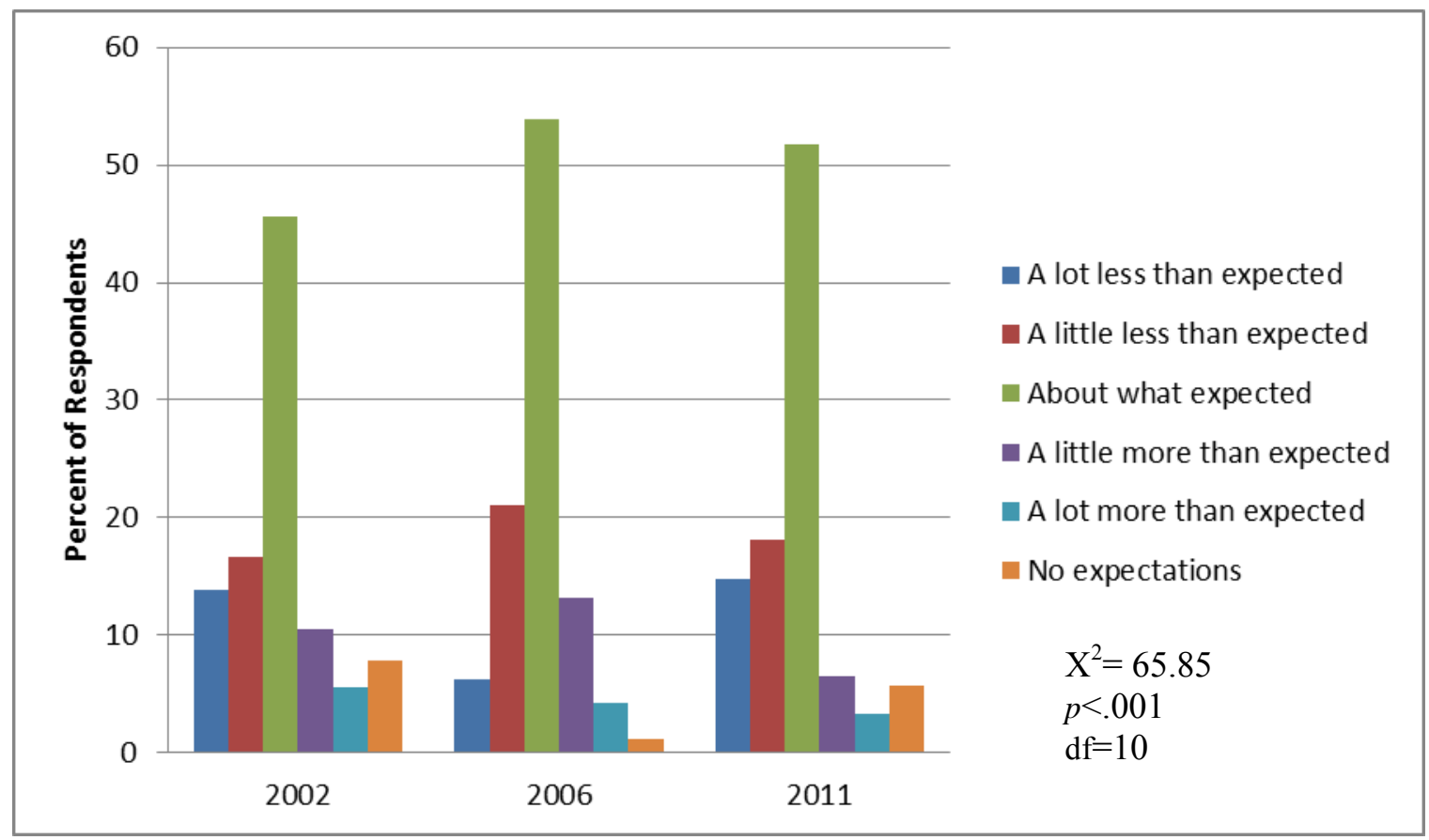

Figure 19. Number of People Expected to see at ODNRA/Sand Lake

Respondents were asked how acceptable was the number of other people they saw at ODNRA/Sand Lake on a nine point scale $(1=$ *ery unacceptable" to $9=$ very acceptable $)$ and the most frequently reported response was - neither acceptable nor unacceptable" (3 to 7 range) amount of people at ODNRA/Sand Lake. The average response in 2002 was 2.79; increased to 7.13 in 2006 and slightly decreased to 6.99 in 2011 (Table 12). Between 2002 and 2011, respondents were happy with the number of people they saw at ODNRA/Sand Lake.

Respondents were asked if they would have like to have seen more or less people. Their responses were measured using a nine point scale ( $1=$ far more people" to $9=$ far less people"). The mean response in $2002(M=4.43)$ was significantly lower $(p<.001)$ than in $2006(M=5.61)$ and in $2011(M=4.85)$. 
Table 12

People Encountered at ODNRA/Sand Lake by Study Year (ANOVA)

\begin{tabular}{lccccc}
\hline \multicolumn{1}{c}{ Survey Question } & $\begin{array}{c}2002 \\
\text { (a) }\end{array}$ & $\begin{array}{c}2006 \\
\text { (b) }\end{array}$ & $\begin{array}{c}2011 \\
\text { (c) }\end{array}$ & F & $\begin{array}{c}\text { Scheffe } \\
\text { Post Hoc }\end{array}$ \\
& $\mathrm{M}$ & $\mathrm{M}$ & $\mathrm{M}$ & & \\
\hline $\begin{array}{l}\text { How acceptable was the number of } \\
\text { other people you saw on }\end{array}$ & 2.79 & 7.13 & 6.99 & $711.19^{* * * *} \mathrm{a}<\mathrm{b}, \mathrm{a}<\mathrm{c}$ \\
$\begin{array}{l}\text { ODNRA/Sand Lake? } \\
\text { ODNA }\end{array}$ & & & & & \\
\end{tabular}

Overall, I would have liked to have $4.43 \quad 5.61 \quad 4.85 \quad 65.59 * * * \quad \mathrm{a}<\mathrm{b}, \mathrm{b}>\mathrm{c}$ seen (more or less people)?

Note: Acceptable number of other people“ were measured using a nine point scale (1=-*ery unacceptable" to $9=-$ very acceptable"), more or less people“ were measured using a nine point scale ( $1=$-far more people" to $9=$-far less people"). ${ }^{*} \mathrm{p}<0.05,{ }^{* *} \mathrm{p}<0.01,{ }^{* * *} \mathrm{p}<0.001$

OHV Encounters. Respondents were asked how the number of OHVs they saw at ODNRA/Sand Lake compared with what they expected to see (Figure 20). Similar to the number of people encountered, the majority of respondents in all three studies $(46 \%$ in $2002,59 \%$ in 2006, and 53\% in 2011) stated that the number of OHVs they saw was the number they expected to see. Other respondents felt that the number of OHVs were a little less than expected (17\% in 2002 and 2006, and 20\% in 2011) followed by a lot less than expected (14\% in $2002,11 \%$ in 2006, and 15\% in 2011). The association between OHVs expected to see and year of study was significant $X^{2}(10, N=1,666)=73.04, p<.001$. 


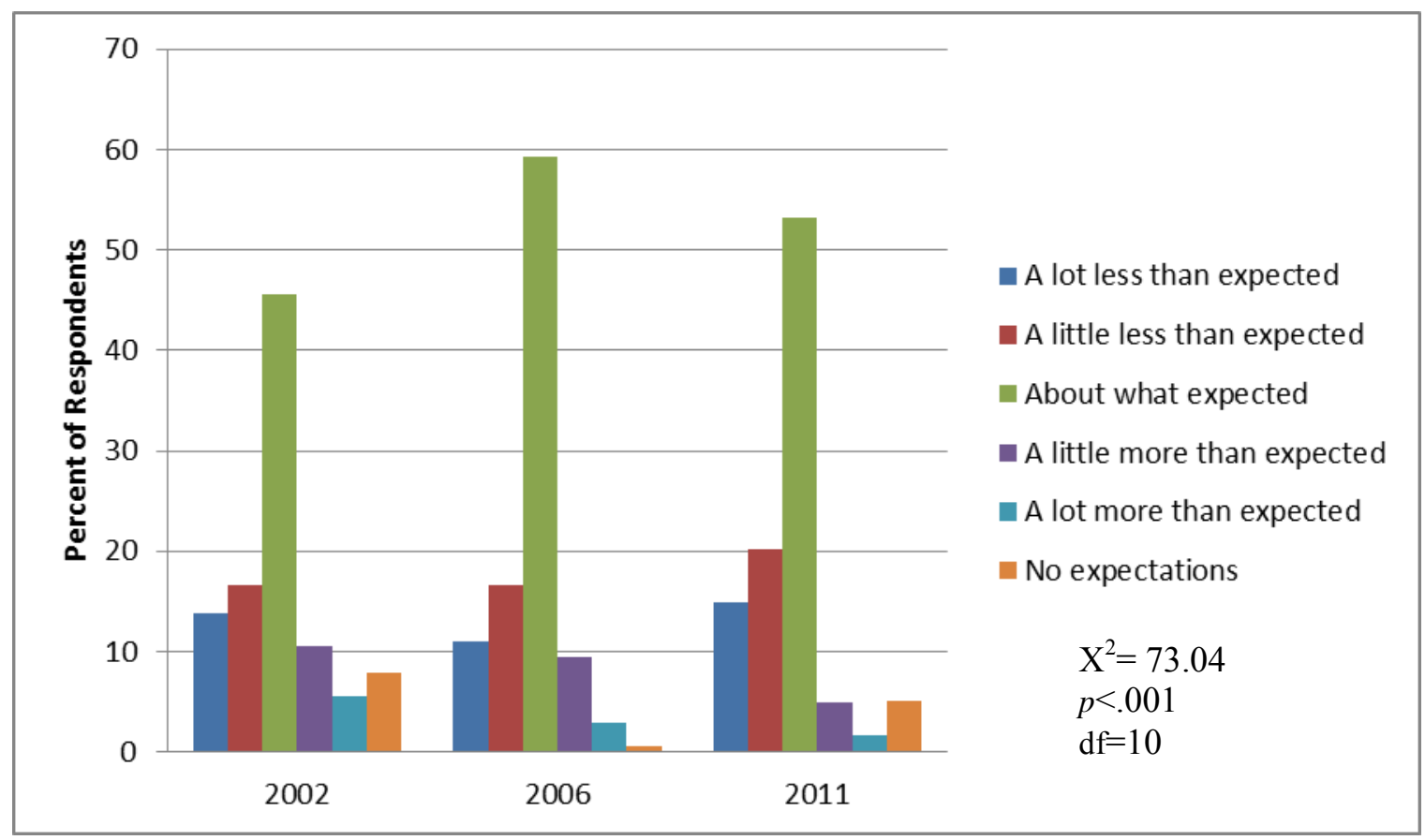

Figure 20. Number of OHVs expected to see at ODNRA/Sand Lake

Respondents were asked how acceptable was the number of other OHVs they saw at ODNRA/Sand Lake on a nine point scale $(1=-$ *ery unacceptable" to $9=$ *ery acceptable $)$. The level of acceptability was rated as _neither acceptable nor unacceptable‘ (3-7 range) $(M=2.86)$ in 2002. Acceptability levels significantly $(p<.001)$ increased $(M=7.32)$ in 2006 and then slightly decreased $(M=6.73)$ in 2011(Table 13). The same trend was observed for other OHV encounter questions. Respondents were asked if OHVs at ODNRA/Sand Lake enhanced or detracted from their enjoyment on a nine point scale $(1=$ greatly enhanced my enjoyment" to $9=$ greatly detracted from my enjoyment") Respondents reported that OHVs neither enhanced nor detracted" from their enjoyment at ODNRA/Sand Lake $(M=3.53)$ in 2002. The responses significantly $(p<.001)$ increased $(M=4.18)$ in 2006, then declined $(M=3.36)$ in 2011 . Respondents were asked if they would have liked to have seen more or less OHVs on a nine point scale $(1=$ far more OHVs" to 9= far less OHVs"). Respondents reported that they would have like to have seen _the same number of $\mathrm{OHVs}^{\star}(M=4.26)$ encountered in 2006 . The responses 
significantly $(\mathrm{p}<.001)$ increased $(M=5.34)$ in 2006 , then declined $(M=4.60)$ in 2011 . These results suggest that respondents were neutral toward the number of OHVs at ODNRA/Sand Lake, and were fine with the number of OHVs they encountered.

Table 13

OHV Encounters at ODNRA/Sand Lake by study year (ANOVA)

\begin{tabular}{|c|c|c|c|c|c|}
\hline Survey Questions & $\begin{array}{l}2002 \\
\text { (a) } \\
M\end{array}$ & $\begin{array}{l}2006 \\
\text { (b) } \\
M\end{array}$ & $\begin{array}{c}2011 \\
(\mathrm{c}) \\
\mathrm{M}\end{array}$ & F & $\begin{array}{l}\text { Scheffe's } \\
\text { Post Hoc }\end{array}$ \\
\hline $\begin{array}{l}\text { How acceptable was the number of } \\
\text { OHVs you saw on ODNRA/Sand } \\
\text { Lake? }\end{array}$ & 2.86 & 7.32 & 6.73 & $677.77 * * *$ & $\mathrm{a}<\mathrm{b}, \mathrm{a}<\mathrm{c}$ \\
\hline $\begin{array}{l}\text { Would you say that the OHVs at } \\
\text { ODNRA/Sand Lake (enhance or } \\
\text { detract enjoyment)? }\end{array}$ & 3.53 & 4.18 & 3.36 & $30.82 * * *$ & $a<b, b>c$ \\
\hline $\begin{array}{l}\text { Overall I would have liked to have } \\
\text { seen (more or less OHVs)? }\end{array}$ & 4.26 & 5.34 & 4.60 & $54.48 * * *$ & $a<b, b>c$ \\
\hline $\begin{array}{l}\text { Note: Acceptable number of other OHVs" } \\
\text { acceptable"), OHV enhancement" was mea } \\
\text { detracted enjoyment"), _more or less OHVs } \\
\text { OHVs"). } \\
{ }^{*} \text { p }<0.05, * * p<0.01,{ }^{*} * * \text { p }<0.001\end{array}$ & $\begin{array}{l}\mathrm{me} \\
\mathrm{d} \text { us }\end{array}$ & $\begin{array}{l}\text { sing } \\
\text { ie p. }\end{array}$ & oi & $\begin{array}{l}1=- \text { very u } \\
\text { ly enhanc }\end{array}$ & $\begin{array}{l}\text { eptable" to } 9=- \text {-rery } \\
\text { ajoyment" to } 9=- \text { gatly } \\
\text { OHVs" to } 9=\text {-far less }\end{array}$ \\
\hline
\end{tabular}

Maximum, Acceptable, and Tolerable OHV Encounter Levels. Similar to studies conducted by Budruk and Manning (2002) and Hammitt and Rutlin (1995), respondents were asked to report the actual number of OHVs encountered, report the maximum number of OHVs acceptable, and the maximum number of OHVs they could tolerate seeing before they would no longer visit. Table 14 shows the mean, median, and standard deviation of actual and maximum OHV encounters for the combined three study years. From both a conceptual and managerial standpoint, it was anticipated that the actual number of OHVs seen would not exceed both the 
maximum number acceptable and maximum number tolerable. Not only does the above pattern match exactly, the results also show that the actual number of OHVs seen was far lower than the maximum number of OHVs acceptable and maximum number of OHVs tolerable. However, it should be noted that because of the large number of missing data, we were unable to determine whether there is a significant difference between the three study years.

Table 14

Actual, Acceptable, and Tolerable Encounters at ODNRA/Sand Lake

\begin{tabular}{cccc}
\hline & Actual & $\begin{array}{c}\text { OHV use encounters } \\
\text { Maximum } \\
\text { Acceptable }\end{array}$ & $\begin{array}{c}\text { Maximum } \\
\text { Tolerable }\end{array}$ \\
\hline Mean & 304.73 & 824.49 & 1609.58 \\
Median & 60.00 & 200.00 & 500.00 \\
Std. Deviation & 1627.93 & 2645.23 & 4549.23 \\
\hline
\end{tabular}

\section{Conclusion}

This section used descriptive statistics, chi-square, ANOVA, and SEM to address the following research questions:

(1) Who are the visitors of ODNRA/Sand Lake?

(2) What are the displacement trends of ODNRA/Sand Lake over the ten year study period (i.e., changes in gender, previous visits, and trip characteristics)?

(3) What are the crowding and conflict sensitivity trends over the ten year study period (i.e., perceptions of crowding, perceptions of conflict, crowding matters, crowding-quality relationships, conflict-quality relationships)?

(4) How does crowding and conflict sensitivity compare by gender and first time visitors?

(5) What are the trends in visitor satisfaction and quality outdoor recreation over the ten year study period? 
(6) How do encounters with people and OHVs compare to visitor norms (i.e., acceptable and tolerable number of encounters)?

The key findings of Chapter IV are:

- Respondents at ODNRA/Sand Lake in 2011 were predominately white males between 41-50 years old with an annual income of $\$ 50,000-\$ 100,000$ a year, travel to the area often and had a high school diploma or less.

- Females gradually increased at Siuslaw National Forest, while at ODNRA/Sand Lake, gender fluctuated dramatically.

- Females and first time visitors appear to be more sensitive to conflict than other visitors.

- Perceptions of crowding and conflict were more evident in 2006 after regulation such as the alcohol ban and stricter sand camping rules were established.

- SEM also indicated significant negative relationships between crowding, EUH, conflict, and quality of outdoor recreation.

- Crowding became a weaker predictor of quality recreation after the regulations were established, but returned as a stronger predictor in 2011.

- The respondents in 2006 felt that the maximum numbers mattered.

- Over the ten year study period, overall satisfaction and quality of recreation opportunities did improve.

- Respondents expected to see the number of other people and OHVs encountered at ODNRA/Sand Lake.

The results of these research questions are further discussed in Chapter Five. 


\section{Chapter V}

\section{Discussion}

This chapter builds upon the previous chapters by elaborating on the results that were reported. The purpose of this research is to combine data from three cross-sectional surveys (2002, 2006, and 2011) to examine OHV user displacement trends, trends in levels of sensitivity to crowding and conflict, and satisfaction trends at ODNRA/Sand Lake. The individual research questions are used to help guide the discussion of the results. The short term and long term trends are summarized in a single table and discussed, and comparisons are made with those trends and previous outdoor recreation research. These results are meant to formulate useful suggestions to OHV managers and improve conditions at ODNRA/Sand Lake. Consequently, this chapter also includes an assessment of the study`s results and the subsequent implications for managers at ODNRA/Sand Lake, as well as other OHV land managers.

RQ1: Who are the visitors of ODNRA/Sand Lake? Similar to Albritton, Stein, and Thapa's (2009) study of OHV users in Ocala National Forest in Florida, OHV users in ODNRA/Sand Lake in 2011 were predominately white males between 41-50 years old with an annual income of $\$ 50,000-\$ 100,000$ a year. However, unlike the Ocala study, the majority of ODNRA/Sand Lake users had a high school diploma or less. Users to ODNRA/Sand Lake are generally visitors with an extensive experience use history. That is, they tend to be repeat visitors with an average of 12 visits per year and 20 years of experience recreating in the area. Because most users drive a great distance to the area, they stay for several days. ODNRA/Sand Lake users travel with a large number of people in their group, and the groups consist mostly of family members. 


\section{RQ2: What are the displacement trends of ODNRA/Sand Lake over the ten year}

study period (i.e., changes in gender, previous visits, and trip characteristics)?

The NVUM data that represent the entire Siuslaw National Forest visitor population indicate a gradual increase in females between 2002 and 2011. There were $37 \%$ females in 2002, $33 \%$ in 2006 , and $42 \%$ in 2011 . At ODNRA/Sand Lake, gender fluctuated dramatically between 2002 and 2011. The female population increased from $18 \%$ in 2002 to $34 \%$ in 2011 . The significant decrease in percentage of males between 2002 and 2006 after regulations were established presents some evidence of Type 2 displacement among males (Hall \& Cole, 2000). This type of displacement is the previously ignored type, in which users sensitive to regulation are displaced.

The majority of ODNRA/Sand Lake users have visited the area over ten years. The number of annual visits per year went from 17 in 2002, 8 in 2006, and 11 in 2011. Respondents, mostly family members, spent 3-4 days at ODNRA/Sand Lake, and they traveled a great distance.

RQ3: What are the crowding and conflict sensitivity trends over the ten year study period (i.e., perceptions of crowding, perceptions of conflict, crowding matters, crowding quality relationships, conflict-quality relationships)? Over the ten year study, perceptions of crowding and conflict were most evident in 2006 after regulation such as the alcohol ban and stricter sand camping rules were established. Perceptions of crowding improved in 2011. When respondents were asked about the maximum number of OHVs acceptable to see and tolerate seeing the respondents in 2006 felt that the maximum numbers mattered, but could not specify a number. SEM indicated significant negative relationships between crowding, EUH, conflict, and quality of outdoor recreation. The model suggests as one variable(s) increases, the other 
variable(s) decreased. Based on the three SEM examined in this study (2002, 2006, and 2011), crowding became a weaker predictor of quality recreation immediately after regulations, but returned as a stronger predictor in 2011. Conflict became a stronger predictor of quality over time. The instability of crowding and conflict indicate \#nexplained effects of time" (Kuentzel \& Heberlein, 2003) where factors other than the ones included in the model were changing visitors ${ }^{6}$ evaluations about crowding and conflict. Also, reaction to crowding can be inconsistent over time and varies by activity, location of the recreation area, country or region (Shindler \& Shelby, 1995; Manning 2011).

\section{RQ4: How does crowding and conflict sensitivity compare by gender and first time}

visitors? SEM shows stronger negative relationships between conflict and quality for females than males; therefore, females in this study tend to be more conflict sensitive. This indicates a Type 1 displacement among females, which occurs when an area is both socially or ecologically heavily used and impacted while males, as previously stated, show evidence of Type 2 displacement, which occurs when an area is highly regulated (Hall \& Cole, 2000). For repeat and first time visitors, SEM shows repeat visitors are sensitive to crowding slightly more than first time visitors, while first time visitors were more sensitive to conflict than repeat visitors. This indicates a potential for Type 1 displacement among both repeat and first time visitors. However, it should be noted that there was a vast variation of respondents who were repeat visitors $(\mathrm{n}=1,501)$ and respondents who were first time visitors $(\mathrm{n}=174)$.

\section{RQ5: What are the trends in visitor satisfaction and quality outdoor recreation over}

the ten year study period? There is some evidence to suggest that the regulations managers established over the ten year study period were successful based on some measures of overall 
satisfaction and quality of outdoor recreation. Based on ANOVA results, we found an increase in satisfaction and quality of outdoor recreation. Satisfaction was significantly higher in 2006 and 2011 and quality of outdoor recreation was highest in 2011.

RQ6: How do encounters with people and OHVs compare to visitor norms (i.e., acceptable and tolerable number of encounters)? Between 2002 and 2011, the number of people and OHVs encountered at ODNRA/Sand Lake were about what respondents expected to see. Respondents were neutral regarding the amount of people and OHVs encountered, were fine with the amount of people and OHVs they saw, and felt that OHVs neither enhanced nor detracted from their enjoyment. Similar to Hammitt and Rutlin's (1995) study, the number of actual number of OHVs encountered were lower than the maximum number acceptable and maximum tolerable of OHVs. Current encounters at ODNRA/Sand Lake appear to be acceptable, but the encounter standards are not clear and could be anywhere between 200 and 500 OHVs.

\section{Synthesis of Study Findings}

The OHV user displacement trends, trends in levels of sensitivity to crowding and conflict, and satisfaction trends at ODNRA/Sand Lake are summarized in Table 15. An image of a triangle pointing up is presented if the percentage/means between study years is significantly larger, an image of a triangle pointing down is presented if the percentage/mean has decreased, and a rectangle is presented if the results are not different. For SEM results, up and down triangles are based on visual comparisons of significant B values and represent stronger or weaker relationships. The shaded areas represent findings that are inconsistent with long term trends between 2002 and 2011. 
Table 15

Synthesis of Study Findings

\begin{tabular}{|c|c|c|c|c|}
\hline & \multicolumn{3}{|c|}{ Short Term Trends } & \multirow{2}{*}{$\begin{array}{c}\begin{array}{c}\text { Long term } \\
\text { Trends }\end{array} \\
2002 \text { to } 2011\end{array}$} \\
\hline & 2002 & 2006 & 2011 & \\
\hline \multicolumn{5}{|l|}{ Displacement Trends } \\
\hline Females & $17.7 \%$ & $\Delta$ & & $\therefore$ \\
\hline Families & $32.9 \%$ & $\Delta$ & $\Delta$ & \\
\hline First time visitors & $7.4 \%$ & $\Delta$ & & \\
\hline Number of years visited & $\mathrm{M}=11.85$ & ש & & \\
\hline Number of visits per year & $\mathrm{M}=17.01$ & & $\Delta$ & \\
\hline Length of stay & $M=2.84$ & $\Delta$ & & \\
\hline Travel distance & $M=184.68$ & ש & $\Delta$ & 入 \\
\hline \multicolumn{5}{|l|}{ Sensitivity Trends } \\
\hline $\begin{array}{l}\text { Perceptions of overall } \\
\text { crowding }\end{array}$ & $\mathrm{M}=2.93$ & $\Delta$ & & \\
\hline Perceptions of conflict & $M=2.16$ & ש & & \\
\hline $\begin{array}{l}\text { Crowding matters } \\
\text { (acceptability scale) }\end{array}$ & $53.0 \%$ & $\Delta$ & & \\
\hline $\begin{array}{l}\text { Crowding matters (tolerance } \\
\text { scale) }\end{array}$ & $52.5 \%$ & $\Delta$ & & \\
\hline $\begin{array}{l}\text { Strength of Crowding-Quality } \\
\text { relationship }\end{array}$ & $B=-.669$ & & 2 & \\
\hline $\begin{array}{l}\text { Strength of Conflict-Quality } \\
\text { relationship }\end{array}$ & $\mathrm{B}=-.152$ & $\Delta$ & $\mathbf{A}$ & $\mathbf{\Delta}$ \\
\hline \multicolumn{5}{|l|}{ Satisfaction Trends } \\
\hline Overall satisfaction & $\mathrm{M}=8.29$ & ש & $\Delta$ & $\Delta$ \\
\hline Thoroughly enjoyed trip & $\mathrm{M}=4.49$ & ש & $\angle$ & $\Delta$ \\
\hline $\begin{array}{l}\text { Recreation area and its } \\
\text { surroundings in good } \\
\text { physical condition }\end{array}$ & $\mathrm{M}=3.97$ & ש & $\Delta$ & \\
\hline $\begin{array}{l}\text { Trip worth the money spent to } \\
\text { take it }\end{array}$ & $\mathrm{M}=4.38$ & ש & $\Delta$ & $\Delta$ \\
\hline $\begin{array}{l}\text { Disappointed some aspects of } \\
\text { trip (reverse coded) }\end{array}$ & $\mathrm{M}=3.63$ & ש & $\Delta$ & $\Delta$ \\
\hline
\end{tabular}

Note: Shaded cells reflect results that are inconsistent with long term trends (2002-2011).

Short Term Trends (2002-2006). After new regulations were implemented such as the 2003 alcohol ban and stricter sand camping rules in 2005, there were significant decreases in regulation sensitive visitors and increases in crowding and conflict sensitive visitors at 
ODNRA/Sand Lake. A decline in the percentage of males along with repeat visitors may be explained by Type 2 displacement. On the other hand, considering females and first time visitors were much more conflict sensitive in this study, it is understandable that their populations increased following efforts to address drinking related problems. The increase in crowding and conflict sensitivity in 2006 are based on 4 of 6 sensitivity trends presented in Table 15, although it is important to note that perceptions of conflict remained the same and the strength of crowding-quality relationships declined in 2006. Perhaps the latter results are explained by other coping mechanisms such as rationalization. Nonetheless, the majority of the displacement trends and sensitivity trends were expected following a period of increased regulations in the area.

Although the average number of visits made by respondents per year decreased, the length of stay at ODNRA/Sand Lake visitors increased. This is likely explained by the increase in travel distance reported by 2006 visitors.

Short Term Trends (2006-2011). Although the percent of males and repeat visitors in the 2006 population declined, those visitors started to return in larger numbers in 2011. This trend corresponds with 5 of 6 crowding and conflict sensitivity trends reported in Table 15 . Males and repeat visitors (regulation sensitive visitors) may have started to return in 2011 because fewer new regulations were implemented in the previous 5 year time period. Those visitors also tend to be less sensitive to crowding. The reduced strength of crowding-quality relationship in 2011 is the only trend that does not support a decline in crowding sensitivity, and perhaps it is better explained by other coping mechanisms such as rationalization.

Long Term Trends (2002-2011). Between 2002 and 2011 female visitors continued to increase at ODNRA/Sand Lake. The number of first time visitors decreased, perhaps suggesting that visitors with more EUH started to return to the area. The number of visits per year continued 
to decrease, but the length of stay at ODNRA/Sand Lake visitors as well as travel distance increased. From 2002 to 2011 sensitivity to conflict and crowding declined. Of the eight SEM models tested for crowding-quality and conflict-quality relationships, seven models (overall, 2002, 2011, males, females, repeat, and first time visitors) had an adequate fit while only one model (2006) had a poor fit.

We expected displacement of regulation sensitive visitors and an increase in crowding and conflict sensitive visitors in 2006 after regulation such as the 2003 alcohol ban and stricter sand camping rules in 2005 were established. However, with no radical regulations implemented after the 2005 sand camping rule, we expected some displacement of crowding and conflict sensitive visitors. Most results seem to follow this trend and support the OHV visitor displacement model (Figure 6). However, unexpected results or discrepancy in the results are shaded and might be better explained with cognitive dissonance theory (rationalization) or other coping behaviors; or perhaps the unexpected results reflect management efforts to improve the quality of experience opportunities using other management tools other than regulation.

\section{Scientific Contributions to the Literature}

The findings in this study supported most previous literature in the study. ODNRA/Sand Lake managers use ROS to outline the range of recreation opportunities that help define the carrying capacity of the area. (ODNRA Management Plan, 1994). The plan relies heavily on direct management tactics (Manning, 2007) such as decibel limits, night riding curfews, and at one point, establishing a permit system to ride at Sand Lake during busy holiday weekends. Similar to previous studies such as Cole and Stewart (2002) that found that crowding mattered some days but did not matter on other days, respondents at ODNRA/Sand Lake felt that crowding mattered during 2002 and 2006 but did not matter as much in 2011. The results of the 
study showed that satisfaction and quality was improved by regulation as suggested by Wagar (1966). Crowding and conflict, which are examples of social OHV impacts (Pierskalla, Schuett, \& Thompson, 2011), were inconsistent over the ten year study period (Schindler \& Shelby, 1995; Manning, 2011). Similar to previous literature examining experience use history, this study found that users who are repeat visitors, thus having more experience, have been found to be more sensitive to crowding conditions (Schreyer, Lime, \& Williams, 1984; Williams, Schreyer, \& Knopf, 1990). In addition to evidence of displacement, the unexpected discrepancies of some of the results suggest rationalization among ODNRA/Sand Lake visitors. Rationalization occurs when a visitor invests a vast amount of resources into their trip and is determined to be highly satisfied with their trip regardless of conditions (Mannning, 2011).

\section{Management Implications}

The findings of this study provide managers with important feedback regarding the management of ODNRA/Sand Lake. Based on the demographic information from the 2011 study, OHV use continues to be predominately an activity for white males. However, over the ten year study period, there appears to be an emergence of more diverse OHV users such as females, families, and visitors with less experience use histories. At the Siuslaw National Forest, which ODNRA/Sand Lake is a part of, the number of females gradually increased over the ten year study period. ODNRA/Sand Lake managers should continue to provide more diverse opportunities for these new users and market OHV recreation as part of a family vacation to a special place. By doing so, greater economic impact in the region where ODNRA/Sand Lake is located. Over the ten year study period, satisfaction and quality of outdoor recreation improved, further suggesting that ODNRA/Sand Lake has become a family friendly destination. Using a mix of regulation such as the alcohol ban and sand camping restrictions as well as other 
management tools is an effective way to better manage OHV areas, which is part of the major issues facing national forests (Chavez \& Knap, 2006). Regulation at ODNRA/Sand Lake reduces crimes and other illegal activities making it safe for a more diversified OHV user population to visit the area.

The findings in this study suggest that the relationship between crowding and quality of outdoor recreation was weaker after regulation was implemented then returned as a stronger and significant relationship in 2011. Also, the relationship between conflict and quality of outdoor recreation became stronger over time. Because of the unstable crowding and conflict indicators over the course of this study it is even more important for managers to set standards of quality and continue to monitor crowding and conflict indicators over time. The findings found evidence for Type 2 displacement among males particularly after regulation such as the alcohol ban and sand camping restrictions were implemented. SEM results revealed females were more sensitive to conflict than males, showing evidence of Type 1 displacement. When examining the SEM results by study year, the user population in 2002 does not fit either Type 1 or Type 2 displacement because they were both regulation and crowding sensitive. The user population became more conflict sensitive in 2006 and 2011, indicating Type 1 displacement. This disclosure of the 2002 user population displaying both Type 1 and Type 2 displacement creates potential for a third category of displacement for users who are sensitive to regulation and crowding. At ODNRA/Sand Lake, users expected to see the number of other people and OHVs encountered and while they felt that the maximum numbers mattered, they could not specify a number. However, more research is needed. Current encounters appear to be acceptable and tolerable, but the encounter standards are not clear and could be anywhere between 200-500 OHVs. 
Management Recommendations. Managers can choose from three options to manage crowding and conflict-related problems in the future. First, managers could minimize the total number of people who will be displaced by management policies. Second, managers could favor OHV purists- those sensitive to crowding and conflict and with longer use experience history. Third, managers could set different policies for different areas of the recreation area such as using ROS or LAC (Hall \& Cole, 2000). This way, managers can develop ways to segment visitors based on their preferred setting (Wynveen et al., 2007). In the case of ODNRA/Sand Lake, managers were faced with the three options outlined in Hall and Cole's (2000) study. Implementing regulations such as the alcohol ban and sand camping restrictions along with other management tools at ODNRA/Sand Lake was very effective with introducing different user groups to the area. Had regulations not been implemented, these user groups would more than likely not recreate at this area. Again, long-term monitoring is essential to ensure conditions at ODNRA/Sand Lake continue to improve.

As part of their current management plan, ODNRA/Sand Lake managers use ROS to define recreation opportunities for the area along with direct management tactics to help make the area safer. While these policies favor OHV purists who are crowding and conflict sensitive, it does displace regulation sensitive users. Managers must make a subjective judgment about the conditions they want to provide and which clientele they will favor and determine whether the group that is being driven away is the group that managers want to drive away. One form of displacement is not necessarily better or worse than another, and some visitors will be displaced regardless of what managers do or fail to do (Hall \& Cole, 2000).

\section{Conclusions}

When considering this study, it should be understood that the concepts evaluated do not 
merely describe the isolated perspectives of ODNRA/Sand Lake visitors. Rather, they provide both managers and researchers with a unique look at OHV use at ODNRA/Sand Lake over a ten year span. More importantly this study combined data collected from three cross-sectional surveys to explore how OHV users were affected by regulations such as the alcohol ban and sand camping restrictions. Generally speaking, it was found that the regulations had a positive effect at ODNRA/Sand Lake; the regulations dealt with inappropriate behavior, introduced different user groups to the area, and improved satisfaction and quality of outdoor recreation. However, SEM showed instability among crowding and conflict indicators, suggesting other factors were changing those indicators. These unexpected results might be better explained with cognitive dissonance theory (rationalization) or other coping behaviors. Therefore it is necessary to continue monitoring crowding and conflict indicators at ODNRA/Sand Lake.

Future research would be helpful to determine why crowding and conflict were unstable in this study. Because this study looked only at common variables from the 2002, 2006, and 2011 study, there may be some factors in the surveys that could explain the unstable indicators, and also better guide the managers at ODNRA/Sand Lake. Future research could also further examine coping behaviors such as rationalization among ODNRA/Sand Lake users. The chisquare analysis suggested that the significant decrease in percentage of males between 2002 and 2006 after regulations were established indicates Type 2 displacement among males at ODNRA/Sand Lake, potentially creating an opportunity for more diverse OHV users there. Compared to the NVUM data of the entire Siulsaw National Forest, there is are growing number of females recreating at that national forest. If future studies were conducted at ODNRA/Sand Lake, it would be interesting to compare demographic information to see if in fact more diverse users are recreating there. Another suggestion for future research would be to look more closely 
at standards of quality by using a visual approach. Visual based studies -an provide additional pertinent information to respondents that would be difficult or awkward to communicate through conventional narrative/numerical approaches" (Manning, 2007, p. 57). In crowding studies, visual research methods are helpful for respondents to not only see the number of visitors encountered, but also important characteristics of those visitors encountered, including recreation activity engaged in, mode of travel, and group size. At ODNRA/Sand Lake, visitors could be shown photographs of different sections of the dunes to more accurately determine their acceptability and tolerance of other OHV users, rather than have the respondents simply come up with a number. Finally, since this study showed that ODNRA/Sand Lake visitors first visited the area on average, over 20 years ago, it would be interesting to further expand on EUH and place bonding at ODNRA/Sand Lake similar to Wynveen et. al's (2007) study.

Overall, this study was successful in examining OHV user displacement trends, trends in levels of sensitivity to crowding and conflict, and satisfaction trends at ODNRA/Sand Lake. Inferences based on the results of this study allow the managers at ODNRA/Sand Lake to make decisions based on scientific data and improve the experience of visitors there. Likewise, this study broadens and contributes to the literature by introducing SEM, along with other analysis, to longitudinal research which examines the concepts of crowding, conflict, satisfaction, and quality of outdoor recreation. 


\section{References}

Absher, J.D. (1998). Customer service measures for national forest recreation. Journal of Park and Recreation Administration, 16(3), 31-42.

Alcohol ban in sand dunes of Oregon curbs trouble. (2003, July 13). The New York Times. Retrieved from http://www.nytimes.com/2003/07/13/us/alcohol-ban-in-sand-dunes-oforegon-curbs-trouble.html.

Aldelman, B., Heberlein, T., \& Bonneckson, T. (1982). Social psychological explanations for the persistence of a conflict between paddling canoeists and motor craft users in the Boundary Waters Canoe Area. Leisure Sciences, 5, 45-61.

Albritton, R., Stein, T.V., \& Thapa, B. (2009). Exploring confict and tolerance between and within off-highway vehicle recreationists. Journal of Park and Recreation Administration, 27(4), 54-72.

Allegretti, A.M., Vaske, J.J., \& Cottrell, S. (2012). Predicting stakeholder support for fishery policies. Coastal Management, 40(1), 20-32.

Anderson, D. (1983). Displacement: One consequence of not meeting people‘s needs. In Research in Forest Productivity, Use, and Pest Control. USDA Forest Service General Technical Report NE-90, 31.37.

Arbuckle, J. L (2010). IBM SPSS Amos 19 User's Guide. Chicago, IL: SPSS.

Arnberger, A., \& Brandenburg, C., (2007). Past on-site experience, crowding perceptions, and use displacement of visitor groups to a peri-urban national park. Environmental Management, 40, 34-45.

Arnberger, A. \& Mann, C. (2008). Crowding in European forests: A review of recent research 
and implications for forest management and policy. Forestry, 81(4), 559-571.

Asah, S.T., Bengston, D.N., Wendt, K., \& DeVaney, L. (2012). Prognostic framing of stakeholders' subjectivities: A case of all-terrain vehicle management on state public lands. Environmental Management, 49(1), 192-206.

Barnard, J. (2003, July 12). Alcohol ban in Oregon dunes upsets some ATV riders. The Associated Press. Retreived from www.ap.org.

Brooks, J.J. \& Champ, P.A.(2006). Understanding the wicked nature of «nmanaged recreation" in Colorado‘s Front Range. Environmental Management, 38, 784-798.

Budruk, M. \& Manning, R.E. (2002). Crowding related norms in outdoor recreation: U.S. versus international visitors. Proceedings of the 2002 Northeastern Recreation Research Symposium. USDA Forest Service General Technical Report GTR-NE-302, 216-221.

Budruk, M., Wilhem Stanis, S.A., Schneider, I.E., \& Heisey, J.J. (2008). Crowding and experience-use history: A study of the moderating effect of place attachment among water based recreationists. Environmental Management, 41, 528-537.

Bullock, S.D. \& Lawson, S.R. (2007). Examining the potential effects of management actions on visitor experiences on the summit of Cadillac Mountain, Acadia National Park. Human Ecology Review, 14(2), 140-156.

Bultena, G., \& Klessig, L. (1969). Satisfaction in camping: A conceptualization and guide to social research. Journal of Leisure Research, 1, 348-364.

Burns, R.C. (2000). Methodological issues associated with customer satisfaction measurement and market segmentation at water-based recreation areas (Doctoral Dissertation, The Pennsylvania State University).

Burns, R.C., Graefe, A.R., \& Absher, J.D. (2003). Alternate measurement approaches to 
recreational customer satisfaction: Satisfaction-only versus gap scores. Leisure Sciences, $25,363-380$.

Burns, R.C., Graefe, A.R., Robinson, K., \& Woodruff, S. (2009). 2008 Central Oregon offhighway vehicle use study: A survey of characteristics, behaviors and perceptions. Bend, OR: USDA Forest Service (Region 6).

Carman, J.(1990). Consumer perceptions of service quality: An assessment of the SERVQUAL dimensions. Journal of Retailing,66, 33-51.

Carothers, P., Vaske, J.J., \& Donnelly, M.P. (2001). Social values versus interpersonal conflict among hikers and mountain bikers. Leisure Sciences, 23, 47-61.

Chavez, D.J., \& Knap, N.E. (2006). Manager perceptions of issues and actions for off-highway vehicle management on National Forests in California. USDA Forest Service Research Paper PSW-RP-250. Pacific Southwest Research Station, Albany, CA.

Clark, R. \& Stankey, G.H. (1979). The Recreation Opportunity Spectrum: A Framework for Planning, Management and Research. USDA Forest Service Research Paper PNW-98.

Cole, D., \& Stankey, G.H. (1997). Historical development of limits of acceptable change: Conceptual clarifications and possible extensions. Proceedings-Limits of Acceptable Change and Related Planning Processes: Progress and Future Directions (pp. 5-9). Washington, D.C.: U.S. Government Printing Office.

Cole, D.N. \& Stewart, W.P. (2002). Variability of user-based evaluative standards for backcountry encounters, Leisure Sciences, 24(3-4), 313-324.

Cole, S.T., \& Crompton, J.L. (2003). A conceptualization of the relationships between service quality and visitor satisfaction, and their links to destination selection. Leisure Studies, 22, 65-80. 
Cooper, R.J. (2010). Encounter norms and perceived crowding on the White Salmon River in Southern Washington (Master's Thesis). Retrieved from http://etda.libraries.psu.edu/paper/10897/.

Crompton, J.L., \& MacKay, K.J. (1989). Users“ perceptions of the relative importance of service quality dimensions in selected public recreation programs. Leisure Science, 11, 367-375.

Crompton, J.L., MacKay, K.J., \& Fesenmaier, D.R. (1991). Identifying dimensions of service quality in public recreation. Journal of Park and Recreation Administration,9(3), 15-27.

Crompton, J.L. \& Love, L.L. (1995). The predictive validity of alternative approaches of evaluating quality of a festival Journal of Travel Research, 34, 11-24.

Crompton, J.L. \& Kim, S.S. (2004). Temporal changes in perceived constraints to visiting state parks. Journal of Leisure Research, 36(2), 160-182.

Deisenroth, D., Loomis, D., \& Bond, C. (2009). Non-market valuation of off-highway vehicle recreation in Larimer County, Colorado: Implications of trail closures. Journal of Environmental Management, 90, 3490-3497.

Ewert, A., Pierser, R., \& Voight, A. (1999). Conflict and the recreational experience. In E. Jackson and T. Burton (Eds.) Leisure Studies: Prospects for the Twenty-first Century. State College, PA: Venture Publishing.

Fulton, D.C. \& Manfredo, M.J. (2004). A panel design to assess the effects of regulatory induced reductions in opportunity on deer hunters' satisfaction. Human Dimensions of Wildlife, 9, $35-56$.

Garson, G.D. (2011). Structural equation modeling. Statnotes: Topics in Multivariate Analysis. Retrieved from http://faculty.chass.ncsu.edu/garson/pa765/statnote.htm

Graefe, A.R., Kuss, F., \& Vaske, J.J. (1990). Visitor Impact Management: The Planning 
Framework. Washington, D.C.: National Parks and Conservation Association.

Graefe, A.R., Cahill, K., \& Bacon, J. (2011). Putting visitor capacity in perspective: A response to the capacity work group. Journal of Park and Recreation Administration, 29(1), 21-37.

Hall, T., \&, Cole, D. (2000). An expanded perspective on displacement: A longitudinal study of visitors to two wildernesses in the Cascade Mountains of Oregon. Wilderness Science in a Time of Change Conference-Volume 4: Wilderness Visitors, Experiences, and Visitor Management. USDA Forest Service Proceedings RMRS-P-15-VOL-4, 113-121.

Hamilton, J.A., Crompton, J.J., \& More, T.A. (1991). Identifying the dimensions of service quality in a park context Journal of Environmental Management, 32, 211-220.

Hammitt, W.E., \& McDonald, C. (1983). Past on-site experience and its relationship to managing river recreation resources. Forest Science, 29, 262-266.

Hammitt, W.E., \& Rutlin, W.M. (1995). Use encounter standards and curves for achieved privacy in wilderness. Leisure Sciences, 17, 245-262.

Hammitt, W.E., Bucklund, E.A., \& Bixler, R.D., (2004). Experience use history, place bonding and resource substitution of trout anglers during recreation engagements. Journal of Leisure Research, 36(3), 256-378.

Heberlein, T., \& Shelby, B. (1977). Carrying capacity, values, and the satisfaction model: A reply to Greist. Journal of Leisure Research, 9, 142-148.

Hof, M., \& Lime, D.W. (1997). Visitor experience and resource protection framework in the national park system: Rationale, current status, and future direction. Proceedings-Limits of Acceptable Change and Related Planning Processes: Progress and Future Direction, USDA Forest Service General Technical Report INT-371, 39-36.

Hubbard, S. (2013, January 20). New lines in the sand: In the Oregon Dunes, reclaiming areas 
from OHVs is under way. The Register-Guard. Retrieved from http://www.registerguard.com

Innes, J.E., \& Booher, D.E. (1999). Consensus building and complex adaptive systems: A framework for evaluating collaborative planning. Journal of the American Planning Association, 65(4), 412-423.

Ivy, M., Stewart, W., \& Lee, C. (1992). Exploring the role of tolerance in recreational conflict. Journal of Leisure Research, 24, 348-360.

Jaccard, J., \& Wan, C. K. (1996). LISREL approaches to interaction effects in multiple regression. Thousand Oaks, CA: Sage Publications. Kline, R. B. (1998). Principles and practices of structural equation modeling. New York, NY: Guilford Press.

Jackson, E.L., \& Wong, R.A.G. (1982). Perceived conflict between urban cross-country skiers and snowmobilers in Alberta. Journal of Leisure Research, 14, 47-62.

Jackson, J.M. (1965). Structural characteristics of norms. In: I.D. Steiner, \& M.F. Fishbein, (Eds.), Current studies in social psychology (pp. 301-309). New York, NY: Holt, Rinehart, and Winston.

Jackson, S., Haider, W., \& Elliot, T. (2002). Resolving inter-group conflict in winter recreation: Chilkoot Trail National Historic Site, British Columbia. In Arnberger, A., Brandenburg, C., \& Muhar, A. (Eds) Proceedings of the Monitoring and Management of Visitor Flows in Recreational and Protected Areas, (pp. 109-114). Bodenkultur University, Vienna, Austria.

Jacob, G., \& Schreyer, R. (1980). Conflict in outdoor recreation: A theoretical perspective. Journal of Leisure Research, 12, 368-380.

Klem, L. (2000). Structural Equation Modeling. In L.G. Grimm \& P.R. Yarnold (Eds.), Reading and understanding more multivariate statistics. (pp. 227-260). Washington, D.C.: 
American Psychological Association.

Kline, R.B. 1998. Principles and practices of structural equation modeling. NY: Guilford Press.

Kuehn, D.M., Luzadis, V.A., Malmsheimer, R.W., \& Schuster, R.M. (2010). Perceptions of public forest managers concerning trail use by off-highway vehicle riders in the Northeast United States. Proceedings of the 2010 Northeastern Recreation Research Symposium GTR-NRS-P-94.

Kuentzel, W.F., \& Heberlein, T.A. (2003). More visitors less crowding: Change and stability of norms over time at the Apostle Islands. Journal of Leisure Research, 35(4), 349-371.

Lawson, S.R., \& Manning, R.E. (2001). Solitude versus access: A study of tradeoffs in outdoor recreation using indifference curve analysis. Leisure Sciences, 23, 179-191.

Legare, A.M. \& Haider, W. (2008). Trend analysis of motivation-based clusters at the Chilkoot Trail National Historic Site of Canada. Leisure Sciences 30(2), 158-176.

Lime, D.W., \& Stankey, G.H. (1971). Carrying capacity: Maintaining outdoor recreation quality. In Larson E., ed. Recreation Symposium proceedings (pp.174-184). Upper Darby, PA: USDA Forest Service, Northeastern Forest Experiment Station.

Lucas, R.C., \& Stankey, G.H. (1974). Social carrying capacity for backcountry recreation. In Outdoor Recreation Research: Applying the Results (pp. 14-23). Marquette, MI: USDA Forest Service North Central Forest Experiment Station.

Manning, R.E., \& Lime, D.W. (1996). Crowding and carrying capacity in the national park system: Toward a social science research agenda. Crowding and Congestion in the National Park System: Guidelines for management and Research. St. Paul: University of Minnesota Agricultural Experiment Station Publication, 86, 27-65.

Manning, R.E. \& Valliere, W. (2001). Coping in outdoor recreation: Causes and consequences of 
crowding and conflict among community residents. Journal of Leisure Research, 33(4), 410-426.

Manning, R.E. (2007). Parks and carrying capacity: Commons without tragedy. Washington, D.C.: Island Press.

Manning, R.E. (2011). Studies in outdoor recreation: Search and research for satisfaction (3 ${ }^{\text {rd }}$ ed.). Corvallis, OR: Oregon State University Press.

Martin, S.R., Marsolas, J., \& Rolloff, D. (2009). Visitor perceptions of appropriate management actions across the recreation opportunity spectrum Journal of Park and Recreation Administration, 27(1), 56-69.

McCool, S.F., \& Christensen, N., (1996). Alleviating congestion in parks and recreation areas through direct management of visitor behavior. Crowding and congestion in the National Park System: Guidelines for Management and Research. St. Paul: University of Minnesota Agriculture Experiment Station Publication 86-1996, 67-83.

McCool, S.F., \& Lime, D.W. (2001). Tourism carrying capacity: Tempting fantasy or useful reality? Journal of Sustainable Tourism, 9(5), 372-388.

Menard, S. (2002). Longitudinal research $\left(2^{\text {nd }} e d.\right)$. Thousand Oaks, CA: Sage Publications. Merriam Webster Online Dictionary (2012). www.merriam-webster.com.

More, T., Echelberger, H., \& Koenemann, E., (1990). Factors affecting recreation participation by Vermont residents. USDA Forest Service Research Paper NE-631.

National Park Service (1997). VERP: The visitor experience and resource protection (VERP) framework-A handbook for planners and managers. Denver, CO: Denver Service Center. Nilsen, P., \& Tayler, G. (1997). A comparative analysis of protected area planning and management frameworks. Proceedings-Limits of Acceptable Change and Related 
Planning Processes: Progress and Future Directions. USDA Forest Service General Technical Report INT-371, 49-57.

Noe, F., Wellman, J., \& Buhyoff, J. (1981). Perception of conflict between off-road vehicle users in a leisure setting. Journal of Environmental Systems, 11, 243-253.

Oregon Dunes Management Plan (1994). Retreived January 3, 2012 from http://www.fs.usda.gov.

Oregon Dunes National Recreation Act of 1972, Pub. L. No. 92-260, §1, 86 Stat. 99 (1972).

Ouren, D.S., Haas, C., Melcher, C.P., Stuart, S.C., Ponds, P.D., Sexton, N.R., Burris, L., Fanchen, T., \& Bowen, Z.H. (2007). Environmental effects of off-highway vehicles on Bureau of Land Management lands: A literature synthesis, annotated bibliographies, extensive bibliographies and internet resources. US Geological Survey Open-File Report 2007-1353.

Parasuraman, A., Zeithaml, V.A., \& Berry, L.L. (1985). A conceptual model of service quality and its implication for further research. Journal of Marketing, 49, 41-50.

Parasuraman, A., Zeithaml, V.A., \& Berry, L.L. (1988). SERVQUAL: A multiple-item scale for measuring consumer perceptions of service quality. Journal of Retailing, 64, 12-40.

Pettergill, P.R., Manning, R.E., Anderson, L.E., Valliere, W., \& Reigner, N. (2012). Measuring and managing the quality at Acadia National Park. Journal of Park and Recreation Administration, 30(1), 68-84.

Pierskalla, C.D., Schuett, M.A., \& Thompson K.A. (2011). Management perceptions of offhighway vehicle use on national forest system lands in Appalachia. Northern Journal of Applied Forestry, 28(4), 208-213.

Schreyer, R., Lime, D., \& Williams, D. (1984). Characterizing the influence of past experience 
on recreation behavior. Journal of Leisure Research, 16, 34-50.

Shelby, B. (1980). Contrasting recreational experiences: Motors and oars in the Grand Canyon. Journal of Soil and Water Conservation, 35, 129-131.

Shelby, B., Vaske, J.J., \& Heberlein, T. (1989). Comparative analysis of crowding in multiple locations: Results from fifteen years of research. Leisure Sciences, 11, 269-291.

Shelby, L., \& Vaske, J.J. (2007). Perceived crowding among hunters and anglers: A metaanalysis. Human Dimensions of Wildlife, 12, 241-261.

Shinder, B., \& Shelby, B. (1995). Product shift in recreation settings: findings and implications from panel research. Leisure Sciences, 17, 97-107.

Shrestha, S.K., Burns, R.C., Pierskalla, C.D., \& Selin, S. (2012). Predicting deer hunting intentions using the theory of planned behavior: A survey of Oregon big game hunters. Human Dimensions of Wildlife, 17(2), 129-140.

Silberman, J., \& Andereck, K.L. (2006). The economic value of off-highway vehicle recreation. Journal of Leisure Research, 38(2), 208-223.

Stankey, G., McCool, S., \& Stokes, G. (1984). Limits of acceptable change: A new framework for managing the Bob Marshall Wilderness Complex. Western Wildlands, 10, 33-37.

Switalski, T.A., \& Jones, A. (2012). Off-road vehicle best management practices for forest lands: A review of scientific literature and guidance for managers. Journal of Conservation Planning, 8, 12-24.

Taris, T.W. (2000). A primer in longitudinal data analysis. London: Sage Publications Ltd.

Thapa, B., \& Graefe, A.R. (2004). Recreation conflict and tolerance among skiers and snowboarders. Journal of Park and Recreation Administration, 22(1), 37-52.

Tindall, D.B., Harshaw, H., \& Taylor, J.M. (2011). The effects of social network ties on the 
public's satisfaction with forest management in British Columbia, Canada. In O. Bodin \& C. Prell (Eds.), Social Networks and natural resource management: Uncovering the social fabric of environmental governance (pp. 147-179). New York, NY: Cambridge University Press.

USDA Forest Service (2012). www.fs.fed.us.

USDA Forest Service National Visitor Use Monitoring (2013). http://apps.fs.usda.gov/nrm/nvum/results/

Vaske, J.J., Donnelly, M.P., Whittmann, K., \& Lailaw, S. (1995). Interpersonal versus socialvalues conflict. Leisure Sciences, 17, 205-222.

Vaske, J.J. \& Donnelly, M.P. (2002). Generalizing the encounter -norm—crowding relationship. Leisure Sciences, 24(3-4), 255-269.

Vaske, J.J., Dyar, R., \& Timmons, N. (2004). Skill level and recreation conflict among skiers and snowboarders. Leisure Sciences, 26, 215-225.

Vaske, J.J., Needham, M.D., \& Cline, R.C. (2007). Clarifying interpersonal and social values conflict among recreationists. Journal of Leisure Research, 39, 182-195.

Vaske, J.J., \& Shelby, L. (2008). Crowding as a descriptive indicator and an evaluative standard: Results from 30 years of research. Leisure Sciences, 30, 111-126.

Vaske, J.J. (2008). Survey research and analysis: Applications in parks, recreation and human dimensions. State College, PA: Venture Publishing.

Vaske, J.J., Beaman, J., Barreto, H., \& Shelby, L.B. (2010). An extension and further validation of the potential for conflict index. Leisure Sciences, 32, 240-254.

Wagar, J.A. (1964). The carrying capacity of wild lands for recreation Forest Science Monograph 7. Washington, D.C.: Society of American Foresters. 
Wagar, J.A. (1966). Quality in outdoor recreation. Trends, 3, 9-12.

Washburne, R., \& Cole, D. (1983). Problems and Practices in Wilderness Management: A Survey of Managers. USDA Forest Service Research Paper, INT-304.

Whisman, S., \& Hollenhorst S. (1998). A path model of whitewater boating satisfaction on the Cheat River of West Virginia. Environmental Management, 22(1), 109-117.

Williams, D. (1989). Great expectations and the limits of satisfaction: A review of recreation and customer satisfaction research. Outdoor Recreation Benchmark 1988: Proceedings of the National Outdoor Recreation Forum. USDA Forest Service General Technical Report SE-52, 422-438.

Williams, D., Schreyer, R., \& Knopf, R. (1990). The effect of experience use history on the multidimensional structure of motivations to participate in leisure activities. Journal of Leisure Research, 22, 36-54.

Wright, B.A., Duray, N., \& Goodale, T.L. (1992). Assessing perceptions of recreation center service quality: An application of recent advancements in service quality research. Journal of Parks and Recreation Administration, 10(3), 33-47.

Wynveen, C.J., Kyle, G.T., Hammitt, W.E., \& Absher, J.D. (2007). Exploring the effect of experience use history and place bonding on resource substitution. Proceedings of the 2007 Northeastern Recreation Research Symposium. USDA Forest Service General Technical Report GTR-NRS-P-23, 114-122. 


\section{Appendix A}

\section{Survey Questionnaire: 2002 \\ Oregon Dunes National Recreation/Sand Lake Area Visitor Survey}

$\begin{array}{ll}\text { ID\# } & \text { Interviewer } \\ \text { Date_ } & \text { Location \# of people at site } \\ \text { Time } & \text { Gender }\end{array}$

Interviewer Script Hello, I am (name and affiliation, i.e. University student, etc.). Have you already been approached and interviewed? Yes - Thank you for your time No - Continue

We are conducting a study for the US Forest Service of visitors to the Oregon Dunes/Sand Lake recreation areas. The information visitors give us will be used to help recreation area managers better serve the visiting public and protect the recreation areas' natural and cultural resources. You have been selected as part of a random sample of visitors to participate in this survey. Participation is voluntary and if you choose to participate, everything you tell us will be kept strictly confidential. The survey will take about 15 minutes to complete. May we proceed with the interview?
If YES - Proceed with survey.
If NO - Thank you for your time.

Were you riding off-highway vehicles here today?

If YES - Continue with survey. If NO - Thank you for your time.

1. Have you ever been to Oregon Dunes/Sand Lake before?

$\begin{aligned} \text { Yes } & \rightarrow \text { Go to } 1.1 \\ \text { No } & \rightarrow \text { Go to } 1.2\end{aligned}$

1.1 What year did you first come here? (year)

2. In a typical year, how many times do you come to Oregon Dunes/Sand Lake for recreation? (times/yr)

3. How many days did you (do you plan to) spend at Oregon Dunes/Sand Lake during this trip?

Days __ Not Sure

4. Where is your primary residence? Town /State /Zip Code

5. About how many miles is it from your primary residence to Oregon Dunes/Sand Lake? miles

6. Including yourself, how many people are in your group at Oregon Dunes/Sand Lake today? people

6a. Which of the following best describes your group? family members family and friends an organized group or club other more than one family unrelated friends one person traveling alone 
7. Why did you choose to come to this particular riding area at Oregon Dunes/Sand Lake?

8. Approximately how many people (excluding members of your own group) have you seen at Oregon Dunes/Sand Lake today?

Number of people: Can't remember

9. What is the maximum number of people per day you would find acceptable to see at Oregon Dunes/Sand Lake?

It is acceptable to see as many as people per day

Does not matter to me

Matters, but I cannot specify a number

10. What is the maximum number of people per day you could tolerate seeing at Oregon Dunes/Sand Lake before you would no longer visit?

It is tolerable to see as many as people per day

Does not matter to me

Matters, but I cannot specify a number

11. Approximately how many OHVs (excluding your own) have you seen at Oregon Dunes/Sand Lake today?

Number of OHV's: Can't remember

12. What is the maximum number of OHVs per day you would find acceptable to see at Oregon Dunes/Sand Lake?

It is acceptable to see as many as OHVs per day

Does not matter to me

Matters, but I cannot specify a number

13. What is the maximum number of OHVs per day you could tolerate seeing at Oregon Dunes/Sand Lake before you would no longer visit?

It is tolerable to see as many as OHVs per day

Does not matter to me

Matters, but I cannot specify a number

14. Following are some statements about your visit to Oregon Dunes/Sand Lake. For each statement, please select the response that best describes your feelings about your visit to this area. If the statement does not apply, do not answer the question.

\begin{tabular}{|l|c|c|c|c|c|}
\hline & $\begin{array}{c}\text { Strongly } \\
\text { Disagree }\end{array}$ & Disagree & Undecided & Agree & $\begin{array}{c}\text { Strongly } \\
\text { Agree }\end{array}$ \\
\hline $\begin{array}{c}\text { I avoided my favorite parts of Oregon } \\
\text { Dunes/Sand Lake because there were too } \\
\text { many people }\end{array}$ & 1 & 2 & 3 & 4 & 5 \\
\hline I thoroughly enjoyed my trip & 1 & 2 & 3 & 4 & 5 \\
\hline $\begin{array}{c}\text { My trip was not as enjoyable as I expected it to } \\
\text { be }\end{array}$ & 1 & 2 & 3 & 4 & 5 \\
\hline There were too many OHVs on the dunes & 1 & 2 & 3 & 4 & 5 \\
\hline $\begin{array}{c}\text { I thought the recreation area and its } \\
\text { surroundings were in good physical } \\
\text { condition }\end{array}$ & 1 & 2 & 3 & 4 & 5 \\
\hline
\end{tabular}




\begin{tabular}{|c|c|c|c|c|c|}
\hline $\begin{array}{c}\text { I wish there were more people on the dunes } \\
\text { during my visit }\end{array}$ & 1 & 2 & 3 & 4 & 5 \\
\hline $\begin{array}{c}\text { The number of OHVs at the recreation area } \\
\text { reduced my enjoyment }\end{array}$ & 1 & 2 & 3 & 4 & 5 \\
\hline $\begin{array}{c}\text { I wish there were more OHVs on the dunes } \\
\text { during my visit }\end{array}$ & 1 & 2 & 3 & 4 & 5 \\
\hline $\begin{array}{c}\text { My trip was well worth the money I spent to } \\
\text { take it }\end{array}$ & 1 & 2 & 3 & 4 & 5 \\
\hline $\begin{array}{c}\text { There were too many people on the dunes } \\
\text { I was disappointed with some aspects of my trip }\end{array}$ & 1 & 2 & 3 & 4 & 5 \\
\hline $\begin{array}{c}\text { The number of people at the recreation area } \\
\text { reduced my enjoyment }\end{array}$ & 1 & 2 & 3 & 4 & 5 \\
\hline $\begin{array}{c}\text { The behavior of other people at the recreation } \\
\text { area lowered the quality of my experience }\end{array}$ & 1 & 2 & 3 & 4 & 5 \\
\hline $\begin{array}{c}\text { (If agree or strongly agree with above } \\
\text { statement) How did other people‘s behavior } \\
\text { reduce your enjoyment? }\end{array}$ & & & \\
\hline
\end{tabular}

15. On a scale of one to ten, how would you rate your overall experience at Oregon Dunes/Sand Lake, with a rating of 10 being the best possible experience, and a rating of 1 being the worst possible experience you can imagine?

\section{Crowding Information}

1. How did the number of people you saw during your visit to Oregon Dunes/Sand Lake compare with what you expected to see?

A lot less than you expected A little less than you expected About what you expected
A little more than you expected

A lot more than you expected

You didn't have any expectations

2. How crowded did you feel on Oregon Dunes/Sand Lake during your visit [Circle one number]

\begin{tabular}{|c|c|c|c|c|c|c|c|c|}
\hline \multicolumn{2}{|c|}{ Not at all Crowded } & \multicolumn{2}{|c|}{ Slightly Crowded } & \multicolumn{3}{|c|}{ Moderately Crowded } & \multicolumn{2}{c|}{ Extremely Crowded } \\
\hline 1 & 2 & 3 & 4 & 5 & 6 & 7 & 8 & 9 \\
\hline
\end{tabular}

3. How acceptable was the number of other people you saw on Oregon Dunes/Sand Lake? [Circle one number]

\begin{tabular}{|c|c|c|c|c|c|c|c|c|}
\hline \multicolumn{2}{|c|}{ Very Acceptable } & \multicolumn{5}{|c|}{ Neither acceptable nor unacceptable } & \multicolumn{2}{c|}{ Very Un-acceptable } \\
\hline+4 & +3 & +2 & +1 & 0 & -1 & -2 & -3 & -4 \\
\hline
\end{tabular}

4. Overall, I would have liked to have seen ...[Circle one number]

\begin{tabular}{|l|l|l|}
\hline Far more people here & The same number of people as I saw & Far less people here \\
\hline
\end{tabular}




\begin{tabular}{|l|l|l|l|l|l|l|l|l|}
\hline+4 & +3 & +2 & +1 & 0 & -1 & -2 & -3 & -4 \\
\hline
\end{tabular}

\section{Off Road Vehicle Information}

1. How did the number of Off Highway Vehicles you saw at Oregon Dunes/Sand Lake during your visit compare with what you expected to see?

A lot less than you expected A little less than you expected About what you expected
A little more than you expected A lot more than you expected You didn't have any expectations

2. How acceptable was the number of Off Highway Vehicles you saw Oregon Dunes/Sand Lake? [Circle one number]

\begin{tabular}{|c|c|c|c|c|c|c|c|c|}
\hline \multicolumn{2}{|c|}{ Very Acceptable } & \multicolumn{5}{|c|}{ Neither acceptable nor unacceptable } & \multicolumn{2}{|c|}{ Very Un-acceptable } \\
\hline+4 & +3 & +2 & +1 & 0 & -1 & -2 & -3 & -4 \\
\hline
\end{tabular}

3. Would you say that the Off Highway Vehicles Oregon Dunes/Sand Lake [Circle one number]

\begin{tabular}{|c|c|c|c|c|c|c|c|c|}
\hline+4 & +3 & +2 & +1 & 0 & -1 & -2 & -3 & -4 \\
\hline \multicolumn{2}{|c|}{$\begin{array}{l}\text { Greatly enhanced my } \\
\text { enjoyment }\end{array}$} & \multicolumn{5}{|c|}{$\begin{array}{l}\text { Neither enhanced or detracted } \\
\text { from my enjoyment }\end{array}$} & \multicolumn{2}{|c|}{$\begin{array}{l}\text { Greatly detracted } \\
\text { from my enjoyment }\end{array}$} \\
\hline
\end{tabular}

1. Overall, I would have liked to have seen ... [Circle one number]

\begin{tabular}{|c|c|c|c|c|c|c|c|c|}
\hline \multicolumn{2}{|c|}{ Far more OHVs } & \multicolumn{4}{|c|}{ The same number of OHVs as I saw } & \multicolumn{3}{c|}{ Far less OHVs } \\
\hline+4 & +3 & +2 & +1 & 0 & -1 & -2 & -3 & -4 \\
\hline
\end{tabular}

Thank You 


\section{Appendix B}

\section{Survey Questionnaire: 2006}

\section{Oregon Dunes National Recreation/Sand Lake Area Visitor Survey}

\begin{tabular}{|c|c|c|}
\hline ID\# & Interviewer & $\#$ of people at site \\
\hline Date & Location & $\#$ of OHV's at site \\
\hline Time & Gender & \\
\hline
\end{tabular}

Interviewer Script Hello, I am (name and affiliation, i.e. University student, etc.). Have you already been approached and interviewed? Yes - Thank you for your time No - Continue

We are conducting a study for the US Forest Service of visitors to the Oregon Dunes/Sand Lake recreation areas. The information visitors give us will be used to help recreation area managers better serve the visiting public and protect the recreation areas' natural and cultural resources. You have been selected as part of a random sample of visitors to participate in this survey. Participation is voluntary and if you choose to participate, everything you tell us will be kept strictly confidential. The survey will take about 15 minutes to complete. May we proceed with the interview?
If YES - Proceed with survey.
If NO - Thank you for your time.

Were you riding off-highway vehicles here today?

If YES - Continue with survey. If NO - Thank you for your time.

1. Have you ever been to Oregon Dunes/Sand Lake before?

$\begin{aligned} & \text { Yes } \rightarrow \text { Go to } 1.1 \\ & \text { No } \rightarrow \text { Go to } 1.2\end{aligned}$

1.2 What year did you first come here?

(year)

2. In a typical year, how many times do you come to Oregon Dunes/Sand Lake for recreation? (times/yr)
2.1. Of those visits, how many are:
day trips
overnight trips

3. How many days did you (do you plan to) spend at Oregon Dunes/Sand Lake during this trip?

Days Not Sure

\begin{tabular}{|l|l|}
\hline [If only one day] & {$[$ If more than one day] } \\
\hline Where did you park your vehicle(s)? & Where did (will) you stay overnight? \\
\hline Forest Service facility & A Forest Service campground \\
\hline Out in the sand & A sand camp \\
\hline At a private residence & A motel \\
\hline Other (specify & Another campground (specify \\
\hline & Another campground (specify \\
\hline
\end{tabular}


4. Where is your primary residence? Town /State /Zip Code

5. About how many miles is it from your primary residence to Oregon Dunes/Sand Lake? miles

6. Including yourself, how many people are in your group at Oregon Dunes/Sand Lake today?

people

6a. Of these how many are under the age of 16 ?

6b. Which of the following best describes your group?

family members

family and friends

an organized group or club other ( more than one family

unrelated friends

one person traveling alone

7. How many OHVs did you bring to Oregon Dunes/Sand Lake on this trip?
4-wheelers
3-wheelers
motorcycles
trucks/jeeps
Other (specify )

8. Why did you choose to come to this particular riding area at Oregon Dunes/Sand Lake?

9. Which riding opportunities do you enjoy the most? Please rank order your preferences, starting with 1 for your most preferred opportunity, 2 for your second preference, and so on.
Open dunes
Hill climbs
Trails
Beaches Other (specify

10. How do you get your OHV information for Oregon Dunes/Sand Lake? [check all that apply]

FS web page

Brochures

Word of mouth

Other website (specify

11. Do you know the decibel limit for the Oregon Dunes/Sand Lake? Yes No 11a. [If yes] What is it?

12. Do you know the decibel output of your vehicle? Yes No 12a. [If yes] What is it?

13. Do you belong to an OHV club or group?

Yes No

[If yes] which one(s)

14. How often do you wear a helmet while riding your OHV?

Never

Occasionally

Most of the time

Always 
15. On a scale of one to ten, how would you rate your overall experience at Oregon Dunes/Sand Lake, with a rating of 10 being the best possible experience, and a rating of 1 being the worst possible experience you can imagine?

16. Following are some statements about your visit to Oregon Dunes/Sand Lake. For each statement, please select the response that best describes your feelings about your visit to this area. If the statement does not apply, do not answer the question.

\begin{tabular}{|c|c|c|c|c|c|}
\hline & $\begin{array}{l}\text { Strongly } \\
\text { Disagree }\end{array}$ & Disagree & Undecided & Agree & $\begin{array}{c}\text { Strongly } \\
\text { Agree }\end{array}$ \\
\hline $\begin{array}{l}\text { I avoided my favorite parts of Oregon Dunes/Sand } \\
\text { Lake because there were too many people }\end{array}$ & 1 & 2 & 3 & 4 & 5 \\
\hline FS employees were courteous and helpful & 1 & 2 & 3 & 4 & 5 \\
\hline OHV riders operated in an unsafe manner & 1 & 2 & 3 & 4 & 5 \\
\hline I thoroughly enjoyed my trip & 1 & 2 & 3 & 4 & 5 \\
\hline I want people to see my face when I ride my OHV & 1 & 2 & 3 & 4 & 5 \\
\hline $\begin{array}{l}\text { I thought the recreation area and its surroundings } \\
\text { were in good physical condition }\end{array}$ & 1 & 2 & 3 & 4 & 5 \\
\hline $\begin{array}{l}\text { I enjoy the place because of the undeveloped } \\
\text { environment }\end{array}$ & 1 & 2 & 3 & 4 & 5 \\
\hline ATV helmets increase rider safety & 1 & 2 & 3 & 4 & 5 \\
\hline $\begin{array}{l}\text { The number of OHVs at the recreation area } \\
\text { reduced my enjoyment }\end{array}$ & 1 & 2 & 3 & 4 & 5 \\
\hline $\begin{array}{l}\text { If free OHV safety education were provided to all } \\
\text { riders, I would most likely attend a training } \\
\text { course }\end{array}$ & 1 & 2 & 3 & 4 & 5 \\
\hline My trip was well worth the money I spent to take it & 1 & 2 & 3 & 4 & 5 \\
\hline Helmets are not sexy or cool & 1 & 2 & 3 & 4 & 5 \\
\hline Riders at the dunes were courteous & 1 & 2 & 3 & 4 & 5 \\
\hline I was disappointed with some aspects of my trip & 1 & 2 & 3 & 4 & 5 \\
\hline $\begin{array}{l}\text { The noise of OHVs reduced my enjoyment on the } \\
\text { dunes }\end{array}$ & 1 & 2 & 3 & 4 & 5 \\
\hline $\begin{array}{l}\text { If insurance companies reduced the insurance } \\
\text { premium by } 25 \% \text { for riders who attended an } \\
\text { educational training course, I would most likely } \\
\text { attend a training course }\end{array}$ & 1 & 2 & 3 & 4 & 5 \\
\hline $\begin{array}{l}\text { The behavior of other people at the recreation area } \\
\text { lowered the quality of my experience }\end{array}$ & 1 & 2 & 3 & 4 & 5 \\
\hline Riding conditions at the dunes were safe & 1 & 2 & 3 & 4 & 5 \\
\hline The signage at the site was acceptable & 1 & 2 & 3 & 4 & 5 \\
\hline $\begin{array}{l}\text { I choose to ride here for the challenging riding } \\
\text { opportunities }\end{array}$ & 1 & 2 & 3 & 4 & 5 \\
\hline I was bothered by OHVs cutting too close to me & 1 & 2 & 3 & 4 & 5 \\
\hline $\begin{array}{l}\text { I stayed off the dunes during parts of the day } \\
\text { because there were too many OHVs in the area }\end{array}$ & 1 & 2 & 3 & 4 & 5 \\
\hline ATV riders should always wear a helmet & 1 & 2 & 3 & 4 & 5 \\
\hline
\end{tabular}


There are adequate law enforcement patrols at the

1 Oregon Dunes/Sand Lake 


\section{Crowding Information}

1. How did the number of people you saw during your visit to Oregon Dunes/Sand Lake compare with what you expected to see?

A lot less than you expected A little less than you expected About what you expected
A little more than you expected

A lot more than you expected

You didn't have any expectations

2. How crowded did you feel on Oregon Dunes/Sand Lake during your visit [Circle one number]

\begin{tabular}{|c|c|c|c|c|c|c|c|c|}
\hline \multicolumn{2}{|c|}{ Not at all Crowded } & \multicolumn{2}{|c|}{ Slightly Crowded } & \multicolumn{3}{|c|}{ Moderately Crowded } & \multicolumn{2}{c|}{ Extremely Crowded } \\
\hline 1 & 2 & 3 & 4 & 5 & 6 & 7 & 8 & 9 \\
\hline
\end{tabular}

3. How acceptable was the number of other people you saw on Oregon Dunes/Sand Lake? [Circle one number]

\begin{tabular}{|c|c|c|c|c|c|c|c|c|}
\hline \multicolumn{6}{|c|}{ Very Unacceptable } & \multicolumn{5}{|c|}{ Neither acceptable nor unacceptable } & \multicolumn{2}{c|}{ Very Acceptable } \\
\hline 1 & 2 & 3 & 4 & 5 & 6 & 7 & 8 & 9 \\
\hline
\end{tabular}

4. Overall, I would have liked to have seen ...[Circle one number]

\begin{tabular}{|c|c|c|c|c|c|c|c|c|}
\hline \multicolumn{5}{|c|}{ Far more people here } & \multicolumn{5}{|c|}{ The same number of people as I saw } & \multicolumn{2}{c|}{ Far less people here } \\
\hline 1 & 2 & 3 & 4 & 5 & 6 & 7 & 8 & 9 \\
\hline
\end{tabular}

5. How crowded do you generally feel during a typical summer weekend when riding at:

\begin{tabular}{|l|c|c|c|c|c|c|c|c|c|}
\hline & \multicolumn{2}{|l|}{$\begin{array}{l}\text { Not at all } \\
\text { Crowded }\end{array}$} & \multicolumn{3}{c|}{ Slightly Crowded } & \multicolumn{3}{c|}{ Moderately Crowded } & \multicolumn{3}{c|}{$\begin{array}{c}\text { Extremely } \\
\text { Crowded }\end{array}$} \\
\hline ODNRA & 1 & 2 & 3 & 4 & 5 & 6 & 7 & 8 & 9 \\
\hline Sand Lake & 1 & 2 & 3 & 4 & 5 & 6 & 7 & 8 & 9 \\
\hline
\end{tabular}

6. How crowded do you generally feel during holiday weekends when riding at:

\begin{tabular}{|l|c|c|c|c|c|c|c|c|c|}
\hline & \multicolumn{2}{|l|}{$\begin{array}{l}\text { Not at all } \\
\text { Crowded }\end{array}$} & \multicolumn{3}{c|}{ Slightly Crowded } & \multicolumn{3}{c|}{ Moderately Crowded } & \multicolumn{3}{c|}{$\begin{array}{c}\text { Extremely } \\
\text { Crowded }\end{array}$} \\
\hline ODNRA & 1 & 2 & 3 & 4 & 5 & 6 & 7 & 8 & 9 \\
\hline Sand Lake & 1 & 2 & 3 & 4 & 5 & 6 & 7 & 8 & 9 \\
\hline
\end{tabular}

7. Do you think a reservation system for Day Use parking sites should be implemented during the summer holiday weekends? ODNRA Yes __ No 
Sand Lake Yes No 


\section{Off Road Vehicle Information}

1. Approximately how many OHVs (excluding your own) have you seen at Oregon Dunes/Sand Lake today? Number of OHV's: $\square$ Can't remember

2. How did the number of Off Highway Vehicles you saw at Oregon Dunes/Sand Lake during your visit compare with what you expected to see?

A lot less than you expected A little less than you expected About what you expected
A little more than you expected A lot more than you expected You didn't have any expectations

3. How acceptable was the number of Off Highway Vehicles you saw Oregon Dunes/Sand Lake? [Circle one number]

\begin{tabular}{|c|c|c|c|c|c|c|c|c|}
\hline \multicolumn{2}{|c|}{ Very Unacceptable } & \multicolumn{4}{|c|}{ Neither acceptable nor unacceptable } & \multicolumn{2}{c|}{ Very Acceptable } \\
\hline 1 & 2 & 3 & 4 & 5 & 6 & 7 & 8 & 9 \\
\hline
\end{tabular}

4. Would you say that the Off Highway Vehicles Oregon Dunes/Sand Lake [Circle one number]

\begin{tabular}{|c|c|c|c|c|c|c|c|c|}
\hline 1 & 2 & 3 & 4 & 5 & 6 & 7 & 8 & 9 \\
\hline \multicolumn{2}{|c|}{$\begin{array}{l}\text { Greatly enhanced my } \\
\text { enjoyment }\end{array}$} & & \multicolumn{4}{|c|}{$\begin{array}{l}\text { Neither enhanced or detracted } \\
\text { from my enjoyment }\end{array}$} & \multicolumn{2}{|c|}{$\begin{array}{l}\text { Greatly detracted } \\
\text { from my enjoyment }\end{array}$} \\
\hline
\end{tabular}

5. Overall, I would have liked to have seen ... [Circle one number]

\begin{tabular}{|c|c|c|c|c|c|c|c|c|}
\hline \multicolumn{2}{|c|}{ Far more OHVs } & \multicolumn{4}{|c|}{ The same number of OHVs as I saw } & \multicolumn{3}{c|}{ Far less OHVs } \\
\hline 1 & 2 & 3 & 4 & 5 & 6 & 7 & 8 & 9 \\
\hline
\end{tabular}

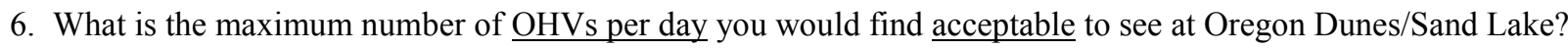

It is acceptable to see as many as OHVs per day Does not matter to me Matters, but I cannot specify a number

7. What is the maximum number of OHVs per day you could tolerate seeing at Oregon Dunes/Sand Lake before you would no longer visit?

It is tolerable to see as many as OHVs per day

Does not matter to me

Matters, but I cannot specify a number 


\section{Camping Questions}

1. Are you camping during your visit to the Oregon Dunes/Sand Lake? Yes No
If YES - Continue to Q2.
If NO - Ask Q1.1

1.1 Have you ever camped at Oregon Dunes/Sand Lake?

Yes

No

\section{If YES continue with survey. If NO - Skip camping questions.}

2. On a scale of 1 to 10 how would you rate the quality of your sand camping experience during this visit?

3. When sand camping at Oregon Dunes/Sand Lake, how do you dispose of your trash?

4. How do you dispose of your human waste?

5. Fire pans can be used to protect the recreation areas from leaving permanent scarring. Would you consider using a fire pan at sand camping sites? Yes No.

6. Overall, how would you rate the quality of each of the following in the developed camping areas of Oregon Dunes/Sand Lake (if applicable)?

\begin{tabular}{|l|c|c|c|c|c|}
\hline \multicolumn{1}{|c|}{ Developed Camping Areas } & Awful & Fair & Good & Very Good & Excellent \\
\hline Health and Cleanliness & 1 & 2 & 3 & 4 & 5 \\
\hline Safety and security & 1 & 2 & 3 & 4 & 5 \\
\hline Condition of facilities & 1 & 2 & 3 & 4 & 5 \\
\hline Responsiveness of staff & 1 & 2 & 3 & 4 & 5 \\
\hline Recreation setting & 1 & 2 & 3 & 4 & 5 \\
\hline
\end{tabular}

7, Overall, how would you rate the quality of each of the following in the dispersed camping areas of Oregon Dunes/Sand Lake (if applicable)?

\begin{tabular}{|l|c|c|c|c|c|}
\hline \multicolumn{1}{|c|}{ Dispersed Camping Areas } & Awful & Fair & Good & Very Good & Excellent \\
\hline Health and Cleanliness & 1 & 2 & 3 & 4 & 5 \\
\hline Safety and security & 1 & 2 & 3 & 4 & 5 \\
\hline Condition of facilities & 1 & 2 & 3 & 4 & 5 \\
\hline Responsiveness of staff & 1 & 2 & 3 & 4 & 5 \\
\hline Recreation setting & 1 & 2 & 3 & 4 & 5 \\
\hline
\end{tabular}




\section{Safety Questions}

Finally we would like to ask your opinion about a few potential Oregon State Law changes for Class 1 (ATV) and Class III (off-road motorcyclists). These changes would only apply to operators and passengers recreating on Class 1 and Class III vehicles on lands open for public use.

1. Currently Oregon only requires those operators and passengers under the age of 18 to wear a DOT-approved motorcycle helmet when riding on Class I and III all-terrain vehicles.

How would you feel about a law requiring all Class I and III operators and passengers, regardless of age, wear a DOT-approved motorcycle helmet?

\begin{tabular}{|c|c|c|c|c|}
\hline $\begin{array}{c}\text { Strongly } \\
\text { Oppose }\end{array}$ & $\begin{array}{c}\text { Somewhat } \\
\text { Oppose }\end{array}$ & Neutral & $\begin{array}{c}\text { Somewhat } \\
\text { Support }\end{array}$ & $\begin{array}{c}\text { Strongly } \\
\text { Support }\end{array}$ \\
\hline 1 & 2 & 3 & 4 & 5 \\
\hline
\end{tabular}

2. Most all-terrain vehicles come with a voluntary operator safety warning against carrying passengers when the vehicle is not designed to carry a passenger. There is however strong evidence in Oregon these warnings are not being followed.

How would you rate your support for a law restricting the number of passengers on Class 1 and III all-terrain vehicles to the number for which the vehicle was designed?

\begin{tabular}{|c|c|c|c|c|}
\hline $\begin{array}{c}\text { Strongly } \\
\text { Oppose }\end{array}$ & $\begin{array}{c}\text { Somewhat } \\
\text { Oppose }\end{array}$ & Neutral & $\begin{array}{c}\text { Somewhat } \\
\text { Support }\end{array}$ & $\begin{array}{c}\text { Strongly } \\
\text { Support }\end{array}$ \\
\hline 1 & 2 & 3 & 4 & 5 \\
\hline
\end{tabular}

3. Currently, there is no mandatory titling for Class I and III all-terrain vehicles in Oregon through the state"s DMV. As a result, there is a lack of clear proof of ownership for such vehicles within the state. Subsequently in recent years the umber of stolen all-terrain vehicles is increasing.

How would you rate your support for a mandatory titling requirement for purchasing new or used vehicles intended to make it more difficult for thieves to sell stolen vehicles to unsuspecting buyers?

\begin{tabular}{|c|c|c|c|c|}
\hline $\begin{array}{c}\text { Strongly } \\
\text { Oppose }\end{array}$ & $\begin{array}{c}\text { Somewhat } \\
\text { Oppose }\end{array}$ & Neutral & $\begin{array}{c}\text { Somewhat } \\
\text { Support }\end{array}$ & $\begin{array}{c}\text { Strongly } \\
\text { Support }\end{array}$ \\
\hline 1 & 2 & 3 & 4 & 5 \\
\hline
\end{tabular}

4. During the period 1984-2004, there were 109 fatalities associated with all-terrain use in the state of Oregon. Approximately half of these fatalities involved youth less than 25 years of age. As a result, the state is considering a one-time mandatory training program for Class I and Class III all-terrain

How would you rate your support for a mandatory on-line safety training course (similar to the Marine Board's boater safety course) for Class I and III all-terrain vehicle operators in Oregon through the Oregon Parks and Recreation Department?

\begin{tabular}{|c|c|c|c|c|}
\hline $\begin{array}{c}\text { Strongly } \\
\text { Oppose }\end{array}$ & $\begin{array}{c}\text { Somewhat } \\
\text { Oppose }\end{array}$ & Neutral & $\begin{array}{c}\text { Somewhat } \\
\text { Support }\end{array}$ & $\begin{array}{c}\text { Strongly } \\
\text { Support }\end{array}$ \\
\hline 1 & 2 & 3 & 4 & 5 \\
\hline
\end{tabular}

If you support such a program, for what age groups should the program be required [Check all that apply] 
6-11

12-15

16-17

18-21 all riders 


\section{Appendix C}

\section{Survey Questionnaire: 2011}

Oregon Dunes National Recreation/Sand Lake Area Visitor Survey

$\begin{array}{ll}\text { ID\# } & \text { Interviewer } \\ \text { Date_ } & \text { Location \# of people at site } \\ \text { Time } & \text { Gender }\end{array}$

Interviewer Script Hello, I am (name and affiliation, i.e. University student, etc.). Have you already been approached and interviewed? Yes - Thank you for your time No - Continue

We are conducting a study for the US Forest Service of visitors to the Oregon Dunes/Sand Lake recreation areas. The information visitors give us will be used to help recreation area managers better serve the visiting public and protect the recreation areas' natural and cultural resources. You have been selected as part of a random sample of visitors to participate in this survey. Participation is voluntary and if you choose to participate, everything you tell us will be kept strictly confidential. The survey will take about 15 minutes to complete. May we proceed with the interview?
If YES - Proceed with survey.
If NO - Thank you for your time.

\section{Were you riding off-highway vehicles here today?}

If YES - Continue with survey. If NO - Thank you for your time.

1. Have you ever been to Oregon Dunes/Sand Lake before?

Yes $\rightarrow$ Go to 1.1
No $\rightarrow$ Go to 1.2

1.1 What year did you first come here? (year)

2. In a typical year, how many times do you come to Oregon Dunes/Sand Lake for recreation? (times/yr)
2.1. Of those visits, how many are:
day trips
overnight trips

3. How many days did you (do you plan to) spend at Oregon Dunes/Sand Lake during this trip?

Days Not Sure

\begin{tabular}{|l|l|}
\hline [If only one day $]$ & {$[$ [f more than one day] } \\
\hline Where did you park your vehicle(s)? & Where did (will) you stay overnight? \\
\hline Forest Service facility & A Forest Service campground \\
\hline Out in the sand & A sand camp \\
\hline At a private residence & A motel \\
\hline Other (specify & Another campground (specify \\
\hline & Another campground (specify \\
\hline & Other (specify__ \\
\hline
\end{tabular}

4. Where is your primary residence? Town /State /Zip Code

5. About how many miles is it from your primary residence to Oregon Dunes/Sand Lake? miles 
6. Including yourself, how many people are in your group at Oregon Dunes/Sand Lake today?

6 a. Of these how many are under the age of 16 ?

$6 \mathrm{~b}$. Which of the following best describes your group?
family members
family and friends
an organized group or club other (
more than one family
unrelated friends
one person traveling alone )

7. How many OHVs did you bring to Oregon Dunes/Sand Lake on this trip?
4-wheelers
3-wheelers
motorcycles
trucks/jeeps
Other (specify

8. Why did you choose to come to this particular riding area at Oregon Dunes/Sand Lake?

9. Which riding opportunities do you enjoy the most? Please rank order your preferences, starting with 1 for your most preferred opportunity, 2 for your second preference, and so on.

_ Open dunes __ Hill climbs __ Trails__ Beaches___ Other (specify ___ _ _ _

10. How do you get your OHV information for Oregon Dunes/Sand Lake? [check all that apply]

FS web page

Brochures

Word of mouth

Other website (specify

11. Do you know the decibel limit for the Oregon Dunes/Sand Lake? Yes No 11a. [If yes] What is it?

12. Do you know the decibel output of your vehicle? Yes

No

12a. [If yes] What is it?

13. Do you belong to an OHV club or group?

Yes

No

[If yes] which one(s) 
14. On a scale of one to ten, how would you rate your overall experience at Oregon Dunes/Sand Lake, with a rating of 10 being the best possible experience, and a rating of 1 being the worst possible experience you can imagine?

15. Following are some statements about your visit to Oregon Dunes/Sand Lake. For each statement, please select the response that best describes your feelings about your visit to this area. If the statement does not apply, do not answer the question.

\begin{tabular}{|c|c|c|c|c|c|}
\hline & $\begin{array}{l}\text { Strongly } \\
\text { Disagree }\end{array}$ & Disagree & Undecided & Agree & $\begin{array}{l}\text { Strongly } \\
\text { Agree }\end{array}$ \\
\hline $\begin{array}{l}\text { I avoided my favorite parts of Oregon Dunes/Sand } \\
\text { Lake because there were too many people }\end{array}$ & 1 & 2 & 3 & 4 & 5 \\
\hline FS employees were courteous and helpful & 1 & 2 & 3 & 4 & 5 \\
\hline OHV riders operated in an unsafe manner & 1 & 2 & 3 & 4 & 5 \\
\hline I thoroughly enjoyed my trip & 1 & 2 & 3 & 4 & 5 \\
\hline I want people to see my face when I ride my OHV & 1 & 2 & 3 & 4 & 5 \\
\hline $\begin{array}{l}\text { I thought the recreation area and its surroundings } \\
\text { were in good physical condition }\end{array}$ & 1 & 2 & 3 & 4 & 5 \\
\hline $\begin{array}{l}\text { I enjoy the place because of the undeveloped } \\
\text { environment }\end{array}$ & 1 & 2 & 3 & 4 & 5 \\
\hline $\begin{array}{l}\text { The number of OHVs at the recreation area } \\
\text { reduced my enjoyment }\end{array}$ & 1 & 2 & 3 & 4 & 5 \\
\hline My trip was well worth the money I spent to take it & 1 & 2 & 3 & 4 & 5 \\
\hline Riders at the dunes were courteous & 1 & 2 & 3 & 4 & 5 \\
\hline I was disappointed with some aspects of my trip & 1 & 2 & 3 & 4 & 5 \\
\hline $\begin{array}{l}\text { The noise of OHVs reduced my enjoyment on the } \\
\text { dunes }\end{array}$ & 1 & 2 & 3 & 4 & 5 \\
\hline $\begin{array}{l}\text { The behavior of other people at the recreation area } \\
\text { lowered the quality of my experience }\end{array}$ & 1 & 2 & 3 & 4 & 5 \\
\hline Riding conditions at the dunes were safe & 1 & 2 & 3 & 4 & 5 \\
\hline The signage at the site was acceptable & 1 & 2 & 3 & 4 & 5 \\
\hline $\begin{array}{l}\text { I choose to ride here for the challenging riding } \\
\text { opportunities }\end{array}$ & 1 & 2 & 3 & 4 & 5 \\
\hline I was bothered by OHVs cutting too close to me & 1 & 2 & 3 & 4 & 5 \\
\hline $\begin{array}{l}\text { I stayed off the dunes during parts of the day } \\
\text { because there were too many OHVs in the area }\end{array}$ & 1 & 2 & 3 & 4 & 5 \\
\hline $\begin{array}{l}\text { There are adequate law enforcement patrols at the } \\
\text { Oregon Dunes/Sand Lake }\end{array}$ & 1 & 2 & 3 & 4 & 5 \\
\hline
\end{tabular}




\section{Crowding Information}

1. How did the number of people you saw during your visit to Oregon Dunes/Sand Lake compare with what you expected to see?

A lot less than you expected A little less than you expected About what you expected
A little more than you expected

A lot more than you expected

You didn't have any expectations

2. How crowded did you feel on Oregon Dunes/Sand Lake during your visit [Circle one number]

\begin{tabular}{|c|c|c|c|c|c|c|c|c|}
\hline \multicolumn{2}{|c|}{ Not at all Crowded } & \multicolumn{2}{|c|}{ Slightly Crowded } & \multicolumn{3}{|c|}{ Moderately Crowded } & \multicolumn{2}{c|}{ Extremely Crowded } \\
\hline 1 & 2 & 3 & 4 & 5 & 6 & 7 & 8 & 9 \\
\hline
\end{tabular}

3. How acceptable was the number of other people you saw on Oregon Dunes/Sand Lake? [Circle one number]

\begin{tabular}{|c|c|c|c|c|c|c|c|c|}
\hline \multicolumn{6}{|c|}{ Very Unacceptable } & \multicolumn{5}{|c|}{ Neither acceptable nor unacceptable } & \multicolumn{2}{c|}{ Very Acceptable } \\
\hline 1 & 2 & 3 & 4 & 5 & 6 & 7 & 8 & 9 \\
\hline
\end{tabular}

4. Overall, I would have liked to have seen ...[Circle one number]

\begin{tabular}{|c|c|c|c|c|c|c|c|c|}
\hline \multicolumn{5}{|c|}{ Far more people here } & \multicolumn{5}{|c|}{ The same number of people as I saw } & \multicolumn{2}{c|}{ Far less people here } \\
\hline 1 & 2 & 3 & 4 & 5 & 6 & 7 & 8 & 9 \\
\hline
\end{tabular}

5. How crowded do you generally feel during a typical summer weekend when riding at:

\begin{tabular}{|l|c|c|c|c|c|c|c|c|c|}
\hline & \multicolumn{2}{|l|}{$\begin{array}{l}\text { Not at all } \\
\text { Crowded }\end{array}$} & \multicolumn{3}{c|}{ Slightly Crowded } & \multicolumn{3}{c|}{ Moderately Crowded } & \multicolumn{3}{c|}{$\begin{array}{c}\text { Extremely } \\
\text { Crowded }\end{array}$} \\
\hline ODNRA & 1 & 2 & 3 & 4 & 5 & 6 & 7 & 8 & 9 \\
\hline Sand Lake & 1 & 2 & 3 & 4 & 5 & 6 & 7 & 8 & 9 \\
\hline
\end{tabular}

6. How crowded do you generally feel during holiday weekends when riding at:

\begin{tabular}{|l|c|c|c|c|c|c|c|c|c|}
\hline & \multicolumn{2}{|l|}{$\begin{array}{l}\text { Not at all } \\
\text { Crowded }\end{array}$} & \multicolumn{3}{c|}{ Slightly Crowded } & \multicolumn{3}{c|}{ Moderately Crowded } & \multicolumn{3}{c|}{$\begin{array}{c}\text { Extremely } \\
\text { Crowded }\end{array}$} \\
\hline ODNRA & 1 & 2 & 3 & 4 & 5 & 6 & 7 & 8 & 9 \\
\hline Sand Lake & 1 & 2 & 3 & 4 & 5 & 6 & 7 & 8 & 9 \\
\hline
\end{tabular}




\section{Off Road Vehicle Information}

1. Approximately how many OHVs (excluding your own) have you seen at Oregon Dunes/Sand Lake today? Number of OHV‘s: $\square$ Can't remember

2. How did the number of Off Highway Vehicles you saw at Oregon Dunes/Sand Lake during your visit compare with what you expected to see?

A lot less than you expected A little less than you expected About what you expected
A little more than you expected A lot more than you expected You didn't have any expectations

3. How acceptable was the number of Off Highway Vehicles you saw Oregon Dunes/Sand Lake? [Circle one number]

\begin{tabular}{|c|c|c|c|c|c|c|c|c|}
\hline \multicolumn{2}{|c|}{ Very Unacceptable } & \multicolumn{5}{|c|}{ Neither acceptable nor unacceptable } & \multicolumn{2}{|c|}{ Very Acceptable } \\
\hline 1 & 2 & 3 & 4 & 5 & 6 & 7 & 8 & 9 \\
\hline
\end{tabular}

4. Would you say that the Off Highway Vehicles Oregon Dunes/Sand Lake [Circle one number]

\begin{tabular}{|c|c|c|c|c|c|c|c|c|}
\hline 1 & 2 & 3 & 4 & 5 & 6 & 7 & 8 & 9 \\
\hline \multicolumn{2}{|c|}{$\begin{array}{l}\text { Greatly enhanced my } \\
\text { enjoyment }\end{array}$} & \multicolumn{5}{|c|}{$\begin{array}{l}\text { Neither enhanced or detracted } \\
\text { from my enjoyment }\end{array}$} & \multicolumn{2}{|c|}{$\begin{array}{l}\text { Greatly detracted } \\
\text { from my enjoymen }\end{array}$} \\
\hline
\end{tabular}

5. Overall, I would have liked to have seen ... [Circle one number]

\begin{tabular}{|c|c|c|c|c|c|c|c|c|}
\hline \multicolumn{2}{|c|}{ Far more OHVs } & \multicolumn{5}{|c|}{ The same number of OHVs as I saw } & \multicolumn{2}{c|}{ Far less OHVs } \\
\hline 1 & 2 & 3 & 4 & 5 & 6 & 7 & 8 & 9 \\
\hline
\end{tabular}

6. What is the maximum number of OHVs per day you would find acceptable to see at Oregon Dunes/Sand Lake?

It is acceptable to see as many as OHVs per day

Does not matter to me

Matters, but I cannot specify a number

7. What is the maximum number of OHVs per day you could tolerate seeing at Oregon Dunes/Sand Lake before you would no longer visit?

It is tolerable to see as many as OHVs per day

Does not matter to me

Matters, but I cannot specify a number

Demographic Questions

What is your age range? 
over 70

What is your educational background?

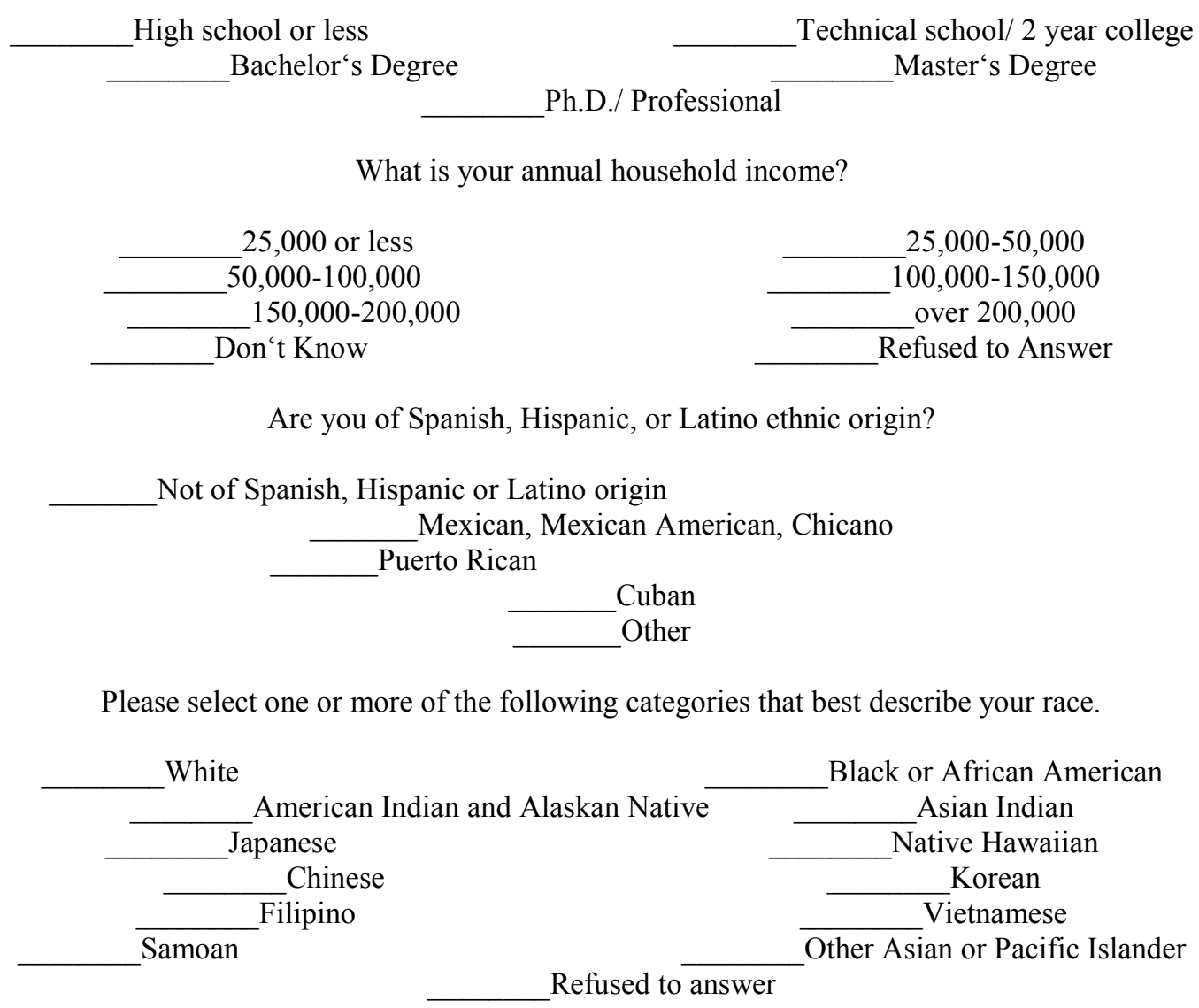




\section{Camping Questions}

1. Are you camping during your visit to the Oregon Dunes/Sand Lake? Yes No

If YES - Continue to Q2.

If NO - Ask Q1.1

1.1 Have you ever camped at Oregon Dunes/Sand Lake?

Yes

No

\section{If YES continue with survey. If NO - Skip camping questions.}

2. On a scale of 1 to 10 how would you rate the quality of your sand camping experience during this visit?

3. When sand camping at Oregon Dunes/Sand Lake, how do you dispose of your trash?

4. How do you dispose of your human waste?

5. Fire pans can be used to protect the recreation areas from leaving permanent scarring. Would you consider using

a fire pan at sand camping sites? Yes No.

6. Overall, how would you rate the quality of each of the following in the developed camping areas of Oregon Dunes/Sand Lake (if applicable)?

\begin{tabular}{|l|c|c|c|c|c|}
\hline \multicolumn{1}{|c|}{ Developed Camping Areas } & Awful & Fair & Good & Very Good & Excellent \\
\hline Health and Cleanliness & 1 & 2 & 3 & 4 & 5 \\
\hline Safety and security & 1 & 2 & 3 & 4 & 5 \\
\hline Condition of facilities & 1 & 2 & 3 & 4 & 5 \\
\hline Responsiveness of staff & 1 & 2 & 3 & 4 & 5 \\
\hline Recreation setting & 1 & 2 & 3 & 4 & 5 \\
\hline
\end{tabular}

7, Overall, how would you rate the quality of each of the following in the dispersed camping areas of Oregon Dunes/Sand Lake (if applicable)?

\begin{tabular}{|l|c|c|c|c|c|}
\hline \multicolumn{1}{|c|}{ Dispersed Camping Areas } & Awful & Fair & Good & Very Good & Excellent \\
\hline Health and Cleanliness & 1 & 2 & 3 & 4 & 5 \\
\hline Safety and security & 1 & 2 & 3 & 4 & 5 \\
\hline Condition of facilities & 1 & 2 & 3 & 4 & 5 \\
\hline Responsiveness of staff & 1 & 2 & 3 & 4 & 5 \\
\hline Recreation setting & 1 & 2 & 3 & 4 & 5 \\
\hline
\end{tabular}

